Sâmia Amire Maluf

\title{
Efeito da reeducação postural global e do alongamento estático segmentar em portadoras de disfunção temporomandibular: um estudo comparativo
}

Tese apresentada à Faculdade de Medicina da Universidade de São Paulo para obtenção do título de Doutora em Ciências

Área de Concentração: Fisiopatologia

Experimental

Orientadora: Profa. Dra. Amélia Pasqual

Marques

São Paulo

2006 
Dados Internacionais de Catalogação na Publicação (CIP)

Preparada pela Biblioteca da

Faculdade de Medicina da Universidade de São Paulo

Creprodução autorizada pelo autor

\section{Maluf, Sâmia Amire}

O efeito da reeducação postural global e do alongamento estático segmentar em portadores de disfunção temporomandibular : um estudo comparativo / Sâmia Amire Maluf. -- São Paulo, 2006.

Tese(doutorado)--Faculdade de Medicina da Universidade de São Paulo para obtenção do título de Doutor em Ciências.

Área de concentração: Fisiopatologia Experimental.

Orientadora: Amélia Pasqual Marques.

Descritores: 1.Fisioterapia (Especialidade) 2.Modalidade de Fisioterapia 3.Articulação temporomandibular 4.Estudo comparativo 5.Mulheres

USP/FM/SBD-419/06 
Aos que vieram antes, na figura dos meus pais, Romeu e Emília. Aos que virão depois, na figura da minha filha Thaís.

À vida que segue... 



\section{AGRADECIMENTOS}

À Profa. Dra. Amélia Pasqual Marques, pela generosidade e simplicidade com as quais distribui seus saberes, fruto de uma vivência que traz inspiração a todos a seu redor.

Ao meu companheiro desta trajetória Prof. Ms. Bruno Gonçalves Dias Moreno, pela parceria e incentivo que renovam a esperança de um futuro melhor.

Ao Prof. Dr. Osvaldo Crivello Júnior, por participar do processo de seleção das pacientes estudadas, pelas sugestões e orientações após o desenvolvimento deste trabalho.

Ao Prof. Dr. Carlos Alberto de Bragança Pereira e à Profa. Dra. Gislaine Bortolotti, pelas contribuições e por se mostrarem sempre disponíveis aos esclarecimentos da análise estatística.

Às pacientes da pesquisa, que confiaram neste trabalho, com uma participação que muitas vezes me comoveu.

Aos colegas e amigos que supriram com maestria as lacunas deixadas pela minha ausência durante este período, e souberam me compreender nos momentos difíceis com paciência e carinho.

Aos meus pais, Romeu e Emília, pelo incentivo e apoio em todos os momentos. 
Esta dissertação está de acordo com as seguintes normas, em vigor no momento desta publicação:

Referências: adaptado de International Committee of Medical Journals Editors (Vancouver). Requisitos uniformes para manuscritos/ International Committee of Medical Journal Editors Rev. Saúde Pública, 33 (1), 1999.

Universidade de São Paulo. Faculdade de Medicina. Serviço de Biblioteca e Documentação. Guia de apresentação de dissertações, teses e monografias. Elaborado por Anneliese Carneiro da Cunha, Maria Julia de A.L. Freddi, Maria F. Crestana, Marinalva de Souza Aragão, Suely Campos Cardoso, Valéria Vilhena. $2^{\mathrm{a} e d . ~ S a ̃ o ~ P a u l o: ~}$ Serviço de Biblioteca e Documentação; 2005.

Abreviaturas dos títulos dos periódicos de acordo com List of Journals Indexed in Index Medicus. 


\section{SUMÁRIO}

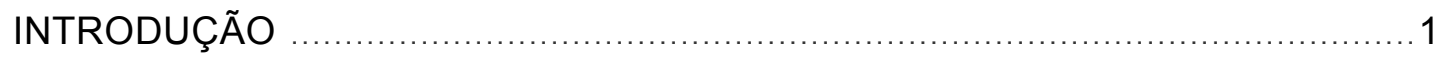

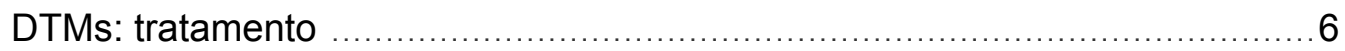

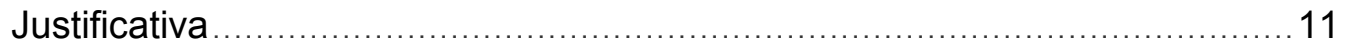

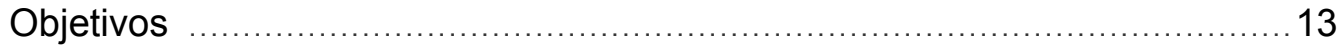

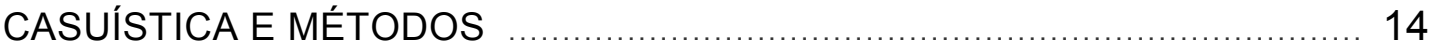

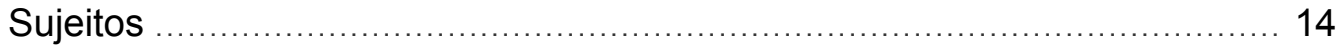

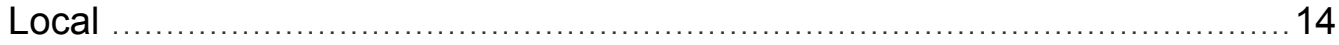

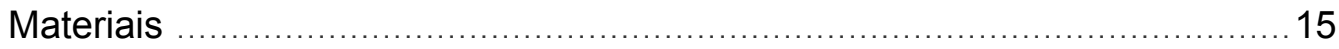

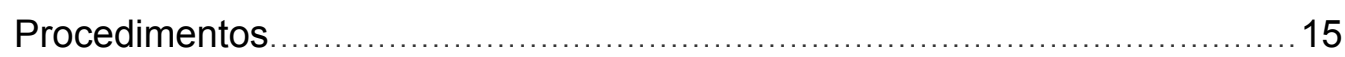

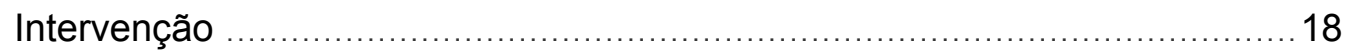

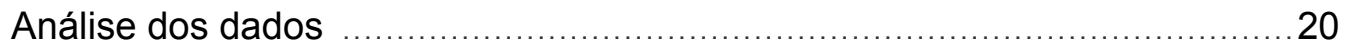

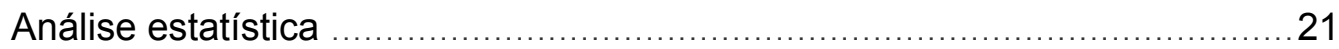

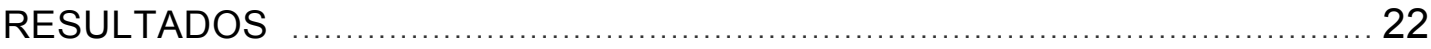

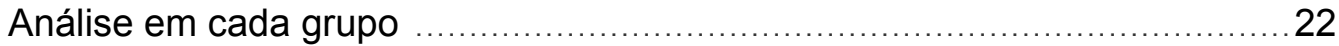

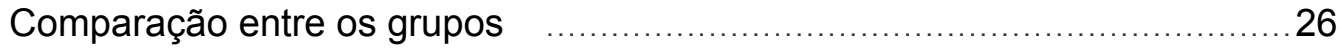

DISCUSSÃO

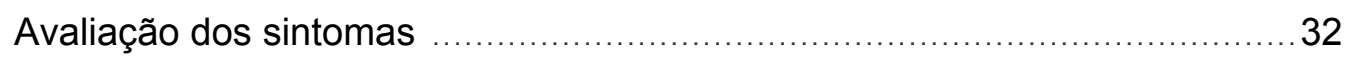

Avaliação da dolorimetria e eletromiografia .......................................... 37

Avaliação da qualidade de vida ....................................................... 40

Alongamento global $X$ alongamento segmentar .............................. 41

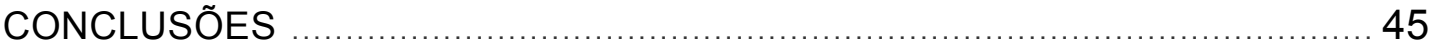

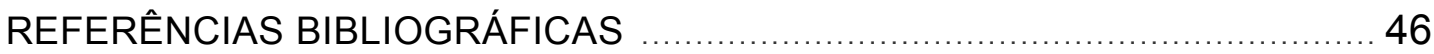

\section{ANEXOS}

Anexo 1: Termo de consentimento livre e esclarecido ..................................55

Anexo 2: Aprovação do Comitê de Ética .................................. 56

Anexo 3: Ficha de avaliação e interpretação do índice de Helkimo . ....... 57

Anexo 4: Ficha de avaliação utilizado com pacientes (modelo) ............... 59

Anexo 5: Questionário de avaliação de qualidade de vida SF-36 ...........61 61

Anexo 6: Descrição e ilustração das pompages e dos exercícios de alongamento 
viii

\section{LISTAS}

\section{Lista de tabelas}

Tabela 1 Características biodemográficas das pacientes

Tabela 2 Média e desvio padrão (DP) dos sintomas avaliados pela EVA, na 1ạ, 2ạ, e 3a avaliações (Av) e valor de p da comparação entre as mesmas

Tabela 3 Média e desvio padrão (DP) da dolorimetria dos músculos masseter, temporal, esternocleidomastóideo (ECOM) e trapézio superior, na 1a, 2a , e 3a avaliações (Av) e valor de $p$ da comparação entre as mesmas .

Tabela 4 Média e desvio padrão (DP) da atividade eletromiográfica (EMG) dos músculos masseter, temporal, esternocleidomastóideo (ECOM) e trapézio superior, na 1a, 2ạ, e $3 \underline{a}$ avaliações (Av) e valor de $p$ da comparação entre as mesmas

Tabela 5 Média e desvio padrão (DP) da qualidade de vida medida pelo questionário SF-36, na 1ạ, 2a , e 3a avaliações (Av) e valor de p da comparação entre as mesmas 


\section{Lista de figuras}

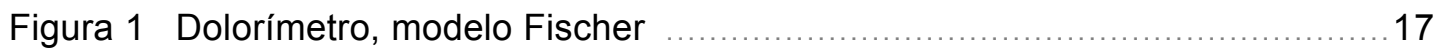

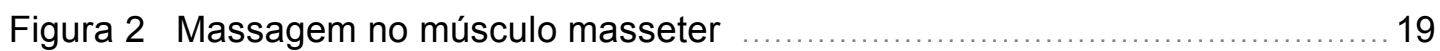

Figura 3 Comparação dos resultados sobre os sintomas dor, ATM, cefaléia e cervicalgia entre os grupos RPG e AES, entre a 1ạ e 2a avaliações (à esquerda) e entre a 1a e $3 \underline{a}$ avaliações (à direita)

Figura 4 Comparação dos resultados sobre os sintomas apertamento, sintomas no ouvido, dificuldade em comer e dormir entre os grupos RPG e AES, entre a 1a e 2a avaliações (à esquerda) e entre a 1a e $3 \underline{a}$ avaliações (à direita)

Figura 5 Comparação dos resultados sobre a abertura da mandíbula entre os grupos RPG e AES, entre a 1a e 2a avaliações (à esquerda) e entre a $1 \underline{a}$ e $3 \underline{a}$ avaliações (à direita)

Figura 6 Comparação dos resultados da dolorimetria nos músculos masseter, temporal, esternocleidomastóideo (ECOM) e trapézio entre os grupos RPG e AES, entre a 1a e 2a avaliações (à esquerda) e entre a 1a e 3a avaliações (à direita)

Figura 7 Comparação dos resultados da eletromiografia nos músculos masseter, temporal, esternocleidomastóideo (ECOM) e trapézio entre os grupos RPG e AES, entre a 1ạ e 2a avaliações (à esquerda) e entre a 1a e $3 \underline{a}$ avaliações (à direita).

Figura 8 Comparação dos resultados da aplicação do questionário sobre qualidade de vida entre os grupos RPG e AES, entre a 1a e 2a avaliações (à esquerda) e entre a 1ạ e $3 \underline{a}$ avaliações (à direita) 



\section{RESUMO}

Maluf AS. Efeito da reeducação postural global e do alongamento estático segmentar em portadoras de disfunção temporomandibular. um estudo comparativo [dissertação]. São Paulo: Faculdade de Medicina, Universidade de São Paulo; 2006. 70p.

Pacientes com desordens temporomandibulares (DTMs) miogênicas em geral apresentam dor nos músculos elevadores da mandíbula durante a palpação e mastigação, com atividade eletromiográfica postural aumentada e limitação de movimento. Além disso, áreas vizinhas como ombros e região cervical podem apresentar tensão, encurtamentos musculares e pontos-gatilho. Os exercícios terapêuticos têm sido utilizados na reabilitação e prevenção das DTMs miogênicas, porém de forma associada a outros recursos da fisioterapia e/ou odontologia, o que impede a verificação clara de seus efeitos nas DTMs. Este estudo teve por objetivo comparar os efeitos da reeducação postural global (RPG) e do alongamento estático segmentar no tratamento de 24 mulheres portadoras de DTM miogênica, Helkimo III. Foram avaliadas a intensidade dos sintomas (por escalas visuais analógicas), a qualidade de vida (pelo questionário SF-36), a eletromiografia e dolorimetria dos músculos masseter, temporal, trapézio e esternocleidomastóideo. As 24 pacientes foram divididas randomicamente em dois grupos. O tratamento do primeiro grupo consistiu de duas posturas da RPG, uma para a cadeia anterior e outra para a cadeia posterior; o tratamento do segundo consistiu em alongamento segmentar dos músculos da mastigação, região cervical e membros superiores. Em ambos os protocolos foram acrescentadas manobras de pompage. Os dois grupos realizaram oito sessões individuais com freqüência semanal e duração de 40 minutos. Os dados foram analisados estatisticamente, com nível de significância de $5 \%$. Os resultados sugerem que os dois tipos de alongamento tiveram igual eficácia no alívio dos sintomas $(p<0,005)$, melhora da qualidade de vida $(p<0,005)$, diminuição da atividade eletromiográfica do músculo masseter $(p<0,005)$ e elevação do limiar de dor $(p<0,005)$, tanto logo após o tratamento quanto na reavaliação realizada dois meses depois por avaliador cego. 



\section{ABSTRACT}

Maluf SA. Postural global reeducation and segmental static stretch in individuals with temporomandibular disorder: a comparative study (dissertation). Sao Paulo: School of Medicine, University of Sao Paulo; 2006. 70p.

Patients with myogenic temporomandibular disorders (TMD) usually present pain at palpation and during mastication in mandible muscles, increased postural electromyographic activity, and movement limitation. Also, nearby areas such as shoulders and cervical region may present tension, muscle shortening and trigger points. Therapeutic exercises have been used in rehabilitation and prevention of myogenic TMDs; however, these are usually associated to other physical therapy or odontology resources, which prevents a clear assessment of the impact of the exercises alone. This study aims at comparing the effects of postural global reeducation (PGR) and segmental static stretch in treating 24 women with myogenic TMD, Helkimo III. Intensity of symptoms was evaluated by means of visual analog scales, quality of life by the SF-36 inventory, and electromyography and dolorimetry were measured at masseter, temporalis, trapezius and sternocleidomastoid muscles. Patients were randomly divided into two groups; group 1 treatment consisted of two PGR postures, one for the anterior chain and the other for the posterior muscle chain; group 2 treatment consisted of segmental stretch of the masticatory muscles, cervical region and upper limbs. Pompage manoeuvres were added to both protocols. Patients of both groups had 8 individual weekly sessions lasting 40 minutes each. Data were statistically analysed, with significance level set at $5 \%$. Results show that both kinds of stretching had the same effectiveness in relieving symptoms $(p<0.005)$, improving quality of life $(p<0.005)$, decreasing electromyographic activity in the masseter muscle $(p<0.005)$, and lifting pain threshold $(p<0.005)$, both immediately after treatment and in reevaluation held two months later by a blind assessor. 



\section{INTRODUÇÃO}

A desordem temporomandibular (DTM) abrange vários sintomas clínicos que envolvem a musculatura da mastigação, a articulação temporomandibular (ATM) e estruturas associadas, cujas características mais comuns são dor crônica, fadiga, sensibilidade nos músculos da mastigação, ruídos e limitação de movimento (Minoru, 1995; Molina, 1989; Mongini, 1998).

A Academia Americana de Disfunções Temporomandibulares caracteriza a etiologia das DTMs como multifatorial, considerando: fatores predisponentes (discrepâncias estruturais, distúrbios psicológicos, comportamentais, desequilíbrios metabólicos); fatores desencadeantes (trauma, resposta adversa ao estresse, problemas artrogênicos, infecção); fatores idiopáticos e fatores perpetuantes (inter-relação dos dois fatores anteriores aliados a uma incapacidade de adaptação por parte do indivíduo). O papel exato de tais agentes etiológicos na fisiopatologia das DTMs varia muito para cada indivíduo (Mcneill, 1993).

Dificilmente os sinais e sintomas relacionados à ATM se apresentam de forma isolada (Steenks e Wijer, 1996). Segundo Okeson (1998), as DTMs podem ser classificadas em: desordens congênitas e de desenvolvimento, desordens de desarranjo de disco com ou sem redução, travamento ou subluxação, desordens inflamatórias locais ou sistêmicas, osteoartrite, fraturas e desordens dos músculos da mastigação.

A DTM pode ser classificada também como miogênica, quando os fatores que levam os pacientes a manifestar sintomas são de origem muscular, e artrogênica, quando esses fatores têm origem articular degenerativa (Conti e Silva, 2004).

A dor de origem muscular representa a queixa mais comum nas DTMs. É um sintoma complexo que envolve alterações periféricas e centrais. A dor não é a simples condução de impulsos nociceptivos que percorrem sua trajetória até o córtex cerebral, onde são interpretados. O que é sentido como dor não necessariamente vem do estímulo dos receptores, mas pode ser uma alteração no mecanismo central de modulação da dor. Sobretudo nos quadros crônicos, o 
impulso nociceptivo contínuo pode provocar deficiências nos caminhos descendentes supressores de dor, desencadeando um círculo vicioso que se retroalimenta. A intensidade da dor está relacionada com a experiência précondicionante, atenção, atitude e temperamento do indivíduo (Douglas, 2000; Okeson, 1998). Dentre as principais características das dores musculares pode-se destacar a dor relacionada à demanda funcional, à palpação com resposta gradual, aumento da atividade eletromiográfica e presença de pontos-gatilho (Conti e Silva, 2004). Ponto-gatilho é uma área bem localizada de hipersensibilidade no músculo e/ou na fáscia, a partir do qual impulsos bombardeiam o sistema nervoso central, causando dor referida (Manheimer e Lampe, 1984; Tollison e Kriegel, 1989).

Steenks e Wijer (1996) relatam que, além da dor, esses pacientes podem apresentar outros sinais e sintomas como cefaléia, ruídos articulares, limitação dos movimentos, dor e fadiga dos músculos mastigatórios, zumbidos no ouvido e vertigens.

Distúrbios do sono são muito comuns em pacientes vítimas de dor crônica, e podem estar presentes nas disfunções musculares. Quando alterações do sono são identificadas, deverá ser verificado se estas representam um fator agravante, como causa ou como conseqüência das desordens de ATM (Marzola et al., 2002).

Evidências disponíveis relacionam a hiperatividade da musculatura mastigatória com alguns tipos de cefaléias tensionais, as quais podem ser precipitadas pela mal-oclusão dentária. Quando existe essa suspeita, é indicado ao paciente tratamento adequado para reduzir a atividade muscular (Okeson, 1998).

Outro fator etiológico importante nas DTMs está relacionado às parafunções, ou funções inadequadas (hábitos de ranger ou apertar os dentes, roer unhas, chupar os dedos, morder bochecha, mascar chiclete) influenciadas por estímulos do sistema nervoso central. Segundo Biasotto-Gonzalez (2005), achados etiológicos mostram que este é o fator mais comum nas DTMs miogênicas e que pode contribuir para desarranjos internos da ATM. Ressalta também que esses hábitos podem ser exacerbados por mal-oclusão, alterações posturais, alterações emocionais, traumas, doenças sistêmicas ou desordens de crescimento. 
O expressivo número de pacientes portadores de DTM e a diversidade de sinais e sintomas por eles apresentados tornam obrigatório um conhecimento adequado da doença e estudos cuidadosos para sua correta ordenação. Nesse sentido, devido à dificuldade em classificar os pacientes portadores de DTM, não só para fins estatísticos e didáticos, mas também para seu acompanhamento e evolução em ambulatórios, onde o número de pacientes é elevado, foram criados índices de classificação que servissem a esses objetivos.

Helkimo (1974a,b,c) propôs um índice clínico para avaliação da ocorrência de DTM entre os lapões do Norte da Finlândia. Esse índice foi criado para estudos de grandes populações, visando categorizar epidemiologicamente as DTMs. Tendo em vista a simplicidade de sua aplicação (pelas informações obtidas pelo exame clínico), a abrangência de seus itens (movimento mandibular, envolvimento muscular e dor na ATM) e a rapidez da classificação dos pacientes em grupos preestabelecidos (pela soma de pontos obtidos em cada um dos itens estudados), a aplicação desse índice, não só para estudos epidemiológicos, como também para classificação de pacientes ambulatoriais, é sem dúvida interessante (Fonseca, 1992).

Outra classificação muito utilizada, referente à oclusão, é a de Angle, que toma como parâmetro a posição da mandíbula no plano sagital, de tal forma que na classe I (normooclusão) a oclusão é normal, na classe II (retrognatismo) a mandíbula encontra-se recuada e, na classe III (prognatismo), a mandíbula encontrase deslocada anteriormente, com o primeiro molar inferior localizado à frente do superior (Conti e Silva, 2004).

As DTMs podem ocorrer em todas as faixas etárias, mas sua maior prevalência é entre 20 e 45 anos. Entre 15 e 30 anos a causa mais freqüente é de origem muscular e, a partir de 40 anos, é de origem articular. As mulheres são mais acometidas que homens em uma proporção de cinco mulheres para cada homem (Okeson, 1998). A prevalência é maior em mulheres principalmente na fase reprodutiva, diminuindo após a menopausa, sugerindo uma participação de hormônios reprodutivos no desenvolvimento ou manutenção das DTMs (Franco et al., 2005). 
De acordo com Ash e Ramfjord (2001), estudos populacionais indicam que $70 \%$ da população apresenta um ou mais sinais de distúrbios temporomandibulares e musculares, e um terço destes apresentam um ou mais sintomas.

A ATM faz parte do sistema estomatognático que, juntamente com os dentes, periodonto, coluna cervical, crânio e cintura escapular, é responsável pela mastigação, fonação, deglutição, respiração e expressão facial (Douglas, 1998). Esse sistema, por sua vez, está unido estrutural e funcionalmente ao corpo como um todo. Um desequilíbrio nessa região poderá afetar todo o conjunto e viceversa, portanto uma intervenção terapêutica pode ser local e/ou sistêmica, para restabelecer o equilíbrio global (Amantea et al., 2004; Bricot, 2001).

Vários estudos com modelo experimental (Bracco et al., 2004; Koolstra e Van Eiden, 2004; Shimazaki et al., 2003; Yoshino et al., 2003) evidenciam a relação entre DTM e alterações posturais, principalmente relacionadas à coluna cervical e cabeça. Alterações do plano oclusal, bem como o desequilíbrio da sinergia dos músculos da mastigação podem alterar a posição da cabeça e/ou do pescoço. Em indivíduos classe II na classificação de Angle, a coluna cervical tende à hiperlordose e os ombros, à protrusão. Na classe III, as curvas tendem a se retificar (Biasotto-Gonzalez, 2005; Bricot, 2001).

Os contatos oclusais podem se modificar conforme a posição da cabeça. Nas inclinações da cabeça, o contato oclusal aumenta ipsolateralmente. Na flexão da cabeça, o contato é maior nos dentes anteriores, ocorrendo o deslocamento anterior da mandíbula, aumento de tensão na musculatura posterior da coluna cervical e diminuição na anterior. Quando a cabeça está em extensão, ocorre o oposto (Biasotto-Gonzalez, 2005).

Os movimentos da mandíbula alteram ainda a posição da cabeça, que realiza uma extensão na abertura da mandíbula, retornando no fechamento (Kohno et al., 2001). Um modelo biomecânico foi aplicado por Koolstra e Van Eiden (2004) para compreender o significado desse movimento; as simulações mostraram que a abertura da mandíbula acompanhada da extensão da cabeça alongam os músculos da abertura, contribuindo para uma amplitude maior. 
A postura também foi estudada por Bracco et al. (2004) em 95 pacientes submetidos a uma análise posturométrica e estabilométrica, utilizando uma plataforma de força computadorizada. Todos os pacientes apresentaram variações posturais à medida que a posição da mandíbula era modificada.

A eletromiografia (EMG) tem sido um recurso importante no auxílio ao diagnóstico, permitindo também avaliar a eficácia de tratamentos aplicados em indivíduos com DTM. Ash e Ramfjord (2001), em estudo clínico e eletromiográfico, avaliaram a relação entre fatores oclusais e dores na região da ATM, concluindo que as alterações oclusais são acompanhadas de contrações musculares assincrônicas e alterações no tônus dos músculos masseter e temporal.

Svensson et al. (2004) testaram a relação entre os efeitos da dor provocada pela injeção de glutamato, registrada por escala visual analógica, e da eletromiografia dos músculos masseter, esternocleidomastóideo e esplênios em 19 homens. O glutamato foi injetado no músculo masseter direito e uma semana depois nos esplênios, e a dor induzida foi registrada na escala visual analógica. Concluíram que a dor experimental no pescoço não está associada com aumento na atividade eletromiográfica da mandíbula, embora a dor nos músculos da mandíbula possa estar relacionada ao aumento da atividade eletromiográfica no pescoço.

Gadotti et al. (2005) analisaram bilateralmente a posição da cabeça e a atividade eletromiográfica da parte anterior do músculo temporal e masseter de pacientes com diferentes classificações de oclusão odontológica usando o método Angle. Os resultados indicaram que indivíduos com oclusão classe II tendem a apresentar maior ocorrência de anteriorização da cabeça, com alterações na atividade muscular padrão nos músculos masseter e temporal.

Kazuyoshi et al. (2005) realizaram um estudo com 103 sujeitos bruxistas de ambos os sexos e concluíram que ambos apresentaram estalidos articulares enquanto permaneciam em ativação eletromiográfica do músculo masseter durante o sono.

Pallegama et al. (2004) estudaram sinais eletromiográficos dos músculos trapézio superior e esternocleidomastóideo de pacientes com DTM miogênica e 
artrogênica e encontraram uma importante associação entre o aumento da atividade eletromiográfica nos pacientes com desordem miogênica. Carlson e Curran (1994) relatam associação de intensidade de dor nas DTMs miogênicas e EMG.

\section{DTMs: tratamento}

A articulação temporomandibular (ATM), sede de comprometimentos de causas multifatoriais, tem sido objeto de estudo da Odontologia. O tratamento mais freqüente da DTM é pois o odontológico, que inclui o uso de placas miorrelaxantes ou interoclusais, com o objetivo de proteger os dentes de forças traumáticas e desprogramar a musculatura tensa, levando a mandíbula a uma posição adequada (Biasotto-Gonzalez, 2005). Apesar de seu sucesso clínico, o mecanismo fisiológico da resposta ao tratamento ainda não é bem conhecido e não existem protocolos científicos bem estabelecidos para a utilização dessas placas; cada caso deve ser avaliado individualmente (Conti e Silva, 2004; Okeson, 1998). Além disso, várias medidas diferentes são adotadas para avaliar seus resultados. Uma padronização dos métodos usados para medir os resultados do tratamento de dor miofascial deveria ser estabelecida em futuras pesquisas (AlAni et al. 2005; Steed, 2004).

Dado que as DTMs têm causas multifatoriais e devido à complexidade do tratamento, bem como à evolução das pesquisas, têm surgido propostas de tratamento em outras abordagens, para que o sucesso esperado de cura seja atingido. Nesse sentido, a fisioterapia tem muito a contribuir, pois a ATM é uma articulação e, como tal, tem a mesma estrutura e segue os mesmos princípios das demais articulações do aparelho locomotor, que é estudado, avaliado e tratado pelos fisioterapeutas.

Os estudos de revisão para verificar a influência da fisioterapia nas DTMs relatam que esta se insere entre as terapias de suporte no tratamento das DTMs visando abolir sinais e sintomas, mantendo ou recuperando a atividade funcional num menor espaço de tempo (Fricton, 1995; Marzola et al., 2002; Medlicott e Harris, 2006; Porto, 2002; Sturdivant e Fricton, 1991). Há uma estreita relação entre disfunções da ATM e alterações posturais, sendo que o tratamento fisioterapêutico é de extrema importância nessas disfunções, bem como após intervenções cirúrgicas (Tedeshi e Marques 1999). 
Os exercícios terapêuticos têm efeitos benéficos na dor e nas seqüelas da inatividade crônica do sistema musculoesquelético (Feine et al., 1997). A melhora dos sintomas e da função é clinicamente significante maior nos grupos tratados do que nos grupos controle/sem tratamento, não havendo, porém, diferença entre as várias formas de procedimento fisioterapêutico (Murphy, 1997). A combinação de várias abordagens terapêuticas é mais eficaz que somente uma (Brown e Gaudet, 2002; Matta e Honorato, 2003), embora Al-Ani et al. (2005), revisando estudos randomizados que comparavam o uso da placa com outro procedimento, inclusive exercícios terapêuticos, referem que a placa sozinha pode ser benéfica em reduzir a dor ao repouso e à palpação .

Um estudo de revisão bibliográfica com o objetivo de verificar a eficácia de exercícios domiciliares na DTM miogênica não chegou a resultados conclusivos, argumentando que existe necessidade de estudos clínicos randomizados (Michelotti et al., 2005).

Mcneely et al. (2006) analisaram a eficácia das intervenções físicas nas DTMs, concluindo que dois estudos forneceram evidência da sustentação de exercícios posturais para reduzir a dor e para melhorar a função e a abertura oral. Um estudo forneceu evidência para o uso da terapia manual em combinação com exercícios ativos na redução da dor e melhora da abertura oral. Outro forneceu evidência da acupuntura para reduzir a dor, quando comparada a nenhum tratamento.

Uma revisão sistemática (Medlicott e Harris, 2006) analisou os estudos que verificaram a eficácia de várias intervenções fisioterapêuticas nas DTMs, concluindo que os exercícios ativos e as mobilizações manuais podem ser eficazes; o treinamento postural pode ser usado em combinação com outras intervenções, porque seus efeitos independentes são desconhecidos; a terapia a laser pode ser mais eficaz do que outras modalidades eletroterapêuticas; os programas que incluem biofeedback, relaxamento e reeducação proprioceptiva podem ser mais eficazes do que o tratamento placebo ou o splint oclusal, e as combinações de exercícios ativos, terapia manual, correção postural e técnicas do relaxamento podem ser eficazes. 
As orientações associadas aos exercícios terapêuticos e terapia manual podem ser uma estratégia eficaz no tratamento de pacientes com deslocamento de disco (Cleland e Palmer, 2004; Yoda et al., 2003). Entretanto, através de ressonância magnética, foi visto que somente em $23,1 \%$ dos pacientes o disco foi reposicionado (Yoda et al., 2003).

A associação de placa e exercícios terapêuticos no deslocamento anterior de disco apresentou taxa mais elevada de eficácia $(60,0 \%)$ no reposicionamento do disco do que o tratamento isolado só com placa de estabilização $(52,6 \%)$ ou só exercício (41,7\%) (Yoda et al., 2006). Já Stiesch-Scholtz et al. (2002) verificaram maior porcentagem de diminuição da dor e aumento da abertura da mandíbula em pacientes com deslocamento anterior de disco sem redução, tratados com placa e medicação do que os tratados com placa e fisioterapia.

O emprego da terapia física no tratamento das desordens temporomandibulares não é recente. A fisioterapia dispõe de recursos manuais, eletro, termo e fototerápicos, além de cinesioterápicos. Esses procedimentos têm se mostrado eficientes no auxílio da analgesia, no pós-cirúrgico e nas alterações miofuncionais dos músculos mastigatórios e posturais (Adiels et al., 2005; Grossi et al., 2002; Marzola et al., 2002; Nicolakis et al., 2002; Yoda et al., 2003).

Os exercícios terapêuticos têm sido muito empregados na reabilitação e prevenção das DTMs miogênicas (Grace et al., 2002; Mcneely et al., 2006; Medlicott e Harris, 2006; Michelotti et al., 2004; Nicolakis et al., 2002; Truelove et al., 2006; Yoda et al., 2003). São utilizados com o objetivo de melhorar a função para atender as demandas da vida diária. Através do relaxamento e do alongamento ocorre diminuição da dor e restauração da função normal, o que reduz a inflamação, diminui e coordena a atividade muscular e promove a reparação e regeneração muscular (Okeson, 1998; Rocabado,1979).

Programas sugeridos para os portadores de DTM com dor muscular e/ou restrição de mobilidade incluem relaxamento, terapia manual, exercícios, treino proprioceptivo e reeducação postural. É ressaltada a importância da boa orientação e motivação para os exercícios em casa (Carlson et al., 2001; Grace et al., 2002; Michelotti et al., 2005). 
Exercícios de alongamento também são empregados. A fisiologia muscular permite afirmar que os exercícios de alongamento têm como efeito imediato um aumento da amplitude de movimento pelo decréscimo em sua viscoelasticidade (Magnusson et al., 2000; Mchught et al., 1992), porém, após um período de treinamento o aumento da amplitude se deve ao aumento do número de sarcômeros em série (Deyne, 2001; Godspink, 1999), o que aumenta o comprimento real do músculo.

Existem vários tipos de alongamento, sendo que o estático é dos mais eficientes, além de constar na literatura como o mais seguro (Alter, 1996; Smith, 1994). Segundo Líber e Friden (1999), a contração excêntrica é mais eficiente que o alongamento estático, embora seja necessário um cuidado maior devido ao risco de lesões. A facilitação neuromuscular proprioceptiva (FNP) produz mais resultados que o alongamento estático, mas é preciso um profissional treinado dando atenção exclusiva ao indivíduo (Cornelius et al., 1992: Hendel et al., 1997; Sady et al., 1982).

Apesar da existência de centenas de trabalhos científicos sobre 0 alongamento, é difícil estabelecer parâmetros exatos, como o tempo de duração, a repetição, freqüência e intensidade do alongamento. A falta de padronização das pesquisas, bem como a diversidade na forma de avaliar, contribuem para isso (Rosário et al., 2004). Entretanto, algumas pesquisas concluem que o tempo de permanência no alongamento estático por 30 segundos obteve melhores resultados que um tempo mais baixo, e obteve resultados semelhantes a um minuto, em uma população jovem (Bandy e Irion, 1994). Um alongamento de curta duração, segundo Kisner e Colby (1992), tem um efeito temporário e, se o mesmo for de 20 minutos ou mais, o efeito seria mais duradouro. Woo e Young (1991) referem que, quando uma força passiva é imposta a um material viscoelástico, o mesmo responde a ela segundo a intensidade e tempo de duração da aplicação da força.

Com relação à duração, ou ao número de semanas de treinamento, Magnusson et al. (2000) realizaram alongamento em isquiotibiais por três semanas e obtiveram aumento de amplitude de movimento. Knight et al. (2001) alongaram os flexores plantares por seis semanas, medindo os resultados na segunda, quarta e sexta semanas, e verificaram que houve aumento de amplitude 
ativa na segunda e quarta semanas; e na amplitude passiva, na sexta semana. Chan et al. (2001), pesquisando o alongamento em isquiotibiais, não encontraram diferença entre o grupo que alongou por quatro semanas e o grupo que alongou por oito semanas. Em todos esses estudos, o treinamento era de no mínimo três vezes por semana.

Apesar de a maioria dos trabalhos se referirem ao alongamento de um único músculo ou grupo muscular, sabe-se que o mesmo se encontra intimamente relacionado com a fáscia que o reveste e contém; é através dela que recebem nutrientes e - o que é importante do ponto de vista mecânico - transmitem e equilibram as tensões. Funcionalmente, não existe separação entre músculo e fáscia, ambos formando uma cadeia que põe em relação todo o sistema miofascial. Não existe um único músculo contraindo-se sozinho, mas colocando em ação uma cadeia cinética funcional, unida estruturalmente pelo sistema miofascial (Bienfait, 1999; Bricot, 2001; Busquet, 2000; Meyers, 2003; Rocabado, 1979; Rolf, 2002; Souchard, 1996).

Apoiados nesse princípio da globalidade, desenvolveram-se vários estudos inspirados nas idéias e experiência clínica da fisioterapeuta francesa Françoise Mézières na década de 1970, segundo a qual os músculos estão estruturados biomecanicamente em cadeias miofasciais (Marques, 2005). Tais cadeias são relacionadas sobretudo com a função estática anti-gravitacional e podem ser divididas em dois sistemas retos: anterior e posterior (Souchard, 2005). Seus componentes musculares, sempre em ação, possuem predominância de fibras lentas (tipo I), que apresentam tendência à hipertonia e grande quantidade de tecido conjuntivo, o que pode causar encurtamento. Daí a necessidade de recobrar seu comprimento e tônus adequado ao correto equilíbrio de tensões. Isso é possível por meio do alongamento global, associado à respiração e a estímulos proprioceptivos. Essa forma de trabalho é chamada de reeducação postural global, ou RPG.

O equilíbrio das tensões é de fundamental importância nas DTMs miogênicas, pois os músculos mastigatórios e cervicais estão submetidos a uma tensão constante e repetitiva, supostamente devido à parafunção, incoordenação, desequilíbrio biomecânico ou fatores emocionais (Nissani, 2001). 
Os estados de tensão emocional induzem espasmos musculares (Noble (1965), produzindo dor em diversos segmentos corporais, dentre os quais a ATM, podendo representar um dos fatores etiológicos da DTM (Yemm, 1969). Portanto, devem ser investigados, antes do tratamento, os hábitos bucais do paciente, traços de depressão e ansiedade, acontecimentos cotidianos estressantes, mudanças de estilo de vida, ganhos secundários e cuidados excessivos com a saúde, ou ausência deles (Okeson, 1998; Steed, 2004; Wexler, 1998).

Michelotti et al. (1998) verificaram a alta prevalência de um perfil psicológico relacionado á ansiedade nos pacientes com dor crônica devido às DTMs. Durante as situações de estresse pode ocorrer um aumento no tônus muscular da região da ATM e aparecimento de parafunção, o que aumenta o gasto energético, a fadiga, a isquemia, a pressão oclusal e articular e o desgaste dental. Todo esse quadro colabora para o aparecimento de disfunções e alterações estruturais; além disso, essas condições facilitam o aparecimento dos pontos-gatilho, provocando dor.

A dor crônica tem um caráter intersubjetivo, pois não atinge somente o indivíduo que a sofre, mas seu meio mais próximo: família, amigos. Apresenta também uma dimensão econômica, se considerarmos os gastos com tratamento, previdência e afastamento do trabalho. Conseqüentemente, o impacto na qualidade de vida deve ser analisado para uma abordagem terapêutica mais ampla.

Um instrumento para avaliar a qualidade de vida relacionada a aspectos da saúde é a versão brasileira do Questionário Genérico de Qualidade de Vida SF36, traduzido e validado por Ciconelli et al. (1999). Esse questionário avalia a qualidade de vida em oito domínios específicos: capacidade funcional, limitação por aspectos físicos, dor, estado geral de saúde, vitalidade, aspectos sociais, limitação por aspectos emocionais e saúde mental, e apresenta um escore de 0 a 100. Quanto maior a pontuação no questionário, melhor a qualidade de vida do indivíduo.

\section{Justificativa}

A DTM é uma síndrome complexa, cuja etiologia multifatorial exige uma abordagem multiprofissional. A utilização da fisioterapia nas DTMs pode contribuir 
para a boa evolução do paciente, porém sua abordagem ainda é tímida e requer mais pesquisas que comprovem sua eficácia, possibilitando a validação e sistematização dos protocolos empregados.

Nas DTMs miofuncionais, a maioria dos pacientes apresenta dor nos músculos elevadores da mandíbula durante a palpação, e aproximadamente $40 \%$ deles relatam dor à mastigação, com atividade eletromiográfica postural aumentada, cefaléia e limitação de movimento. Além disso, áreas vizinhas como ombros e região cervical podem apresentar tensão, encurtamentos musculares e pontosgatilho. A quantificação dos sintomas, bem como das respostas aos procedimentos fisioterapêuticos aplicados, demonstraria a eficácia das técnicas utilizadas.

Os exercícios terapêuticos têm sido muito empregados na reabilitação e prevenção das DTMs miogênicas. São utilizados com o objetivo de melhorar a função para atender as demandas da vida diária. Por meio do relaxamento e do alongamento, ocorre diminuição da dor e restauração da função normal, o que reduz a inflamação, equilibra a atividade muscular e promove a reparação e regeneração muscular. O alongamento pode ser feito de forma global, trabalhando uma ou mais cadeias musculares, ou segmentar, enfatizando um único grupo muscular. A escassez de trabalhos que avaliem e comparem a eficácia dessas diferentes técnicas evidencia a necessidade de novos estudos.

Nos trabalhos consultados, referentes a ensaios clínicos, os recursos fisioterapêuticos são empregados de forma combinada entre si (exercícios, terapia manual, termoterapia, fototerapia, eletroterapia e reeducação postural) ou integrados à odontologia, o que impede a verificação clara da contribuição dos exercícios de alongamento nas DTMs.

Além disso, considerando que o quadro da DTM tende a se tornar crônico, comprometendo a capacidade funcional e a qualidade de vida dos pacientes, justifica-se a utilização de instrumento que evidencie a dimensão do impacto da DTM na vida do paciente. 


\section{Objetivos}

Este estudo teve por objetivo comparar os efeitos da reeducação postural global (RPG) e do alongamento estático segmentar (AES) na dor, qualidade de vida, apertamento, dificuldade de dormir, mobilidade articular, dolorimetria e

eletromiografia dos músculos masseter, temporal, trapézio e esternocleidomastóideo, em mulheres portadoras de DTM miogênica, Helkimo III.

\section{Objetivos secundários}

- Avaliar a atividade elétrica dos músculos temporal, masseter, trapézio superior e esternocleidomastóideo, antes e após intervenção fisioterapêutica.

- $\quad$ Avaliar as medidas dos movimentos da mandíbula, antes e após intervenção fisioterapêutica.

- $\quad$ Avaliar a intensidade dos sintomas antes e após intervenção fisioterapêutica.

- Verificar se existe correlação entre alteração dos sintomas e os diferentes tipos de alongamento (global e segmentar).

- Verificar se existe correlação entre alteração na qualidade de vida e os diferentes tipos de alongamento (global e segmentar). 


\section{CASUÍSTICA E MÉTODO}

\section{Sujeitos}

Foram selecionadas para esta pesquisa 28 mulheres, com idade variando de 19 a 40 anos, divididas por sorteio em dois grupos: um foi submetido a alongamento global em duas posturas do método da Reeducação Postural Global (RPG); e o outro praticou alongamento estático segmentar (AES).

As pacientes com DTM foram encaminhadas pelo Departamento de Cirurgia, Prótese e Traumatologia Maxilo-Faciais da Faculdade de Odontologia da Universidade de São Paulo. Todas as voluntárias assinaram o termo de consentimento livre e esclarecido (Anexo 1) e o projeto de pesquisa foi aprovado pela CAPPesp - Comissão de Ética para Análise de Projeto de Pesquisa da Diretoria Clínica do Hospital das Clínicas da Faculdade de Medicina da Universidade de São Paulo (Anexo 2).

Os critérios de inclusão para as pacientes eram: apresentar quadro clínico correspondente ao Índice de Helkimo III (Anexo 3), DTM do tipo miogênica e ter hábito parafuncional. Foram excluídas pacientes que apresentavam mais de duas falhas dentárias, eram portadoras de trauma direto ou cirúrgico na região orofacial, portadoras de doença sistêmica ou degenerativa, pacientes que estivessem sob tratamento odontológico, psicológico ou fisioterapêutico.

Das 28 pacientes selecionadas, quatro foram excluídas, duas de cada grupo. Uma abandonou por motivo desconhecido, as demais pelos seguintes motivos: incompatibilidade de horário, sintomas relacionados a complicações de fratura nas duas primeiras vértebras cervicais (causada por acidente de carro) e constatação de patologia associada (fibromialgia). Os dados apresentados a seguir referem-se pois a 24 pacientes.

\section{Local}

A pesquisa foi realizada no Laboratório de Avaliação Fisioterapêutica Clínica e Eletromiografia do Centro de Docência e Pesquisa do Departamento de Fisioterapia, Fonoaudiologia e Terapia Ocupacional da FMUSP. 


\section{Materiais}

Foram utilizados os seguintes materiais:

- $\quad$ eletromiógrafo CAD 12/32 (EMG System do Brasil): amplificador de oito canais e conversor analógico-digital com resolução de 12 bits, interfaciado com um computador e programa de aquisição de dados (AqDados 5.0), sendo as coletas realizadas com freqüência de amostragem de $1000 \mathrm{~Hz}$. A largura de faixa foi determinada com passa-alta de $20 \mathrm{~Hz}$ e passa- baixa de $500 \mathrm{~Hz}$;

- $\quad$ eletrodos: ativos de superfície (EMG System do Brasil ${ }^{\circledR}$ ), acoplados a uma cápsula de poliuretano contendo um microcircuito elétrico, o qual permitiu que o sinal EMG fosse pré-amplificado com um ganho de 20 vezes por eletrodo e um ganho total de 1000 vezes; material dos eletrodos $\mathrm{Ag} / \mathrm{AgCl}$, bipolar, com distância de $10 \mathrm{~mm}$, forma circular e tamanho de $1 \mathrm{~cm}$;

- $\quad$ gerador universal de pulsos Nemesys (Quark ${ }^{\circledR}$ );

- $\quad$ esparadrapo Transpore $\left(3 \mathrm{M}^{\circledR}\right)$;

- $\quad$ eletrodos adesivos (Meditrace ${ }^{\circledR}$ );

- $\quad$ Escala Visual Analógica (EVA): constituída por uma linha de $10 \mathrm{~cm}$ de comprimento traçada em uma folha de papel, tendo em sua extremidade esquerda uma expressão indicando a ausência do sintoma (por exemplo, "nenhuma dor") e, em sua extremidade direita, uma expressão referente ao extremo oposto (“dor insuportável”);

- dolorímetro Fischer: é um instrumento com ponta de $1 \mathrm{~cm}$ de diâmetro revestida de borracha firme, com função de registrar a pressão aplicada sobre a pele em libras ou kgf (quilograma-força);

- $\quad$ computador Pentium III;

- $\quad$ paquímetro plástico (Marberg ${ }^{\circledR}$ )

- mesa para RPG

- $\quad$ radiografias: realizadas em perfil esquerdo, filme de 18 por $24 \mathrm{~cm}$, a $1,80 \mathrm{~m}$ de distância da paciente e uma voltagem de $70 \mathrm{kV}$ (quilovolts).

\section{Procedimentos}

\section{Avaliação}

Foi realizado o mesmo procedimento de avaliação com todas as voluntárias participantes da pesquisa em três momentos: antes, logo após a intervenção, e dois meses mais tarde, por um avaliador cego. Os dados foram registrados em 
uma ficha (Anexo 4). Consistiu de avaliação da intensidade da dor e de sintomas, dolorimetria, mensuração da amplitude de movimento da abertura da mandíbula, registro eletromiográfico da atividade muscular, raios $X$ da coluna cervical $e$ aplicação de questionário sobre qualidade de vida.

Para avaliar cada um dos sintomas - dor, cefaléia, cervicalgia, sintomas no ouvido, apertamento dos dentes e dificuldade de dormir e comer - foram utilizadas escalas analógicas visuais (EVA) tal como descritas acima. As expressões indicadas nas extremidades da régua, para cada sintoma, foram ( $v$. Anexo 4):

dor, cefaléia e cervicalgia - sem dor, dor insuportável;

apertamento dos dentes - ausência de apertamento, apertamento máximo; sintomas no ouvido - sem sintoma, sintoma insuportável;

dificuldade de dormir e de comer - nenhuma dificuldade, muita dificuldade.

Explicando-se à paciente o que representava a reta traçada, pedia-se que assinalasse o ponto que melhor correspondia a sua situação com um traço vertical na reta.

Para avaliar o limiar de dor dos músculos mastigatórios e cervicais foi utilizado um dolorímetro (Figura 1), aparelho que mede a força aplicada sobre um ponto de sensibilidade dolorosa (Fischer, 1987). $\mathrm{Na}$ extremidade emborrachada do dolorímetro, cuja superfície tem $1 \mathrm{~cm}$ de diâmetro, é aplicada pressão perpendicular à superfície da pele, enquanto um manômetro registra essa pressão. Quando a paciente refere dor, o valor da pressão aplicada corresponde ao limiar de dor naquele ponto. Quando um indivíduo percebe dor com uma pequena intensidade de pressão, maior é sua sensibilidade. Assim, quanto mais baixo o limiar, mais intensa maior é a sensibilidade dolorosa.

Simons e Hong (1998) relatam em seu estudo haver uma relação entre a região de formação de pontos-gatilho musculares e a localização do ponto motor dos músculos, portanto a dolorimetria foi realizada nos pontos motores dos músculos esternocleidomastóideo, trapézio superior, temporal anterior e masseter, no lado correspondente à queixa maior de dor. Todas as participantes permaneceram deitadas em decúbito dorsal, com a cabeça levemente rodada 
para o lado oposto ao avaliado. A avaliação foi padronizada nos referidos pontos para garantir não só que o mesmo local fosse avaliado, como também para assegurar a reprodutibilidade do procedimento.

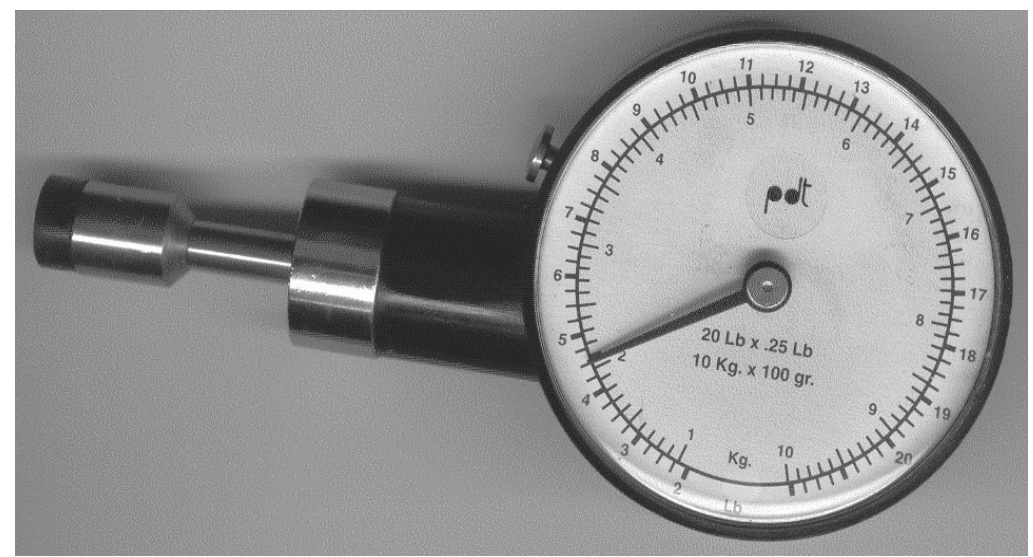

Figura 1 Dolorímetro modelo Fischer

Neste estudo consideraram-se resultados positivos da dolorimetria aqueles abaixo de 2,6 kg/cm ${ }^{2}$, limite este que equivale ao de $4,0 \mathrm{~kg} / \mathrm{cm}^{2}$ descrito nos estudos de Wolfe et al. (1990). Quando esses autores definiram o limite de 4,0 kg/cm ${ }^{2}$, foi utilizado um dolorímetro com ponta de $1,54 \mathrm{~cm}$ de diâmetro. $O$ utilizado neste estudo tem apenas $1,0 \mathrm{~cm}$; por uma simples regra de três, chega-se ao valor de $2,6 \mathrm{~kg} / \mathrm{cm}^{2}$, correspondente ao de Wolfe. Assim, os pontos positivos são aqueles em que o sujeito sente dor com pressão inferior a 2,6 kg/ $\mathrm{cm}^{2}$ (Marques et al., 2005).

Para localização do ponto-motor, a pele foi previamente limpa com gaze embebida em solução alcoólica e os pontos rastreados com um eletrodo de caneta acoplada ao aparelho Nemesys, modulado com uma corrente ultra excitante, tempo de pulso de 0,5 milissegundos, freqüência de $150 \mathrm{~Hz}$, ciclo on de 0,5 segundos, ciclo off de 0,5 segundos e amplitude entre 4 a 6 miliamperes, de acordo com a sensibilidade de cada voluntária. O ponto motor coincide com o local onde ocorre maior contração muscular.

A avaliação da atividade eletromiográfica (EMG) foi realizada nos músculos esternocleidomastóideo, trapézio superior, temporal anterior e masseter, no lado onde referiam os sintomas de DTM. Os eletrodos foram colocados nos pontos motores, localizados de acordo com o procedimento descrito anteriormente, uma 
vez que estudos têm demonstrado que essa técnica promove maior confiabilidade na aquisição do sinal eletromiográfico, diminuindo a possibilidade de ruído (cross talk), além de permitir a reprodução de estudos antes e depois de intervenções clínicas (Sacco et al., 2006); o eletrodo terra foi colocado na superfície ventral do pulso dos sujeitos avaliados (Suvinen et al., 2003). Durante a captura da atividade muscular, os indivíduos permaneceram em repouso, sentados em um banco sem apoio para as costas, com as mãos repousando sobre os joelhos, com os pés calçados e apoiados com igual distribuição de carga. Em cada participante, foram registradas três coletas da atividade, com duração de sete segundos cada.

A amplitude do movimento de abertura da mandíbula foi mensurada com um paquímetro. Nessa avaliação foram usadas as marcações propostas por Steenks e Wijer (1996), onde a abertura da boca foi medida pela distância máxima dos incisivos superior e inferior.

Por último, foi avaliada a qualidade de vida, por meio da versão brasileira do Questionário Genérico de Qualidade de Vida SF-36 (Anexo 5), traduzido e validado por Ciconelli et al. (1999). Esse questionário avalia a qualidade de vida em oito domínios específicos: capacidade funcional (CF), limitação por aspectos físicos (LAF), dor, estado geral de saúde (EGS), vitalidade (VT), aspectos sociais (AS), limitação por aspectos emocionais LAE) e saúde mental (SM). Cada domínio avaliado pode apresentar um escore final de 0 a 100; quanto maior a pontuação no questionário, melhor a qualidade de vida do indivíduo.

\section{Intervenção}

O tratamento foi realizado durante dois meses em sessões individuais uma vez por semana durante 40 minutos, com um total de oito sessões.

No início de cada sessão foram realizadas manobras preparatórias de pompage descritas por Bienfait (1999), com o objetivo de alongar a fáscia que recobre os músculos da coluna, posicionando a coluna vertebral de forma mais alinhada. Foram realizadas as seguintes pompages: diafragmática, global, dorsal, trapézio superior e escaleno (Anexo 6).

Antes de iniciar o tratamento de alongamento, foi explicado a cada 
paciente o objetivo do exercício, para o desenvolvimento de uma melhor percepção do próprio corpo, o que contribui para o processo terapêutico.

\section{Grupo RPG}

As pacientes do grupo RPG foram tratadas com alongamento das cadeias musculares estáticas anterior e posterior (Marques, 2005; Souchard, 2005). Em cada sessão foram realizadas duas posturas globais sem carga em decúbito dorsal, mantidas por 15 minutos cada uma, sendo uma postura para a cadeia anterior e outra para a posterior, cuja descrição e ilustração detalhada encontramse no Anexo 6. Todas as compensações, como bloqueio inspiratório, protrusão de ombros, flexão e/ou pronação de antebraço e flexão de punho e dedos, bem como alteração da posição da cabeça, foram evitadas. A paciente foi orientada a manter a respiração com ênfase na expiração, devido à tendência ao bloqueio inspiratório muito comum nesse tipo de alongamento.

\section{Grupo AES}

As pacientes do grupo AES realizaram alongamento segmentar estático para os músculos da coluna cervical, cabeça, membros superiores e mandíbula. Foram orientadas a permanecer na posição de alongamento por 30 segundos, mantendo um ritmo respiratório lento, não permitindo possíveis compensações. Foi respeitado o limite e a possibilidade de cada paciente. Cada exercício foi repetido, bilateralmente, três vezes após 10 segundos de descanso. Durante o alongamento, a paciente recebia estímulos proprioceptivos, através de um toque superficial paralelo à direção das fibras do músculo alongado, realizado com a polpa do polegar. A descrição dos exercícios, bem como sua ilustração, encontram-se no Anexo 6.

Após a realização dos alongamentos eram feitas manobras no músculo masseter, que foi abordado em pinça intra e extra-bucal, desde o arco zigomático

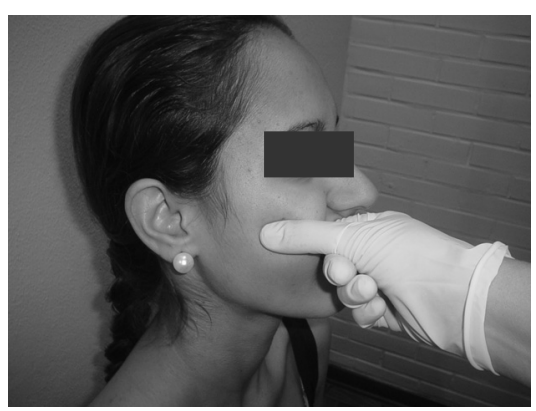
até o ângulo da mandíbula, com fricção transversal (Figura 2).

Figura 2 Massagem no músculo masseter 
Dois meses depois do final do tratamento, as pacientes foram reavaliadas e receberam um treinamento para realização dos exercícios em casa, bem como uma apostila com orientações gerais e desenho com os exercícios, como material de apoio. Cada grupo foi instrumentalizado segundo o tratamento recebido, global ou segmentar.

\section{Análise dos dados}

Para avaliar a intensidade de dor na região da ATM, cefaléia, cervicalgia, sintomas de ouvido, apertamento e dificuldade de dormir, foi utilizada uma régua com escala em milímetros, medindo-se a distância do traço vertical marcado pelas participantes até a extremidade esquerda da linha horizontal. Assim, o valor dessa distância corresponde à intensidade da dor, apertamento e à dificuldade de dormir e comer relatada pelas participantes.

O processamento dos dados eletromiográficos foi realizado em rotina do programa Origem 6.0. Para melhor interpretação foram descartados o primeiro e último segundo de cada coleta; o sinal foi retificado, normalizado por sua média (Ervilha et al., 1998) e posteriormente transformado em valor RMS (root mean square), que corresponde a quantidade de sinal contínuo capaz de conter a mesma quantidade de energia, expressa em microvolts $(\mu v)$, calculado pela raiz quadrada da média dos sinais. Posteriormente, para a análise estatística foi utilizada a média das três coletas de cada participante.

Para identificar o tipo de curvatura cervical, as radiografias das pacientes com DTM foram apreciadas por três avaliadores, fisioterapeutas com experiência clínica em avaliação postural. A normalidade, aumento ou ausência da curvatura foi definida pela concordância do diagnóstico de, ao menos, dois dos três avaliadores. Cada fisioterapeuta realizou, individualmente, sua análise e nenhum deles tinha conhecimento a respeito da finalidade da pesquisa, nem tampouco a que grupo os indivíduos pertenciam.

$\mathrm{Na}$ avaliação da qualidade de vida das participantes, realizada pelo questionário SF-36, foi utilizada, além da pontuação dos oito domínios, a média de todos eles, representando a pontuação total do questionário. 


\section{Análise estatística}

Para comparação dos resultados antes e após o tratamento e na reavaliação feita dois meses depois, foi utilizado o teste de Friedman nãoparamétrico abrangendo três amostras relacionadas, para comparação das respectivas médias, cujos escores são mensurados em escala nominal ou ordinal (postos). $\mathrm{Na}$ análise entre grupos foram utilizados os diagramas de dispersão. Nesse tipo de gráfico são marcados pontos, onde as duas variáveis de interesse, (x) antes e (y) depois, correspondem às abscissas cartesianas de um plano. Foi também traçada a linha correspondente $a x=y$. O objetivo foi verificar se os pontos traçados estão acima (em caso de piora), abaixo (em caso de melhora) e em torno da linha, se não houve alteração. Os pontos foram marcados correspondentes aos dois grupos e estão em cores diferenciadas. Na comparação entre os tratamentos, se os pontos dos dois grupos estiverem em espaços distintos, indicam diferença entre eles; caso estejam próximos, sugerem que os tratamentos são equivalentes. 


\section{RESULTADOS}

No interior de cada grupo, foi feita análise comparativa dos resultados entre as três avaliações realizadas: antes do tratamento (1a avaliação), após o tratamento (2a avaliação) e dois meses mais tarde (3ạ avaliação); para a comparação dos resultados entre os grupos, e através de gráficos de dispersão na comparação entre grupos.

As características biodemográficas das participantes, tais como idade, profissão, abertura da mandíbula e curvatura cervical, são descritas na Tabela 1. Em relação à curva cervical do total da amostra, $50 \%$ das pacientes apresentaram retificação cervical e três $(12,5 \%)$, hiperlordose cervical.

Tabela 1 Características biodemográficas dos sujeitos da pesquisa

\begin{tabular}{lcc}
\hline Variável & $\begin{array}{c}\text { Grupo RPG } \\
(\mathrm{N}=12)\end{array}$ & $\begin{array}{c}\text { Grupo AES } \\
(\mathrm{N}=12)\end{array}$ \\
\hline Idade (anos) - média (DP) & $30,0(4,30)$ & $30,08(7,07)$ \\
\hline Profissão & 1 & 3 \\
$\quad$ Estudante & 2 & 1 \\
Faxineira & 3 & 2 \\
Auxiliar administrativo & 3 & 4 \\
Do lar & 2 & 1 \\
Profissão nível técnico & 1 & 1 \\
Profissão nível superior & & \\
\hline Curvatura cervical & 5 & 4 \\
$\quad$ Normal & 1 & 2 \\
Hiperlordose & 6 & 6 \\
$\quad$ Retificação & $3,9(0,73)$ & $4,0(0,70)$ \\
\hline Abertura da mandíbula $(\mathrm{cm})$ - média (DP) & & \\
\hline
\end{tabular}

\section{Análise em cada grupo}

Os valores médios e desvio padrão da intensidade dos sintomas avaliados pela Escala Visual Analógica (EVA) dos dois grupos, bem como o valor de $p$ entre as avaliações (Av) são apresentados na Tabela 2. Apenas os sintomas de ouvido do grupo RPG e a dificuldade em dormir no grupo AES não tiveram melhora estatisticamente significante após o tratamento. Entretanto, na 3ạ avaliação, houve aumento na intensidade dos sintomas, exceto na cefaléia e sintomas no ouvido do grupo RPG - porém os valores permaneceram inferiores aos medidos 
na 1a avaliação. A dificuldade de comer e dormir nos dois grupos, e a intensidade dos sintomas de cervicalgia e apertamento no grupo AES, aumentaram na $3 \underline{a}$ avaliação, registrando uma diferença não significante em relação à $1 \underline{a}$ avaliação.

Tabela 2 Média e desvio padrão (DP) dos sintomas avaliados pela EVA, na 1ạ, 2ạ, e 3a avaliações (Av) e valor de $p$ da comparação entre as mesmas

\begin{tabular}{|c|c|c|c|c|c|c|c|c|c|c|}
\hline \multirow{2}{*}{$\begin{array}{l}\text { Grupos } \\
\text { Sintomas }(\mathrm{cm})\end{array}$} & \multicolumn{5}{|c|}{ RPG } & \multicolumn{5}{|c|}{ AES } \\
\hline & 1a $\mathrm{Av}$ & 2a $\mathrm{Av}$ & 3a $\mathrm{Av}$ & $\mathrm{p} 1 \underline{\mathrm{a}}-2 \underline{\mathrm{a}}$ & p1a-3a & 1a Av & 2a $\mathrm{A} v$ & 3a $\mathrm{Av}$ & p1a-2a & $\mathrm{p} 1 \underline{\mathrm{a}}-3 \mathrm{a}$ \\
\hline $\begin{array}{r}\text { Dor - média } \\
(\mathrm{DP})\end{array}$ & $\begin{array}{c}8,47 \\
(1,38)\end{array}$ & $\begin{array}{c}3,02 \\
(2,51)\end{array}$ & $\begin{array}{c}3,74 \\
(2,44)\end{array}$ & $<0,05$ & $<0,05$ & $\begin{array}{l}7,20 \\
(1,1)\end{array}$ & $\begin{array}{c}2,28 \\
(1,93)\end{array}$ & $\begin{array}{c}3,45 \\
(1,93)\end{array}$ & $<0,05$ & $<0,05$ \\
\hline $\begin{array}{r}\text { Cefaléia - média } \\
\text { (DP) }\end{array}$ & $\begin{array}{c}7,35 \\
(2,62)\end{array}$ & $\begin{array}{c}3,92 \\
(2,98)\end{array}$ & $\begin{array}{c}3,55 \\
(2,65)\end{array}$ & $<0,05$ & $<0,05$ & $\begin{array}{c}6,57 \\
(2,17)\end{array}$ & $\begin{array}{c}1,64 \\
(1,66)\end{array}$ & $\begin{array}{c}3,0 \\
(1,90)\end{array}$ & $<0,05$ & $<0,05$ \\
\hline $\begin{array}{l}\text { Cervicalgia - média } \\
\text { (DP) }\end{array}$ & $\begin{array}{c}7,33 \\
(2,71)\end{array}$ & $\begin{array}{c}3,59 \\
(2,80)\end{array}$ & $\begin{array}{c}3,85 \\
(2,09)\end{array}$ & $<0,05$ & $<0,05$ & $\begin{array}{c}5,68 \\
(2,59)\end{array}$ & $\begin{array}{c}2,41 \\
(1,92)\end{array}$ & $\begin{array}{c}3,45 \\
(1,93)\end{array}$ & $<0,05$ & $>0,05$ \\
\hline $\begin{array}{r}\text { Apertamento - média } \\
\text { (DP) }\end{array}$ & $\begin{array}{c}7,14 \\
(2,71)\end{array}$ & $\begin{array}{c}4,25 \\
(2,55)\end{array}$ & $\begin{array}{c}4,33 \\
(3,09)\end{array}$ & $<0,05$ & $<0,05$ & $\begin{array}{c}6,45 \\
(2,51)\end{array}$ & $\begin{array}{c}2,90 \\
(2,35)\end{array}$ & $\begin{array}{c}3,52 \\
(1,46)\end{array}$ & $<0,05$ & $>0,05$ \\
\hline $\begin{array}{l}\text { Ouvido - média } \\
\text { (DP) }\end{array}$ & $\begin{array}{c}4,69 \\
(3,31)\end{array}$ & $\begin{array}{c}2,99 \\
(3,11)\end{array}$ & $\begin{array}{c}2,55 \\
(2,94)\end{array}$ & $>0,05$ & $<0,05$ & $\begin{array}{c}5,85 \\
(1,93)\end{array}$ & $\begin{array}{c}2,80 \\
(2,08)\end{array}$ & $\begin{array}{c}3,52 \\
(2,07)\end{array}$ & $<0,05$ & $<0,05$ \\
\hline $\begin{array}{l}\text { Dif em comer - média } \\
\text { (DP) }\end{array}$ & $\begin{array}{c}4,57 \\
(2,79)\end{array}$ & $\begin{array}{c}2,34 \\
(2,38)\end{array}$ & $\begin{array}{c}4,01 \\
(3,01)\end{array}$ & $=0,05$ & $>0,05$ & $\begin{array}{c}4,36 \\
(2,72)\end{array}$ & $\begin{array}{c}2,23 \\
(2,29)\end{array}$ & $\begin{array}{c}2,93 \\
(2,37)\end{array}$ & $<0,05$ & $>0,05$ \\
\hline $\begin{array}{l}\text { Dif em dormir - média } \\
\text { (DP) }\end{array}$ & $\begin{array}{c}5,69 \\
(3,45)\end{array}$ & $\begin{array}{c}3,08 \\
(3,05)\end{array}$ & $\begin{array}{c}3,22 \\
(3,31)\end{array}$ & 0,05 & $>0,05$ & $\begin{array}{c}4,65 \\
(3,36)\end{array}$ & $\begin{array}{c}3,00 \\
(2,38)\end{array}$ & $\begin{array}{c}3,02 \\
(2,33)\end{array}$ & $>0,05$ & $>0,05$ \\
\hline
\end{tabular}

Dif.= dificuldade

A Tabela 3 mostra os valores da média e desvio padrão do limiar de dor avaliado com o dolorímetro. É importante salientar que foram considerados positivos valores abaixo de $2,6 \mathrm{~kg} / \mathrm{cm}^{2}$. Pode-se observar que o ponto no músculo esternocleidomastóideo (ECOM) foi o que apresentou os valores mais baixos antes e após o tratamento. Observou-se melhora estatisticamente significante em todos os músculos avaliados logo após o tratamento (2a avaliação), porém aumento na intensidade dos sintomas após dois meses (3a avaliação), embora os valores obtidos nesta última tenham sido inferiores aos iniciais (1a avaliação). Houve significância na comparação dos dados entre a 1ạ e 2ạ avaliações. Já na terceira avaliação o grupo AES manteve significância somente em relação ao músculo masseter, sendo que o músculo trapézio nos dois grupos aumentou o limiar de dor, apresentando diferença não significativa em relação à 1a avaliação. 
Tabela 3 Média e desvio padrão (DP) da dolorimetria dos músculos masseter, temporal, esternocleidomastóideo (ECOM) e trapézio superior, na 1a 2a , e 3a avaliações (Av) e valor de $p$ da comparação entre as mesmas

\begin{tabular}{|c|c|c|c|c|c|c|c|c|c|c|}
\hline \multirow{2}{*}{$\begin{array}{r}\text { Grupos } \\
\text { Dolorimetria }\left(\mathrm{kg} / \mathrm{cm}^{2}\right)\end{array}$} & \multicolumn{5}{|c|}{ RPG } & \multicolumn{5}{|c|}{ AES } \\
\hline & $1 \underline{a} A v$ & 2a Av & 3a Av & $\mathrm{p} 1 \underline{a}-2 \underline{a}$ & $\mathrm{p} 1 \underline{\mathrm{a}}-3 \underline{\mathrm{a}}$ & $1 \underline{a} \mathrm{Av}$ & 2a Av & 3a Av & $\mathrm{p} 1 \underline{\mathrm{a}}-2 \underline{\mathrm{a}}$ & $\mathrm{p} 1 \underline{\mathrm{a}}-3 \underline{\mathrm{a}}$ \\
\hline $\begin{array}{r}\text { Masseter - média } \\
(\mathrm{DP})\end{array}$ & $\begin{array}{c}2,01 \\
(0,63)\end{array}$ & $\begin{array}{c}2,81 \\
(0,82)\end{array}$ & $\begin{array}{c}2,65 \\
(0,94)\end{array}$ & $<0,05$ & $<0,05$ & $\begin{array}{c}1,95 \\
(0,61)\end{array}$ & $\begin{array}{c}2,73 \\
(0,29)\end{array}$ & $\begin{array}{l}2,75 \\
(0,42)\end{array}$ & $<0,05$ & $<0,05$ \\
\hline $\begin{array}{l}\text { Temporal- média } \\
\text { (DP) }\end{array}$ & $\begin{array}{c}2,43 \\
(0,52)\end{array}$ & $\begin{array}{c}3,39 \\
(0,82)\end{array}$ & $\begin{array}{c}3,22 \\
(0,92)\end{array}$ & $<0,05$ & $<0,05$ & $\begin{array}{c}2,3 \\
(0,43)\end{array}$ & $\begin{array}{c}3,35 \\
(0,62)\end{array}$ & $\begin{array}{c}2,87 \\
(0,61)\end{array}$ & $<0,05$ & $>0,05$ \\
\hline $\begin{array}{c}\text { ECOM - média } \\
\text { (DP) }\end{array}$ & $\begin{array}{c}1,59 \\
(0,42)\end{array}$ & $\begin{array}{c}2,41 \\
(0,59)\end{array}$ & $\begin{array}{c}2,11 \\
(0,48)\end{array}$ & $<0,05$ & $<0,05$ & $\begin{array}{c}1,49 \\
(0,73)\end{array}$ & $\begin{array}{c}2,22 \\
(0,83)\end{array}$ & $\begin{array}{c}1,75 \\
(0,74)\end{array}$ & $<0,05$ & $<0,05$ \\
\hline $\begin{array}{r}\text { Trapézio - média } \\
\text { (DP) }\end{array}$ & $\begin{array}{c}2,05 \\
(0,43)\end{array}$ & $\begin{array}{c}3,25 \\
(0,91)\end{array}$ & $\begin{array}{c}2,60 \\
(0,50)\end{array}$ & $<0,05$ & $<0,05$ & $\begin{array}{l}2,11 \\
(0,64)\end{array}$ & $\begin{array}{c}3,04 \\
(0,96)\end{array}$ & $\begin{array}{c}2,67 \\
(0,67)\end{array}$ & $<0,05$ & $<0,05$ \\
\hline
\end{tabular}

Os valores médios e desvio padrão da atividade eletromiográfica dos músculos estudados são apresentados na Tabela 4. Houve melhora estatisticamente significante no músculo masseter nos dois grupos logo após o tratamento (2a avaliação) e, no grupo AES, dois meses mais tarde (3a avaliação). Quanto ao músculo temporal, somente o grupo RPG apresentou melhora significante, na 2a avaliação. No músculo esternocleidomastóideo a melhora foi significante somente na 3a avaliação no grupo AES, e no músculo trapézio não houve diferença significativa nos dois grupos em qualquer das avaliações.

Tabela 4 Média e desvio padrão (DP) da atividade eletromiográfica (EMG) dos músculos masseter, temporal, esternocleidomastóideo (ECOM) e trapézio superior, na 1a, 2a , e $3 \underline{a}$ avaliações (Av) e valor de $p$ da comparação entre as mesmas

\begin{tabular}{|c|c|c|c|c|c|c|c|c|c|c|}
\hline \multicolumn{3}{|c|}{ Grupos } & \multicolumn{3}{|l|}{ RPG } & \multicolumn{5}{|c|}{ AES } \\
\hline EMG (RMS) & $1 \underline{a} \mathrm{Av}$ & 2a $\mathrm{Av}$ & 3ạ Av & p1a-2aㅡ & p1aa-3a & 1a Av & $2 \underline{a} A v$ & $3 \underline{a} \mathrm{Av}$ & $\mathrm{p} 1 \underline{\mathrm{a}}-2 \underline{\mathrm{a}}$ & p1a-3a \\
\hline $\begin{array}{r}\text { Masseter - média } \\
\text { (DP) }\end{array}$ & $\begin{array}{c}0,80 \\
(0,13)\end{array}$ & $\begin{array}{c}0,68 \\
(0,04)\end{array}$ & $\begin{array}{c}0,73 \\
(0,05)\end{array}$ & $<0,05$ & $>0,05$ & $\begin{array}{c}0,81 \\
(0,13)\end{array}$ & $\begin{array}{c}0,68 \\
(0,08)\end{array}$ & $\begin{array}{c}0,71 \\
(0,08)\end{array}$ & $<0,05$ & $<0,05$ \\
\hline $\begin{array}{r}\text { Temporal- média } \\
\text { (DP) }\end{array}$ & $\begin{array}{c}0,82 \\
(0,09)\end{array}$ & $\begin{array}{c}0,69 \\
(0,58)\end{array}$ & $\begin{array}{c}0,75 \\
(0,06)\end{array}$ & $<0,05$ & $>0,05$ & $\begin{array}{c}0,82 \\
(0,09)\end{array}$ & $\begin{array}{c}0,74 \\
(0,06)\end{array}$ & $\begin{array}{c}0,76 \\
(0,09)\end{array}$ & $>0,05$ & $>0,05$ \\
\hline $\begin{array}{l}\text { ECOM - média } \\
(\mathrm{DP})\end{array}$ & $\begin{array}{c}0,79 \\
(0,08)\end{array}$ & $\begin{array}{c}0,69 \\
(0,10)\end{array}$ & $\begin{array}{c}0,69 \\
(0,08)\end{array}$ & $>0,05$ & $>0,05$ & $\begin{array}{c}0,76 \\
(0,13)\end{array}$ & $\begin{array}{c}0,67 \\
(0,06)\end{array}$ & $\begin{array}{c}0,66 \\
(0,11)\end{array}$ & $>0,05$ & $<0,05$ \\
\hline $\begin{array}{r}\text { Trapézio - média } \\
\text { (DP) }\end{array}$ & $\begin{array}{c}0,81 \\
(0,08)\end{array}$ & $\begin{array}{c}0,72 \\
(0,14)\end{array}$ & $\begin{array}{c}0,77 \\
(0,10)\end{array}$ & $>0,05$ & $>0,05$ & $\begin{array}{c}0,78 \\
(0,09)\end{array}$ & $\begin{array}{c}0,69 \\
(0,05)\end{array}$ & $\begin{array}{c}0,77 \\
(1,18)\end{array}$ & $>0,05$ & $>0,05$ \\
\hline
\end{tabular}

Os valores médios da qualidade de vida avaliada pelo SF-36 podem ser vistos na Tabela 5 . Os efeitos do alongamento na melhora da qualidade de vida 
foram significativos na média geral. Houve melhora significante desta nos dois grupos, tanto na 2a como na 3ạ avaliação. Porém, dos oito domínios avaliados pelo SF-36, apenas a dor apresentou significância nos dois grupos logo após o tratamento, o que é coerente com a diminuição das dores avaliadas pela EVA e dolorimetria. A capacidade funcional nos dois grupos não apresentou melhora significativa logo após o tratamento.

Quanto aos demais itens do SF-36, apenas no grupo RPG houve diferença significante na 2a avaliação nos seguintes itens, além da dor: limitação por aspectos físicos, vitalidade e saúde mental; e, na $3 \underline{a}$ avaliação, nos itens aspectos sociais e estado geral de saúde. Por sua vez, o grupo AES só apresentou diferença significativa no item dor.

Tabela 5 Média e desvio padrão (DP) da qualidade de vida medida pelo questionário SF-36, na 1a, 2a , e 3a avaliações (Av) e valor de p da comparação entre as mesmas

\begin{tabular}{|c|c|c|c|c|c|c|c|c|c|c|}
\hline \multirow{2}{*}{$\begin{array}{r}\text { Grupos } \\
\text { Pontuação no SF-36 }\end{array}$} & \multicolumn{5}{|c|}{ RPG } & \multicolumn{5}{|c|}{ AES } \\
\hline & $1 \underline{a} \mathrm{Av}$ & 2a $\mathrm{a}$ Av & $3 \underline{a} \mathrm{Av}$ & $\mathrm{p} 1 \underline{a}-2 \underline{a}$ & $\mathrm{p} 1 \underline{\mathrm{a}}-3 \underline{\mathrm{a}}$ & 1a Av & $2 \underline{a} \mathrm{Av}$ & $3 \underline{a} A v$ & p1ㅁ-2a & $\mathrm{p} 1 \underline{a}-3 \underline{a}$ \\
\hline $\begin{array}{l}\text { Capacidade funcional } \\
\text { média (DP) }\end{array}$ & $\begin{array}{c}83,8 \\
(19,0)\end{array}$ & $\begin{array}{c}87,5 \\
(16,3)\end{array}$ & $\begin{array}{c}87,9 \\
(16,5)\end{array}$ & $>0,05$ & $>0,05$ & $\begin{array}{c}82,9 \\
(19,6)\end{array}$ & $\begin{array}{c}83,8 \\
(18,5)\end{array}$ & $\begin{array}{c}84,5 \\
(13,4)\end{array}$ & $>0,05$ & $>0,05$ \\
\hline $\begin{array}{r}\text { Asp físicos - média } \\
\text { (DP) }\end{array}$ & $\begin{array}{c}41,7 \\
(37,4)\end{array}$ & $\begin{array}{c}81,2 \\
(28,4)\end{array}$ & $\begin{array}{c}70,8 \\
(33,5)\end{array}$ & $<0,05$ & $>0,05$ & $\begin{array}{c}52,1 \\
(27,1)\end{array}$ & $\begin{array}{c}70,0 \\
(31,9)\end{array}$ & $\begin{array}{c}60,4 \\
(41,4)\end{array}$ & $>0,05$ & $>0,05$ \\
\hline $\begin{array}{l}\text { Dor - média } \\
\text { (DP) }\end{array}$ & $\begin{array}{c}34 \\
(22,0)\end{array}$ & $\begin{array}{c}54,9 \\
(14,8)\end{array}$ & $\begin{array}{c}51,0 \\
(19,0)\end{array}$ & $<0,05$ & $>0,05$ & $\begin{array}{c}36,0 \\
(16,0)\end{array}$ & $\begin{array}{c}58,6 \\
(18,5)\end{array}$ & $\begin{array}{c}52,2 \\
(22,5)\end{array}$ & $<0,05$ & $>0,05$ \\
\hline $\begin{array}{l}\text { Estado de saúde } \\
\text { média (DP) }\end{array}$ & $\begin{array}{c}62,6 \\
(17,8)\end{array}$ & $\begin{array}{c}75,6 \\
(17,0)\end{array}$ & $\begin{array}{c}74,3 \\
(20,9)\end{array}$ & $>0,05$ & $<0,05$ & $\begin{array}{c}62,3 \\
(24,7)\end{array}$ & $\begin{array}{c}70,4 \\
(24,2)\end{array}$ & $\begin{array}{c}63,6 \\
(23,2)\end{array}$ & $>0,05$ & $>0,05$ \\
\hline $\begin{array}{l}\text { Vitalidade - média } \\
\text { (DP) }\end{array}$ & $\begin{array}{c}38,3 \\
(14,0)\end{array}$ & $\begin{array}{c}60,8 \\
(16,0)\end{array}$ & $\begin{array}{c}57,1 \\
(17,1)\end{array}$ & $<0,05$ & $>0,05$ & $\begin{array}{c}45,0 \\
(16,0)\end{array}$ & $\begin{array}{c}63,3 \\
(19,0)\end{array}$ & $\begin{array}{l}54,16 \\
(16,5)\end{array}$ & $>0,05$ & $>0,05$ \\
\hline $\begin{array}{c}\text { Asp sociais - média } \\
\text { (DP) }\end{array}$ & $\begin{array}{c}50,0 \\
(29,7)\end{array}$ & $\begin{array}{c}66,7 \\
(18,7)\end{array}$ & $\begin{array}{c}78,1 \\
(21,1)\end{array}$ & 05 & $<0,05$ & $\begin{array}{c}53,1 \\
(24,5)\end{array}$ & $\begin{array}{c}71,9 \\
(18,6)\end{array}$ & $\begin{array}{c}70,8 \\
(16,4)\end{array}$ & $>0,05$ & $>0,05$ \\
\hline $\begin{array}{l}\text { Asp emocionais } \\
\text { média (DP) }\end{array}$ & $\begin{array}{c}38,9 \\
(44,6)\end{array}$ & $\begin{array}{c}63,9 \\
(41,3)\end{array}$ & $\begin{array}{c}61,1 \\
(40,4)\end{array}$ & $>0,05$ & $>0,05$ & $\begin{array}{c}36,1 \\
(43,7)\end{array}$ & $\begin{array}{c}63,9 \\
(41,3)\end{array}$ & $\begin{array}{c}72,2 \\
(35,6)\end{array}$ & $>0,05$ & $>0,05$ \\
\hline $\begin{array}{r}\text { Saúde mental - média } \\
\text { (DP) }\end{array}$ & $\begin{array}{c}48,6 \\
(23,0)\end{array}$ & $\begin{array}{c}70,0 \\
(17,6)\end{array}$ & $\begin{array}{c}59,7 \\
(19,9)\end{array}$ & $<0,05$ & $>0,05$ & $\begin{array}{c}52,3 \\
(18,0)\end{array}$ & $\begin{array}{c}64,0 \\
(14,6)\end{array}$ & $\begin{array}{c}63,7 \\
(22,6)\end{array}$ & $>0,05$ & $>0,05$ \\
\hline $\begin{array}{r}\text { Média geral - média } \\
\text { (DP) }\end{array}$ & $\begin{array}{c}49,6 \\
(16,4)\end{array}$ & $\begin{array}{c}70,0 \\
(10,8)\end{array}$ & $\begin{array}{c}67,5 \\
(12,3)\end{array}$ & 05 & $<0,05$ & $\begin{array}{c}52,4 \\
(15,2)\end{array}$ & $\begin{array}{c}68,8 \\
(8,06)\end{array}$ & $\begin{array}{c}65,1 \\
(10,5)\end{array}$ & $<0,05$ & $<0,05$ \\
\hline
\end{tabular}

Asp $=$ Aspectos 


\section{Comparação entre os grupos}

A comparação estatística dos resultados entre os grupos é apresentada sob a forma de gráficos de dispersão. Os resultados relativos à intensidade da dor na ATM, cefaléia e cervicalgia, avaliadas pela EVA, após o tratamento (2a avaliação) e no período de seguimento (3a avaliação), estão dispostos na Figura 3. É importante salientar que dados abaixo da reta indicam melhora. Pode-se observar que, logo após o tratamento, houve diminuição na intensidade da dor nos dois grupos, com exceção de uma paciente do grupo RPG, cuja dor se manteve inalterada na ATM e cervicalgia. Após dois meses, todas as pacientes do grupo RPG mantiveram os resultados nos referidos sintomas, exceto uma, na cervicalgia. No grupo AES, uma paciente não apresentou alteração na dor na ATM e cefaléia e três na cervicalgia.
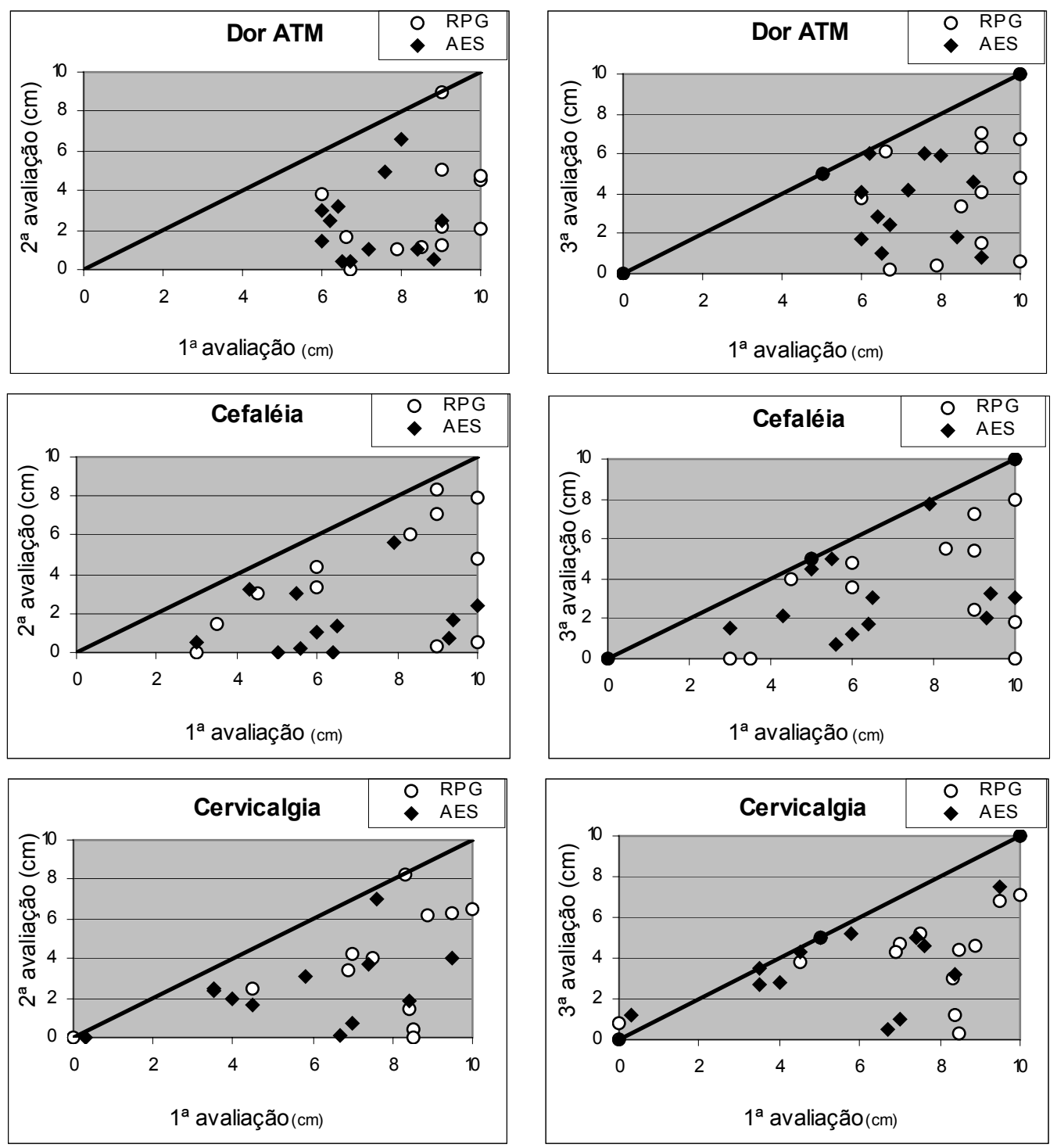

Figura 3 Comparação dos resultados sobre os sintomas dor na ATM, cefaléia e cervicalgia entre os grupos RPG e AES, entre a 1a e 2a avaliações (à esquerda) e entre a $1 \underline{a}$ e $3 \underline{a}$ avaliações (à direita) 

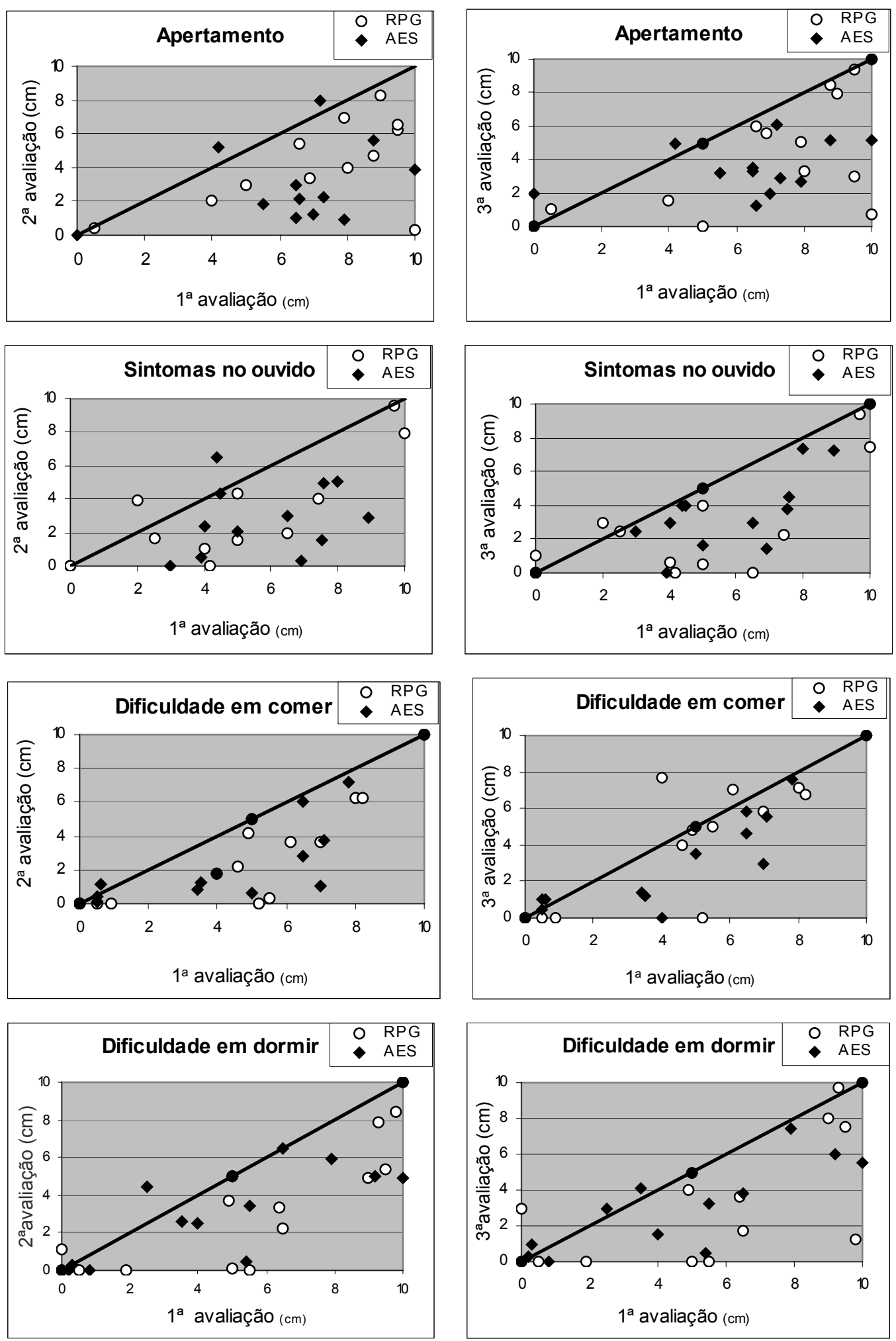

Figura 4 Comparação dos resultados sobre os sintomas apertamento, sintomas no ouvido, dificuldade em comer e dormir entre os grupos RPG e AES, entre a $1 \underline{a}$ e $2 \underline{a}$ avaliações (à esquerda) e entre a 1ạ e $3 \underline{a}$ avaliações (à direita) 
A Figura 4 mostra a intensidade do apertamento, sintomas no ouvido, dificuldade em comer e dormir. Houve diminuição de todos os sintomas logo após o tratamento de fisioterapia e discreta perda na 3a avaliação, porém foi mantida a diminuição dos sintomas na maioria da amostra nos dois grupos.

A amplitude do movimento de abertura da mandíbula apresentou discreta alteração após o tratamento, bem como no período de seguimento de dois meses, como pode ser visto na Figura 5 .
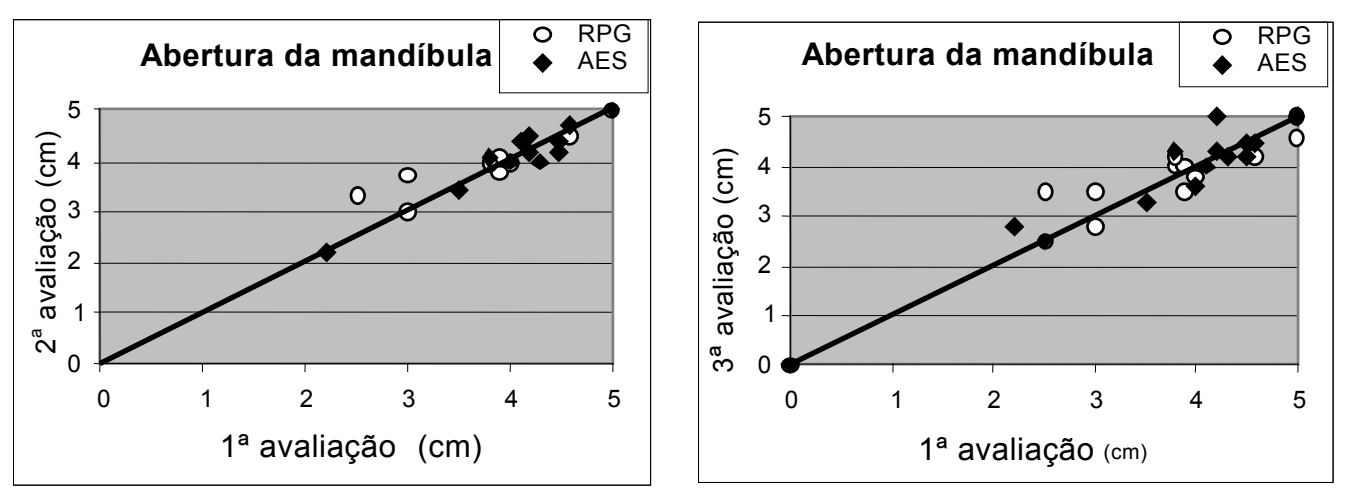

Figura 5 Comparação dos resultados sobre a abertura da mandíbula entre os grupos RPG e AES, entre a 1a e 2a avaliações (à esquerda) e entre a $1 \underline{a}$ e $3 \underline{a}$ avaliações (à direita)

Os resultados referentes à dolorimetria estão dispostos na Figura 6. É importante salientar que valores mais altos (acima da reta) significam aumento no limiar de dor, ou seja, maior tolerância à pressão do dolorímetro. Pode-se observar uma diminuição na sensibilidade dos pontos motores dos músculos estudados logo após o tratamento. Somente três pacientes, duas do grupo RPG e uma do grupo AES, não apresentaram diminuição da sensibilidade dolorosa no músculo trapézio superior, e uma do grupo AES no músculo temporal. Após dois meses foi verificado que no grupo RPG três pacientes apresentaram aumento da sensibilidade dolorosa, duas no músculo masseter e uma no músculo trapézio superior. Já no grupo AES, seis pacientes aumentaram o limiar de dor, três no músculo temporal, duas no esternocleidomastóideo e uma no trapézio. 

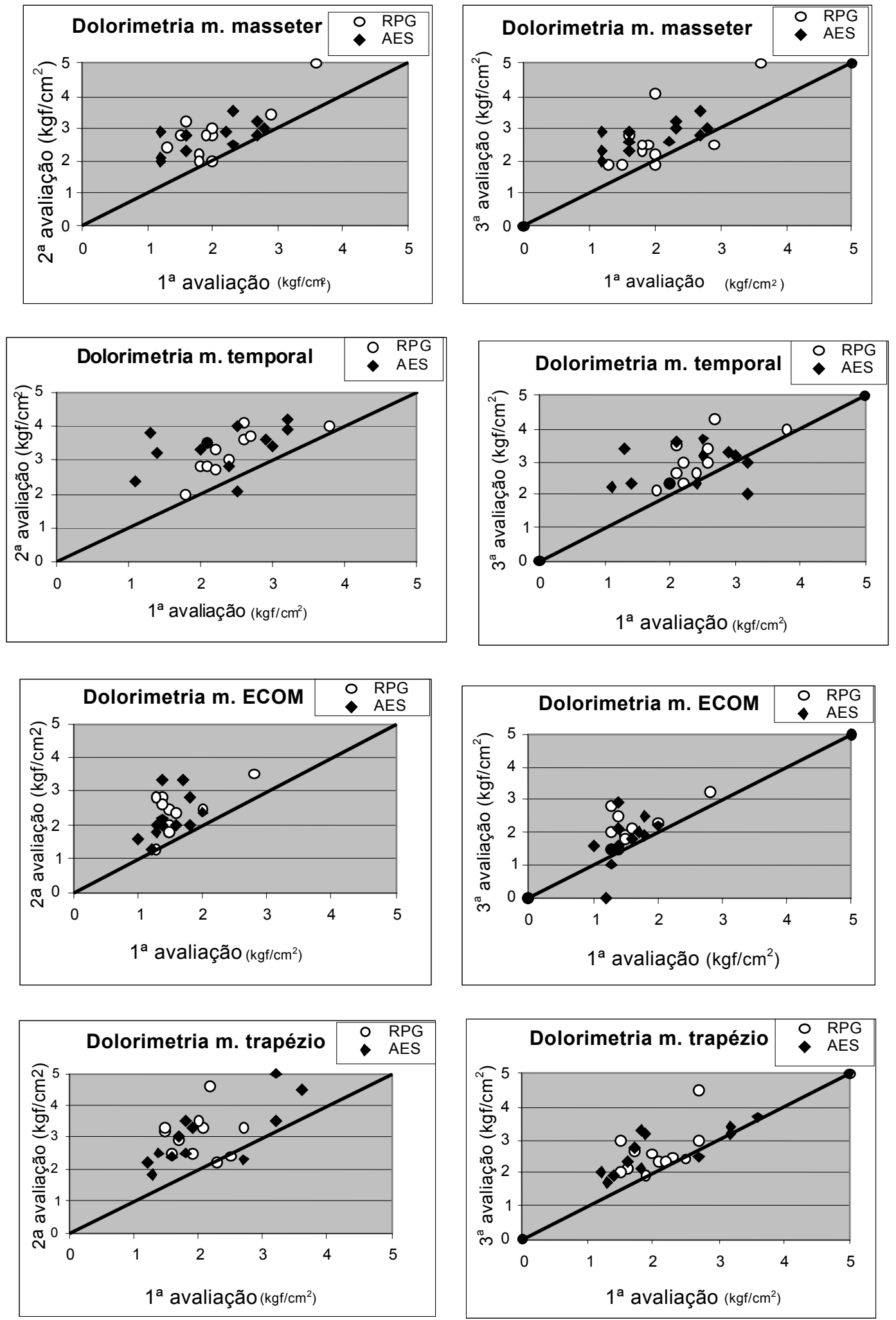

Figura 6 Comparação dos resultados da dolorimetria nos músculos (m.) masseter, temporal, esternocleidomastóideo (ECOM) e trapézio entre os grupos RPG e AES, entre a 1a e 2a avaliações (à esquerda) e entre a $1 \underline{a}$ e $3 \underline{a}$ avaliações (à direita) 

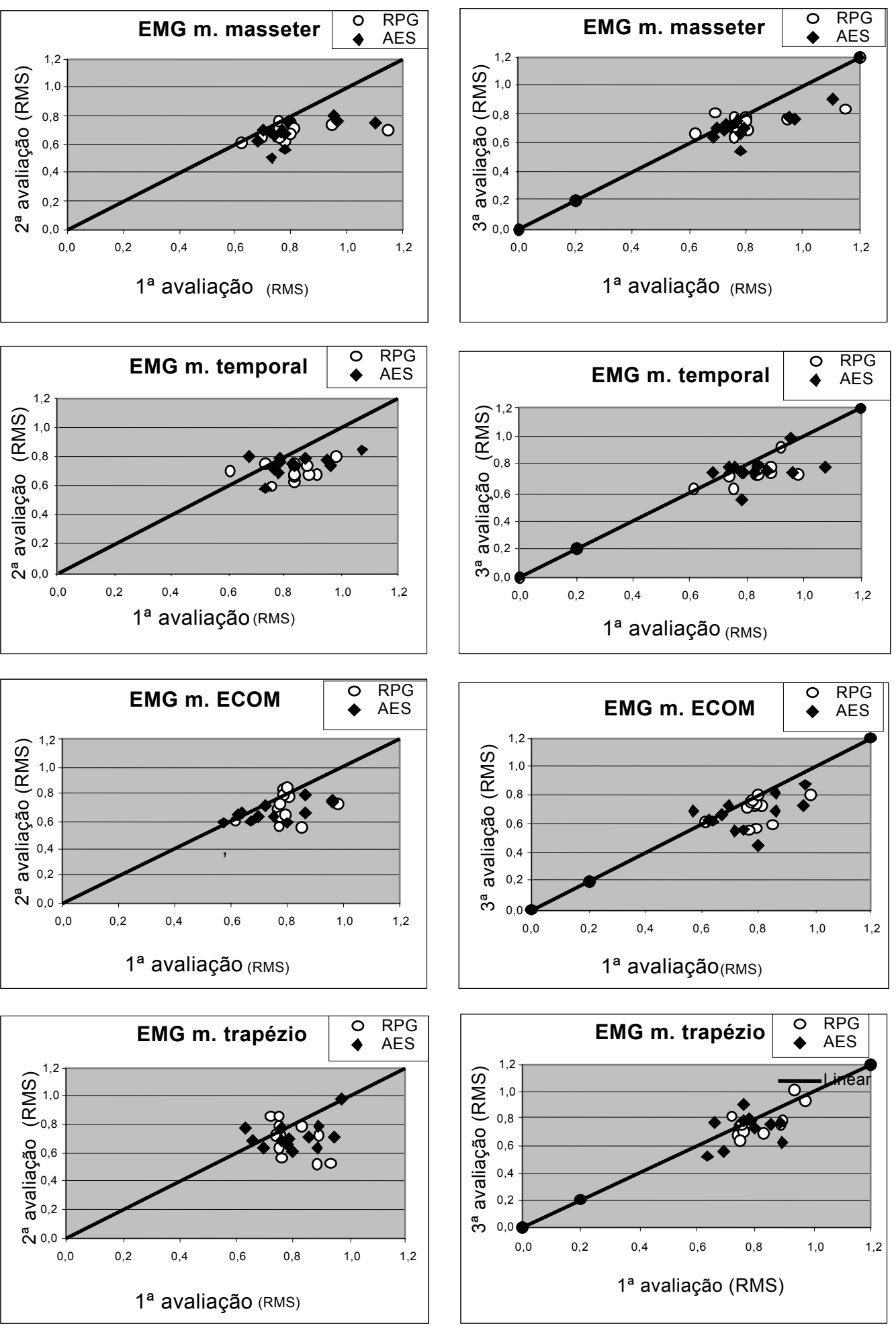

Figura 7 Comparação dos resultados da eletromiografia nos músculos (m.) masseter, temporal, esternocleidomastóideo (ECOM) e trapézio entre os grupos RPG e AES, entre a 1a e 2a avaliações (à esquerda) e entre a 1a e $3 \underline{a}$ avaliações (à direita) 
A Figura 7 mostra os resultados dos sinais eletromiográficos em RMS, expressos em $\mu v$, dos músculos estudados. Os valores da EMG abaixo da linha indicam diminuição da atividade eletromiográfica. Pode-se notar que os valores diminuíram mais acentuadamente no músculo masseter, e diminuíram menos no músculo trapézio superior.

A Figura 8 apresenta os dados da qualidade de vida avaliada pelos oito domínios do SF-36. É importante salientar que altos valores significam boa qualidade de vida. Pode-se observar que, logo após o tratamento, com exceção de duas pacientes do grupo RPG e quatro do grupo AES, as demais apresentaram_melhora, sendo que em algumas os valores estão próximos de 100 .
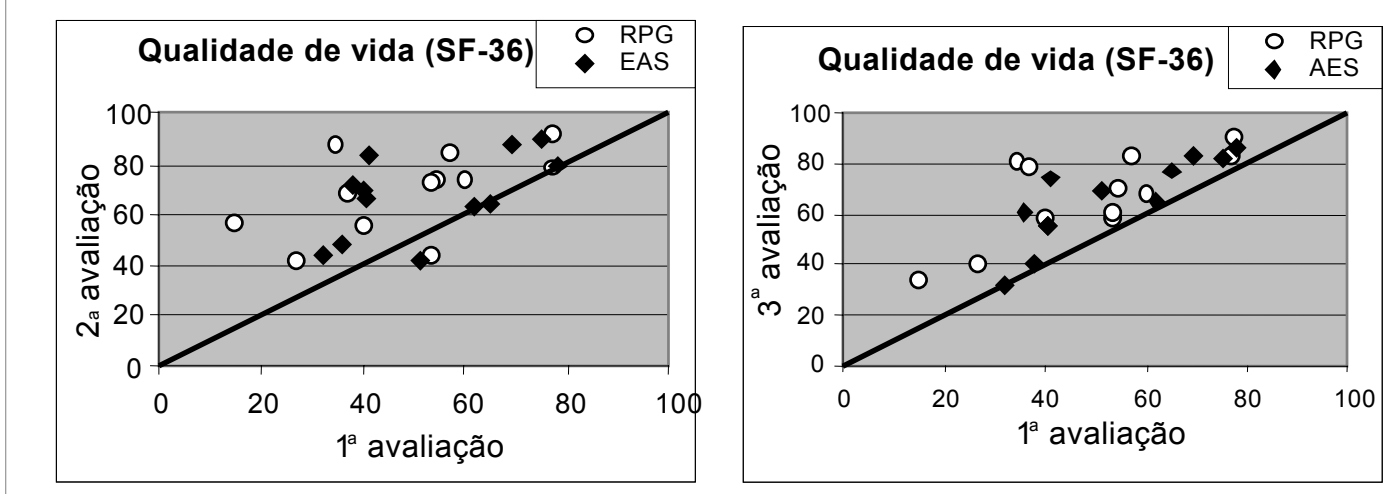

Figura 8 Comparação dos resultados da aplicação do questionário sobre qualidade de vida entre os grupos RPG e AES, entre a 1a e 2a avaliações (à esquerda) e entre a 1ạ e $3 \underline{a}$ avaliações (à direita)

Em resumo: os dados obtidos indicam alívio dos sintomas, exceto da dificuldade em dormir; aumento do limiar de dor (embora menor no músculo trapézio), diminuição da atividade eletromiográfica no músculo masseter; melhora geral da qualidade de vida e efeitos semelhantes nos dois grupos. 


\section{DISCUSSÃO}

O objetivo deste trabalho foi comparar os efeitos da reeducação postural global (RPG) e do alongamento estático segmentar (AES) na dor, qualidade de vida, apertamento dos dentes, dificuldade de dormir e comer, mobilidade articular, dolorimetria e eletromiografia dos músculos masseter, temporal, trapézio e esternocleidomastóideo, em mulheres portadoras de DTM miogênica, Helkimo III.

\section{Avaliação dos sintomas}

Os resultados obtidos após o tratamento de fisioterapia (2a avaliação) e no período de seguimento (3a avaliação) indicam que a intensidade da dor na ATM, a cefaléia e a cervicalgia, verificadas por meio de EVAs, diminuíram nos dois grupos. Neste trabalho o procedimento utilizado foi o alongamento, tanto global, por cadeias musculares, quanto segmentar, acrescido de pompage. Na maioria dos ensaios clínicos consultados, os exercícios terapêuticos foram empregados de forma combinada com outros recursos da fisioterapia (terapia manual, termoterapia, fototerapia e eletroterapia e reeducação postural) ou integrada com a atuação odontológica, o que dificulta verificar a real contribuição dos exercícios terapêuticos nas DTMs.

A literatura relata que o exercício terapêutico associado à placa interoclusal tem um efeito importante no alívio da dor e da disfunção (Felício et al., 1991; Magnusson et al., 2002). Em alguns estudos, só o exercício terapêutico foi eficaz, podendo ser recomendado como primeira opção de tratamento nas DTMs miogênicas (Carlson et al., 2001; Magnusson e Syren, 1999; Truelove et al., 2006). Por outro lado, Grace et al. (2002) não observaram diferença no grau de melhora entre os grupos tratados com terapias tradicionais, associadas ao uso de placa e exercício, e os tratados por orientações associadas à placa.

A literatura também focaliza a eficácia da associação de exercícios terapêuticos e eletroterapia no tratamento das DTMs miogênicas (De Laat et al., 2003; Dworkin et al., 2002; Feine et al., 1997; Matta e Honorato 2003; Rohling et al., 2003; Suvinen, 1997; Waid et al., 1992) e no pós-cirúrgico (Waid et al., 1992), obtendo como resultado a normalização da amplitude do movimento mandibular, eliminação da dor e inflamação, além de eliminação das restrições à função 
mandibular. Também o uso do gelo associado a outras modalidades de tratamento melhora a mobilidade mandibular, elimina a dor e a inflamação (Waid et al., 1992); e, associado ao alongamento, pode diminuir a dor à palpação nos casos de dor miofascial (Rohling et al., 2003).

Feine et al. (1997), num artigo de revisão sobre a eficácia da fisioterapia em lesões musculoesqueléticas crônicas, incluindo as DTMs, ressaltam que os exercícios melhoram a mobilidade e apresentam alguma evidência na redução da dor, não importando o tipo de exercício utilizado. O sucesso no tratamento das dores crônicas consiste em redução da dor, melhora funcional e conseqüente melhora na qualidade de vida. Outra revisão realizada por Murphy (1997) conclui que a melhora dos sintomas e da função é clinicamente mais significante nos grupos tratados por fisioterapia do que nos grupos controle ou sem tratamento, não havendo porém diferença entre as várias formas de procedimentos fisioterapêuticos. Concordando com outros trabalhos, refere ainda que a combinação de várias abordagens terapêuticas é mais eficaz do que somente uma (Anastassaki e Magnusson, 2000; Brown e Gaudet, 2002; Matta e Honorato, 2003).

Uma modalidade de exercício muito utilizada é o alongamento, que tem como efeito imediato o aumento da amplitude do movimento por meio do decréscimo na viscoelasticidade e de um aumento na tolerância ao alongamento, que pode estar relacionada a um possível efeito analgésico, evidenciado recentemente, cujo mecanismo é desconhecido (Shrier e Gossal, 2000). Quando um estímulo é aplicado a um receptor sensorial e mantido por uma força constante, o mesmo inicialmente responde de forma proporcional à intensidade do estímulo. Com o tempo, porém, ele se adapta, diminuindo seu potencial gerador. Segundo Levtov e Schusshtova (1985, apud Alter, 1999), após o alongamento ocorre uma hiperemia e um aumento na velocidade do fluxo sangüíneo nos capilares próximos à região alongada, o que auxilia no alívio da dor. Os músculos mastigatórios e cervicais estão submetidos a uma tensão constante e repetitiva, supostamente devido à parafunção, incoordenação, desequilíbrio biomecânico ou fatores emocionais (Nissani, 2001). Essa tensão excessiva tende a aumentar o gasto energético e diminuir a percepção sensorial e circulação sangüínea (Alter, 1999). O suporte sangüíneo diminuído resulta em falta de oxigênio e nutrientes e origina produtos 
tóxicos que se acumulam nas células, predispondo à fadiga e à dor.

A pompage, que consiste em tração manual tangente à fáscia muscular, foi utilizada neste estudo com o objetivo de preparar as pacientes para o alongamento, amenizando a tensão e promovendo um estímulo proprioceptivo na fáscia correspondente, favorável ao relaxamento e consciência corporal (Bienfait, 1999). Tem ainda como benefício reduzir a percepção da dor, melhorar a circulação local, prevenir aderências e produzir a circulação de opióides endógenos (Cassar, 2001). Outros estudos (Adiels et al., 2005; Capellini et al., 2006; Chiba, 2005; Huddleston et al., 2005), relatam melhora, provocada por terapia manual, dos sinais e sintomas clínicos subjetivos em portadores de DTM. Em um estudo de cervicalgia, Cunha (2004) comparou o efeito da RPG e do alongamento segmentar, associados a pompage nos músculos cervicais, e encontrou resultados significantes no alívio da dor; porém, tal como na presente pesquisa, não encontrou diferença entre os tipos de alongamento utilizados.

Apesar dos resultados favoráveis encontrados na literatura, um fator limitante na análise da maior parte dos estudos sobre terapia manual é a ausência freqüente de uma descrição explícita das técnicas enfocadas, tendo em vista que os termos terapia manual, mobilização e manipulação são genéricos e podem incluir muitas formas de movimento passivo.

No presente trabalho, freqüentemente, após as sessões realizadas, as pacientes relatavam uma sensação de relaxamento e alívio da sintomatologia, embora nenhuma técnica específica de relaxamento tivesse sido utilizada. Esse efeito é muito positivo na redução ou prevenção das dores relacionadas à contratura dos músculos mastigatórios e cervicais. Segundo Alter (1999), para que o alongamento seja efetivo, o músculo deve relaxar-se previamente, isto é, deve haver uma quantidade mínima de tensão nos componentes contráteis. Como resultado dessa tensão interna reduzida, o alongamento atua no tecido conjuntivo, que de fato limita a extensibilidade. A célula muscular é capaz de aumentar $50 \%$ de seu comprimento, o que é realizado pelo deslizamento longitudinal dos filamentos de actina e miosina. Se o músculo estiver contraído, ou seja, houver muita interação entre esses filamentos pelas pontes cruzadas, a resistência muscular 
impedirá o alongamento, o que torna o relaxamento importante nesse procedimento. Mongini (1998) ilustra com vários exemplos clínicos de disfunções neuromusculares a importância do relaxamento muscular. Segundo esse autor, uma pessoa com o sistema neuromuscular íntegro é capaz de relaxar completamente seus músculos, quando então a resistência ao alongamento passivo e lento é mínima.

Alguns estudos relatam a associação de técnicas de relaxamento, principalmente o autógeno, como recurso importante nas DTMs (Carlson et al., 2001; Nicolakis et al., 2000). Os estados de tensão emocional induzem espasmos musculares, produzindo dor em diversos segmentos corporais, dentre os quais a ATM, podendo representar um dos fatores desencadeantes de dor na DTM (Noble, 1965). Raphael et al. (2003) realizaram um revisão de literatura sobre a utilização das terapias complementares nas DTMs e verificaram que os tipos de tratamento alternativo mais utilizados tinham por objetivo o relaxamento.

Em nosso estudo todas as pacientes apresentavam cefaléia, sintoma este muito prevalente na população em geral (Okeson, 1998; Stiesche-Scholz et al., 2002; Visscher et al., 2001) e também muito freqüente nas DTMs miogênicas. Uma das causas pode ser a contratura dos músculos cervicais (Jensen, 2005).

Neste estudo, os resultados mostram que a intensidade da cefaléia diminuiu, enquanto elevou-se o limiar de dor avaliado pela dolorimetria. Estes resultados estão de acordo com os de Krogstad et al. (1996a,b) que, ao estudar pacientes que apresentavam dor de cabeça associada à DTM, observaram diminuição da sensibilidade à palpação muscular. Bernhardt et al. (2005) realizaram um estudo epidemiológico para avaliar o papel dos sinais e sintomas das DTMs no desenvolvimento da cefaléia, e observaram uma relação significante entre maior sensibilidade à palpação dos músculos mastigatórios e intensidade da cefaléia.

Vargo e Hickman (1997) relatam dois casos clínicos com DTM apresentando cefaléia em salvas e síndrome miofascial, e verificaram respostas positivas ao tratamento com fisioterapia e placa miorrelaxante, sugerindo que a associação entre as DTMs e as tensões cervicais contribuem para o desenvolvimento da cefaléia. As fibras aferentes do nervo trigêmeo e os nervos espinhais de $C 1, C 2$ e 
C3 convergem formando o núcleo cervicotrigeminal, criando uma base anatômica para a cefaléia cervicogênica (Jensen, 2005).

Neste estudo, aproximadamente $50 \%$ da amostra apresentava retificação cervical, tal como nos estudos de Ferraz et al. (2004), que observaram retificação da coluna cervical em 74\%, e de Farias et al. (2001), em 90\% dos casos. Resultados opostos foram obtidos por Munhoz et al. (2005) que, após avaliarem radiografias cervicais em perfil, encontraram maior prevalência de aumento de lordose cervical em pacientes também classificados como Helkimo III. Entretanto, em sua amostra, foram selecionados pacientes com manifestação artrogênica, o que representa uma importante diferença das pacientes avaliadas neste estudo.

De acordo com Wijer (1998), não existe consenso na literatura científica a respeito do papel exato da postura corporal no aparecimento e perpetuação dos sinais e sintomas das DTMs. A maioria dos estudos são realizados por observação clínica, e apresentam deficiências metodológicas que impedem chegar a uma conclusão. Além disso, não é possível comparar alguns estudos devido às diferentes técnicas utilizadas para obtenção dos dados e às diferenças das populações estudadas.

Os resultados da intervenção terapêutica conservadora nas cefaléias, sobretudo cervicogênicas, indicam que a combinação de abordagens é mais eficaz do que um único tratamento. Os recursos mais utilizados na fisioterapia são: mobilização vertebral, manipulação miotensiva, exercícios de alongamento, relaxamento, orientações de autocuidado, reeducação postural, TENS, ultra-som e laser (Bove e Nilsson, 1998; Bronfort et al., 2005; Gross et al., 2005; Hammil et al., 1996; Jull et al., 2002, 2005; Mcdonnell et al., 2005; Torelli et al., 2004). Porém, os trabalhos que utilizaram somente mobilização vertebral como recurso terapêutico não ofereceram evidências de melhora (Astin e Ernst, 2003; Fernández de las Penãs et al., 2005). No presente estudo, a pompage foi associada ao alongamento, produzindo um efeito benéfico na melhora da cefaléia.

A intensidade do apertamento medido pela EVA também diminuiu nos dois grupos. O fato de estar sob cuidado terapêutico já leva o indivíduo a prestar mais atenção à região o que, além dos procedimentos utilizados, melhora a 
propriocepção. O tônus muscular, bem como o controle motor, são influenciados pela propriocepção que, por sua vez, depende dos fusos musculares, receptores articulares e mecanorreceptores cutâneos (Ekman, 2000), que tendem a diminuir seu limiar de excitação com a pompage. Pesquisas epidemiológicas que estudam o grau de severidade das DTMs sugerem que uma força de apertamento moderada, relatada pelos pacientes, pode ter um papel importante nos sinais e sintomas da doença (Carlson et al., 2002; Locker e Slade, 1988). Comentando seus achados etiológicos de DTM, Biasotto-Gonzalez (2005) afirma que o fator mais comum do comprometimento miogênico é a hiperatividade muscular, que pode ser diretamente influenciada pelos hábitos parafuncionais. Os resultados da EMG deste estudo mostraram que houve diminuição da atividade eletromiográfica do músculo masseter, o que talvez tenha contribuído para a melhora no apertamento.

Houve redução significativa na intensidade dos sintomas no ouvido no grupo AES, o mesmo não ocorrendo no grupo RPG. Como o protocolo do grupo AES incluiu massagem intra-oral, isso pode ter contribuído para este resultado, uma vez que a abordagem próxima à região auricular pode levar a um aporte sangüíneo maior.

Não foi notada alteração na abertura da boca após o tratamento nos dois grupos avaliados neste estudo. A média dos valores obtidos para as pacientes com DTM foi próxima a 4 centímetros $(3,9 \mathrm{~cm}$ no grupo RPG e 4,0 cm no grupo AES) antes do tratamento, o que corresponde aos valores normais de amplitude do movimento de abertura (Donega et al., 1997; Magnusson, 1994; Uno, 1993). Apesar disso, os resultados mostram que houve diminuição na dificuldade de comer, concordando com vários trabalhos que referem melhora da capacidade funcional após o tratamento (De Laat et al., 2003; Feine et al., 1997; McNeely, 2006; Porto, 2002; Rohling et al., 2003; Waide et al., 1992).

\section{Avaliação da dolorimetria e eletromiografia}

Os resultados obtidos indicam que houve aumento do limiar de dor medido pela dolorimetria nos dois grupos, cujos valores após o tratamento se aproximaram do padrão de normalidade (maiores que $2,6 \mathrm{~kg} / \mathrm{cm}^{2}$ ). Pesquisas realizadas com dolorímetro concluíram que a pressão suportada por pacientes com DTM é 
consideravelmente mais baixa que no grupo controle, sem DTM (Bendtsen 2000; Liljestrom et al., 2005; Svensson et al., 2001). Quando há dor, segundo Bell (1990) e Wijer (1996), esse estímulo nociceptivo constante gera um acúmulo de substâncias neurotransmissoras que ativam neurônios adjacentes, podendo ocorrer um efeito excitatório central. Portadores de DTM freqüentemente apresentam dor difusa, assim como maior sensibilidade à dor provocada, quando comparada com grupo controle saudável, sugerindo participação de mecanismos fisiopatológicos centrais que processam o impulso nociceptivo de forma hiperexcitada (Svensson et al., 2001). Recorrendo à EVA, Sarlani e Greenspan (2005) compararam as respostas de 25 portadoras de DTM, 25 mulheres saudáveis e 25 homens saudáveis à aplicação de estímulos mecânicos nos dedos com uma pequena sonda. Verificaram que a somação temporal da dor, bem como o desconforto após a estimulação, foram maiores nas pacientes do que nos outros grupos, sendo que as mulheres saudáveis apresentaram maior desconforto e dor que os homens. Os achados sugeriram uma hiperexcitabilidade no sistema nociceptivo central, o que contribui para o desenvolvimento ou manutenção da dor crônica na DTM.

Os procedimentos utilizados neste trabalho (alongamento e pompage) podem ter influenciado a diminuição da tensão muscular, contribuindo para a diminuição da ativação dos nociceptores. Vários estudos também observaram diminuição da dor à palpação nos músculos da mastigação após intervenção com exercícios (Carlson et al., 2001; Krogstad et al., 1996, 1998; Magnusson e Syren, 1999; Rohling et al., 2003; Wright et al., 2000).

Os valores da atividade muscular obtidos pela eletromiografia dos músculos mastigatórios indicam maior atividade em pacientes com DTM (Kotani et al., 1980, Moeller et al., 1984). No presente estudo, foi observada diminuição da atividade eletromiográfica em repouso, após o tratamento de fisioterapia, nos músculos masseter (nos dois grupos), temporal (grupo RPG) e ECOM (grupo $A E S)$.

Um aspecto importante é que além da atividade eletromiográfica, os valores de sensibilidade dolorosa e intensidade de apertamento dos dentes 
também diminuíram nessas pacientes, permitindo supor que há uma associação entre eles. Carlson e Curran (1994) fizeram extensa revisão de literatura sobre o efeito do alongamento no relaxamento muscular avaliado por medidas subjetivas de dor e por eletromiografia (EMG), e os achados foram positivos, com melhora no nível de dor e decréscimo da atividade elétrica muscular.

Resultados contrários foram obtidos por Capellini et al. (2006), que registraram diminuição da intensidade da dor, mas não da atividade eletromiográfica (em repouso), sugerindo que a pequena amostra talvez tenha contribuído para os resultados. No presente trabalho, a pompage foi combinada com o alongamento, o que deve ter influenciado no bom resultado.

O músculo masseter foi o que apresentou maior redução da atividade eletromiográfica, concordando com Carlson e Curran (1994), que também compararam tratamentos diferentes, reeducação postural e alongamento. No presente estudo, o músculo trapézio superior foi o que apresentou menor redução, talvez devido à sua importante função estabilizadora na cintura escapular, coluna cervical e cabeça, além de ser local freqüente de tensão na população em geral (Cunha, 2005).

Pallegama et al. (2004) e Chandu et al. (2005) observaram relação entre intensidade de dor e atividade eletromiográfica em repouso nos músculos trapézio superior e esternocleidomastóideo em portadores de DTM miogênica. Esses achados sugerem que há uma ligação funcional entre os músculos mastigatórios e cervicais, provavelmente por um mecanismo de co-ativação, sendo esse aspecto avaliado na musculatura cervical durante a mastigação (So et al., 2004) e no movimento combinado de depressão mandibular e extensão da cabeça (Mckay e Christensen, 1999). Essa co-ativação também foi encontrada na musculatura extensora do tronco (Erlich et al., 1999). O esternocleidomastóideo nesse contexto promove um suporte da cabeça, o qual permite o aumento da eficiência mastigatória durante a função. Já os músculos elevadores da mandíbula possuem função postural estática antigravitacional importante e, durante os movimentos do corpo, a mandíbula é estabilizada principalmente pelo músculo temporal (Grossi et al., 2002), que apresenta maior quantidade de fibras lentas tipo I. Asano et al. (2006) 
verificaram aumento da atividade eletromiográfica dos músculos mastigatórios durante exercícios forçados da coluna lombar, principalmente no digástrico. Essa estreita sinergia, tanto na função estática como dinâmica, justifica a necessidade de uma intervenção terapêutica que não se restrinja somente à ATM, pois seu comprometimento pode desequilibrar outras regiões do corpo e vice-versa.

\section{Avaliação da qualidade de vida}

Neste trabalho os efeitos do alongamento na melhora da qualidade de vida foram significantes na média geral nos dois grupos. Porém, dentre os oito domínios avaliados pelo SF-36, apenas a dor apresentou significância nos dois grupos logo após o tratamento, o que é coerente com a diminuição das dores, avaliada pela EVA e dolorimetria. A capacidade funcional nos dois grupos não apresentou melhora significativa logo após o tratamento. Quando se fala da capacidade física, o resultado parece contraditório, pois esperava-se que a diminuição da dificuldade de comer e dormir, bem como a melhora das dores, se refletissem na melhora da capacidade funcional. Isso talvez se deva ao fato de o questionário SF-36 ser muito genérico; quando este tema é estudado, a introdução de questões específicas adicionais possivelmente permitiria obter maior sensibilidade.

O grupo RPG apresentou significância na segunda avaliação nos seguintes itens, além da dor: limitação por aspectos físicos, vitalidade e saúde mental, e na terceira avaliação, nos itens aspectos sociais e estado geral de saúde, enquanto o grupo AES só apresentou melhora significativa no item dor. A abordagem global do trabalho de cadeia muscular pode ter contribuído para esse resultado, uma vez que os músculos dos membros inferiores, pélvis e coluna lombar foram alongados durante as intervenções.

Com relação à limitação por aspectos emocionais e sociais, devem estar presentes outros fatores que não foram abordados neste estudo, ou talvez o tempo tenha sido insuficiente para alterar o padrão comportamental. Tsukimoto et al. (2006), num estudo longitudinal sobre dor lombar crônica, em que aplicaram o questionário SF-36, observaram significado estatístico na melhora da limitação por aspectos emocionais e sociais somente na reavaliação após quatro meses, e não logo após o tratamento. Além disso, por ser a DTM de etiologia multifatorial, o 
tratamento psicológico associado em alguns casos é fundamental para o sucesso da terapia. Turner et al. (2005) concluíram que a dor exerce importante papel nas alterações físicas e psicológicas de pacientes com DTM, concordando com Pallegama et al. (2005), que verificaram altos índices de ansiedade em pacientes com DTM e cervicalgia, quando comparados a um grupo sem DTM, concluindo que a ansiedade poderia influenciar diretamente a manifestação de dor cervical.

Poucos estudos sobre DTM avaliam a qualidade de vida, o que talvez melhor demonstrasse a eficácia da fisioterapia nas condições crônicas (Feine et al., 1997). A remoção dessa lacuna é necessária, pois a elaboração de programas terapêuticos, educativos e preventivos deve ser direcionada no sentido de promover mudanças de comportamento compatíveis com a proposta de melhora integral do paciente.

\section{Alongamento global $X$ alongamento segmentar}

Os resultados não apontaram diferença entre os dois grupos, apesar dos procedimentos serem distintos. A Reeducação Postural Global (RPG) foi aplicada por um período de tempo longo, 15 minutos em cada uma das duas posturas feitas a cada sessão; enquanto o grupo de alongamento estático segmentar realizou alongamentos de 30 segundos, repetidos três vezes para cada grupo muscular da coluna cervical, cabeça, membros superiores e músculos mastigatórios, totalizando também 30 minutos.

Bandy e Irion (1994) e Zakas (2004) afirmam que o alongamento estático dos músculos isquiotibiais por 30 segundos mostrou-se efetivo no ganho de amplitude de movimento. Para Warren et al. (1976), porém, o tempo necessário para alongar um tecido é inversamente proporcional à força aplicada. Portanto, o alongamento de longa duração requer menos força para produzir um ganho de flexibilidade que só seria possível em alongamento de menor duração com a aplicação de uma força maior, com maior risco de lesão. Neste estudo, o tempo de permanência na posição de alongamento, embora diferente nos dois grupos, não alterou a amplitude da abertura da mandíbula. Como já mencionado, antes do tratamento as pacientes com DTM já apresentavam valores normais de amplitude, com média próxima a 4 centímetros ( $3,9 \mathrm{~cm}$ no grupo RPG e $4,0 \mathrm{~cm}$ no grupo AES). 
Os resultados obtidos com o alongamento por cadeias musculares ou por músculos isoladamente tiveram resultados equivalentes. Isso pode ser atribuído ao fato de que ambos foram realizados seguindo os mesmos princípios: não permitindo compensações, estimulando um ritmo respiratório lento sem bloqueio inspiratório e respeitando o limite suportado pela paciente, ou seja, sem provocar dor. O alongamento estático segmentar é de execução mais simples, o que facilita sua aprendizagem, porém seu procedimento adequado, com atenção cuidadosa, faz-se necessário para obtenção da eficácia observada no presente estudo.

Outra diferença importante nos dois procedimentos é que a abordagem da ATM foi direta no grupo AES e indireta no RPG - e esta última, mesmo assim, repercutiu positivamente nos resultados, em acordo com os trabalhos de cadeia muscular que referem melhora de sintomas à distância graças ao caráter global dessa forma de atuação (Bienfait, 1999; Bricot, 2001; Busquet, 2000; Marques, 2005; Meyers, 2003; Rocabado, 1979; Rolf, 2002; Souchard, 2005). Uma ilustração disso é oferecida pelo estudo de Fink et al. (2003), que verificaram a existência de ligação entre o sistema craniomandibular, o sistema craniocervical e a região sacropélvica; nesse estudo prospectivo experimental, 20 estudantes saudáveis foram submetidos a uma interferência artificial na oclusão, sendo detectadas alterações significantes na mobilidade dos referidos sistemas.

A RPG, como o nome sugere, tem como objetivo exercer influência na postura, uma vez que pretende alongar a musculatura antigravitacional (tipo I); além disso, segundo Marques et al. (1994), a RPG utiliza alongamento ativo, que requer atenção do paciente, dando oportunidade de maior conscientização corporal. Alguns trabalhos relatam que a reeducação postural tem efeito positivo na restauração da amplitude de movimento e no alívio da dor. Komyama et al. (1999) compararam a terapia cognitiva comportamental com a reeducação postural, Wright et al. (2000) compararam orientação e reeducação postural e Carlson et al. (2001) compararam uso de placa com reeducação postural e exercícios de relaxamento. Todos esses autores referem maior eficácia do tratamento nos pacientes que receberam reeducação postural. Nicolakis et al. (2000, 2001a,b, 2002) realizaram estudos por tratamentos compostos de reeducação postural associada a exercícios terapêuticos, terapia manual e relaxamento, concluindo que esses 
procedimentos parecem ser úteis nos casos de deslocamento anterior do disco com redução, síndrome dolorosa miofascial e nas DTMs miogênicas.

Fica o questionamento sobre o que pode ter contribuído para que os dois grupos obtivessem resultados semelhantes. A aplicação da pompage nos dois protocolos pode ter influenciado esse resultado, dificultando a análise individual de cada técnica. Podem, ainda, existir outros aspectos não avaliados neste estudo, tais como a postura e a amplitude de movimento da coluna cervical.

Outro aspecto a considerar é o papel que a fisioterapeuta exerceu em não somente solicitar a realização dos exercícios físicos, mas também de promover uma parceria com a própria paciente. As sessões individuais podem ter contribuído, pois permitiram um atendimento personalizado; e o fato de terem sido realizadas sempre pela mesma fisioterapeuta facilita a criação de vínculos e fortalece a motivação na busca das metas terapêuticas. O cuidado e a orientação na condução e aprendizagem dos exercícios - que configuram o papel pedagógico da fisioterapeuta - sem dúvida influenciam positivamente os resultados.

Neste trabalho não foi dada qualquer instrução às pacientes durante o tratamento, pois o objetivo era verificar os efeitos dos alongamentos ao longo das sessões. Na reavaliação após dois meses, porém, elas receberam uma cartilha, elaborada para esta pesquisa, que continha orientações de autocuidado e instruções para a realização dos exercícios praticados nas sessões. O mesmo procedimento foi utilizado em outros trabalhos (De Laat et al., 2003, Michelotti et al., 2004, 2005). Alguns referem que as orientações devem ser associadas a outros recursos, pois a eficácia do tratamento só foi encontrada em grupos de pacientes que receberam orientações associadas a outras modalidades de tratamento (Carlson et al., 2001; De Laat et al., 2003, Michelotti et al., 2004; Wright et al., 2000). As orientações de autocuidado, o esclarecimento dos fatores de risco e o treinamento de exercícios domiciliares proporcionam ganhos de ordem psicológica, uma vez que dão mais segurança ao paciente e diminuem sua ansiedade (Dworkin et al., 2002).

Michelotti et al. (2004) compararam a eficácia entre dois tratamentos: um grupo recebeu somente orientação básica (sobre cuidados e fatores de risco) e 
outro, essa mesma orientação combinada à orientação para a realização de exercícios domiciliares de alongamento. Após três meses, foi verificada $57 \%$ de melhora no grupo que recebeu somente orientação e $77 \%$ no grupo que recebeu também a orientação dos exercícios. A melhora nesse grupo foi atribuída ao alongamento.

Quando comparados os resultados obtidos ao final do tratamento com os verificados dois meses mais tarde, apresentaram discreta perda. Possivelmente as perdas seriam minimizadas se as mesmas fossem instruídas com auto-cuidado e prática de exercícios. Truelove et al. (2006) realizaram um ensaio clínico com 200 pacientes que receberam tratamento conservador, orientações e uso de placa e foram reavaliados três meses, seis meses e um ano após o tratamento, e concluíram que todos os pacientes obtiveram melhora a longo prazo. Possivelmente se o número de sessões tivesse maior freqüência, e o período fosse mais longo, o resultado da terceira avaliação poderia ser melhor. Magnusson e Syren (1999) e Carlson et al. (2001) comparam o uso de placa e exercícios em portadores de DTM miogênica com um protocolo de tratamento de seis meses e na reavaliação a longo prazo concluíram que ambos procedimentos obtiveram resultado positivo nos sintomas avaliados. Os autores referem, ainda, que os exercícios terapêuticos podem ser a primeira opção no tratamento da DTM miogênica, pois o seu custo é menor que a placa.

Várias pesquisas concluem que a aplicação dos exercícios terapêuticos podem contribuir na melhora dos sintomas das DTMs miogênicas, tal como aconteceu em nosso estudo. Não obstante, a elaboração de parâmetros ideais para a aplicação dos exercícios terapêuticos - como por exemplo tipo, tempo de duração, repetição, freqüência e intensidade - requer maiores investigações, com padronização de procedimentos de avaliação e intervenção. 


\section{CONCLUSÕES}

Considerando os resultados obtidos neste estudo, foi possível concluir que a reeducação postural global e o alongamento segmentar estático aplicados em portadoras de DTM miogênica Helkimo III:

- foram igualmente eficazes na redução da intensidade dos sintomas, no aumento do limiar de dor dos músculos estudados e na melhora da qualidade de vida.

- A atividade eletromiográfica do músculo masseter diminuiu nos dois grupos, do músculo temporal no grupo RPG e do músculo esternocleidomastóideo no grupo AES, sendo que no músculo trapézio não houve alteração nos dois grupos.

- Na reavaliação após dois meses do término do tratamento, houve discreta perda dos ganhos obtidos em todas as variáveis, porém sem retorno aos valores observados na avaliação inicial. 


\section{REFERÊNCIAS BIBLIOGRÁFICAS}

Adiels AM, Helkimo M, Magnusson T. Tactile stimulation as a complementary treatment of temporomandibular disorders in patients with fibromyalgia syndrome. Swed Dent J 2005;29(1):17-25.

Al-Ani Z, Gray RJ, Davies SJ, Sloan P, Glenny, AM. Stabilizantion splint therapy for the treatment of temporomandibular miofascial pain: a systematic review. J Dent Educ 2005;69(11):1242-50.

Alter MJ. Ciência da flexibilidade. São Paulo: Artmed; 1999.

Amantea DV, Novaes AP, Campolongo GD, Barros TP. A importância da avaliação postural no paciente com disfunção da articulação temporomandibular. Acta Ortop Bras 2004;12(3):252-60.

Anastassaki A, Magnusson T. Patients referred to a specialist clinic because of suspected temporomandibular disorders: a survey of 3194 patients in respect of diagnoses, treatments, and treatment outcome. Acta Odont Scand 2004; 62(4):183-92.

Asano T, Kawara M, Suzuki H, Komiyama O, Fukumoto M, Lida T. Masticatory muscle activity during exertion of the back. Nihon Hotetsu Shika Gakkai Zasshi 2006;50(1):45-53.

Ash MM, Ramfjord S. Oclusão. 2aed. São Paulo: Ed. Santos; 2001.

Astin JA, Ernst $E$. The effectiveness of spinal manipulation for the treatment of headache disorders: a systematic review of randomized clinical trials. Cephalalgia 2003;23(6):479-80.

Bandy WD, Irion JM. The effect of static stretch on flexibility of the hamstring muscles. Phys Ther 1994;77:1090-6.

Bendtsen L. Central sensibilization in tension-type headache: possible pathophysiological mechanisms. Cephalalgia 2000;20(5):486-508.

Bernhardt O, Gesch D, Schwan C, Mack F, Meyer G, John U, et al. Risk factors for headache, including TMD signs and symptoms, and their impact on quality of life; results of the studies of health in Pomerania (SHIP). Quintessence International 2005;36(1):55-64.

Bell WE. Dores orofaciais: classificação, diagnóstico, tratamento. Rio de Janeiro: Quintessence, 1990. Cap. Efeitos secundários da dor profunda, p.66-78.

Biasotto-Gonzalez DA. Abordagem interdisciplinar das disfunções temporomandibulares. São Paulo: Manole; 2005.

Bienfait M. Estudo e tratamento do esqueleto fibroso. São Paulo: Summus; 1999.

Bove G, Nilsson N. Spinal manipulation in the treatment of episodic tension-type headache: a randomized controlled trial. Jama 1998;280(18):1576-9.

Bracco P, Deregibus A, Piscetta R. Effects of different jaw relations on postural stability in human subjects. Neurosci Lett 2004; 356(3):228-30.

Bricot B. Postura normal e postura patológica. Posturologia. 2aed. São Paulo: Ícone; 2001.

Bronfort G, Nelsson N, Haas M, Evans R, Goldsmith CH, Assendelfit WJJ, et al. Noninvasive physical treatments for chronic/recurrent headache. Cochrane Database of Systematic Reviews 4; 2005.

Brown DT, Gaudet EL. Temporomandibular disorder treatment outcomes: second repot of large-scale prospective clinical study. Cranio 2002;20(4):244-53.

Busquet L. Les chaînes musculaires. T.1. 5.éd. Paris: Frison-Roche, 2000. 
Capellini KV, Souza SG, Faria SRC. Massage therapy in the management of myogenic TMD: a pilot study. J Appl Oral Sci 2006;14(1):1-11.

Carlson CR, Curran SL. Stretch-based relaxation training. Patient Educ Couns 1994; 23(1):5-12.

Carlson GE, Egermark I, Magnusson T. Predictors of signs and symptoms of temporomandibular disorders: a 20-year follow-up study from childhood to adulthood. Acta Odontol Scand 2002;60:80-5.

Carlson CR, Bertrand PM, Ehrlich AD, Maxwell AW, Burton RG. Physical self-regulation training for the management of temporomandibular disorders. J Orofac Pain 2001;15(1):47-55.

Cassar MP. Manual de massagem terapêutica: um guia completo de massoterapia para o estudante e para o terapeuta. São Paulo: Manole; 2001. Cap. Os efeitos da massagem, p.23-42.

Chan SP, Hong Y, Robinson PD. Flexibility resistance of hamstrings of young adults using two different static stretching protocols. Scand J Med Sci Sports 2001;11:81-6.

Chandu A, Suvinen TI, Reade PC, Borromeo GL. Electromyographic activity of frontalis and sternocleidomastoid muscles in patients with temporomandibular disorders. J Oral Rehabil 2005;32:571-6.

Chiba, M., Echigo, S. Longitudinal MRI follow-up of temporomandibular joint internal derangement with closed lock after successful disk reduction with mandibular manipulation. Dentomaxillofac Radiol 2005;34(2):106-11.

Ciconelli RM, Feraz MB, Santos W. Tradução para a língua portuguesa e validação do questionário genérico de qualidade de vida SF-36 (Brasil SF-36). Rev Bras Reumatol 1999;39:143-9.

Cleland J, Palmer J. Effectiveness of manual physical therapy, therapeutic exercise, and patient education on bilateral disc displacement without reduction of the temporomandibular joint: a single-case design. J Orthop Sports Phys Ther 2004; 34(9):535-48.

Conti PCR, Silva RS. Oclusão e disfunção temporomandibular: conceitos atuais para conduta clínica. Biodonto 2004;1(5):9-59.

Cornelius WL, Ebrahim K, Watson J, Hill DW. The effects of cold application and modified PNF stretching techniques on hip joint flexibility in college males. Res $Q$ Exerc Sport 1992;63(3):3111-14.

Cunha ACV. Reeducação postural global e alongamento segmentar no tratamento da cervicalgia: um estudo comparativo [dissertação]. São Paulo: Faculdade de Medicina da Universidade de São Paulo; 2004.

De Laat A, Stappaerts K, Papy S. Counseling and physical therapy as treatment for myofascial pan of masticatory system. J Orofac Pain 2003;17(1):42-9.

Deyne PGD. Aplications for passive stretch and its implications for muscle fibers. Phys Ther 2001;81(2):819-27.

Donega SHP, Cardoso R, Procópio ASF, Luz JGC. Análise da sintomatologia em pacientes com disfunção intra-articular da articulação temporomandibular. Rev Odontol Univ São Paulo 1997;11:77-83.

Douglas CR. Tratado de Fisiologia aplicada à saúde. 4ªed. São Paulo: Robe, 2000. Cap. Patofisiologia da nocicepção, p.56-72.

Douglas CR. Patofisiologia oral. São Paulo: Pancast, 1998.

Dworkin SF, Huggins KH, Wilson L, Mancl L, Turner J, Massoth D, et al. A randomized clinical trial of a tailored comprehensive care treatment program for temporomandibular disorders. J Orofac Pain 2002;16(4):259-76. 
Ekman L. Neurociência: fundamentos para reabilitação. Rio de Janeiro: Guanabara Koogan; 2000.

Erlich R, Garlick D, Ninio M. The efecct of jaw clenching on the electromiographic activities of 2 neck and 2 trunk muscles. J Orofac Pain 1999;14:115-20.

Ervilha UF, Duarte M, Amadio AC. Estudo sobre procedimentos de normalização do sinal eletromiográfico durante o movimento humano. Rev Bras Fisioter 1998;3(1):15-9.

Farias ACR. Estudo da relação entre a disfunção da articulação temporomandibular e as alterações posturais. Rev Odontol UNICID 2001; 13(2):125-33.

Feine JS, Widmer CG, Lund P. Physical therapy: a critique. Oral Surg Oral Med Oral Pathol Oral Radiol Endod 1997; 83(1):123-7.

Felício CM, Silva MA, Mazzetto MO, Centola AL. Myofunctional therapy combined with occlusal splint in treatment of temporomandibular joint dysfunction - pain syndrome. Braz Dental J 1991;2(1):27-33.

Fernandez de las Penãs C, Alonso-Blanco C J, Cuadrado ML, Miangolarra CJ, Barrigga FJ, Pareja JA. Manual therapies in the management of tension-type headache. Headache 2005;45(2):169-171.

Ferraz Jr AML, Guimarães JP, Rodrigues MF, Lima RHM. Avaliação da prevalência das alterações posturais em indivíduos com desordem temporomandibular: uma proposta terapêutica. Rev Serviço ATM 2004; 4(2):24-32.

Fink M, Wähling K, Stiesch-Scholz M, Tschernischek $\mathrm{H}$. The function relationship between the craniomandibular system, cervical spine, and the sacroiliac joint: a preliminary investigation. Cranio 2003; 21(3):202-8.

Fischer AA. Pressure algometry over normal muscle: standard values, validity and reproducibility of pressure threshold. Pain 1987; 30:115-26.

Fonseca DM. Disfunção crâniomandibular (DCM): elaboração de índice anamnésico [dissertação]. Bauru [SP]: Faculdade de Odontologia de Bauru da Universidade de São Paulo; 1992.

Franco RLR, Guimarães JP, Posselini AF. Desordem temporomandibular e reposição hormonal em pacientes com síndrome climatérica: prevalência e terapêutica. Rev Serviço ATM 2005; 5(1):32-9.

Fricton JR. Management of masticatory myofascial pain. Seminars in Orthodontics 1995;1(4):229-43.

Gadotti IC, Bérzin F, Biasotto-Gonzalez D. Preliminary rapport on head posture and muscle activity in subjects with class I and II. J Oral Rehabil 2005; 32(11):794-9.

Grace EG, Sarlane E, Reid B. The use of an oral exercise device in the treatment of muscular TMJ. J Craniomand Pract 2002; 20:2004-8.

Goldspink G. Changes in muscle mass and phenotype and expression of autocrine and systemic growth factors by muscle in response to stretch and oversold. J Anatomy 1999; 194:323-34.

Gross AR, Hoving JL, Haines TA, Goldsmith CH, Kay T, Aker P, et al. Manipulation and mobilization for mechanical neck disorders. Cochrane Database of Systematic Reviews. 2005;4.

Grossi DB, Monteiro VP, Guirro RRJ, Bérzen F. A physiotherapeutic approach to craniomandibular disorders: a case report. J Oral Rehabil 2002;29:268-73.

Hammil JM, Cook TM, Rosecrance JC. Effectiveness of a physical therapy regimen in the treatment of tension-type headache. Headache 1996;36(3):149-53. 
Helkimo, M. Studies on function and dysfunction of the masticatory system I: an epidemiological investigation of symptoms of dysfunction lapps in the North of Finland. Proc Finn Dent Soc 1974a; 70(2):37-49.

Helkimo, M. Studies on function and dysfunction of the masticatory system. II: index for anamnestic and clinical dysfunction and occlusal state. Sven Tandlakt 1974b; 67(2):101-21.

Helkimo, M. Studies on function and dysfunction of the masticatory system III: analyses of anamnestic and clinical recordings of dysfunction with the aid of indices. Sven Tandlakt 1974c; 67(3):165-81.

Hendel M, Horstmann T, Dickhuth H, Gulch, RW. Effects of contract-relax training on muscle performance in athletes. Eur J Appl Phisiol 1997;76:400-8.

Huddleston SJJ, Lobbeso F, Hofman N, Naeije M. Case report of a posterior disc displacement without and with reduction. J Orofac Pain 2005;19(4):337-42.

Jensen S. Neck related causes of headache. Aust Fam Physician 2005; 34(8):635-9.

Jull GA, Stanton WR. Predictors of responsiveness to physiotherapy management of cervicogenic headache. Cephalalgia 2005;25(2):101-8.

Jull G, Trott P, Potter H, Zito G, Niere K, Shirley D, et al. A randomized controlled trial of exercise and manipulative therapy for cervicogenic headache. Spine 2002; 27(17):1835-43.

Kazuyoshi B, Tadasu H, Yoshiyuki S, Takashi O, Glenn TC. Association between masseter mucle activity levels recorded during sleep and signs and symptoms of temporomandibular disorders in healthy young adults. J Orofac Pain 2005;19(3):226-31.

Kisner C, Colby LA. Exercícios terapêuticos: fundamentos e técnicas. São Paulo: Manole; 1992.

Knight C, Rutledge CR, Cox ME, Acosta M, Halls SJ. Effect of superficial heat, deep heat, and active warm-up on the extensibility of the plantar flexors. Phys Ther 2001;81(6):1206-14.

Kohno S, Matsuyama T, Medina RU, Arai Y. Functional-rhythmical mandibular opening movements. J Oral Rehabil 2001;28:161-7.

Komiyama O, Kawara M, Arai T, Kobayashi A, Kobayashi K. Posture correction as part of behavioural therapy in treatment of myofascial pain with limited opening. J Oral Rehabil 1999;26:428-35.

Koolstra JH, Van Eijden TM. Functional significance of the coupling between head and jaw movements. J Biomech 2004; 37(9):1387-92.

Krogstad BS, Jokstad A, Dahl BL, Vassend O. Relationships between risk factors and treatment outcome in a group of patients with temporomandibular disorders $\mathrm{J}$ Orofac Pain 1996;10(1):48-53.

Krogstad BS, Jokstad A, Dahl BL, Soboleva U. Somatic complaints, psychologic distress, and treatment outcome in two groups of TMD patients, one previously subjected to whiplash injury. J Orofac Pain 1998;12(2):136-44.

Kotani H, Kawazoe Y, Hamada T, Yamada S. Quantative electromyographic diagnosis of myofascial pain-dysfunction syndrome. J Prosthet Dent 1980;43(4):450-6.

.Lee WY, Okesson JP. The relationship between forward head posture and temporomandibular disorders. J Orofac Pain 1995; 9(2):161-7.

Levtov VA, Schusshtova NY. Topographic and hydrodinamic heterogeneity of the terminal bed of the cat gastrocnemius muscle vessel. Fiziologicheski Zurnal, 1985; 71(9):1105-11. 
Líber RL, Friden J. Mechanisms of muscle injury after excentric contration. J Sci Med Sport 1999;2(3):253-65.

Liljestron MR, Le Bell Y, Aromaa M, Jãmsã T, Metsãhonkala H, Viander S, et al. Headache children with temporomandibular disorders have several types of pain and other symptoms. Cephalalgia 2005;25:1054-60.

Locker D, Slade G. Prevalence of symptoms associated with temporomandibular disorders in Canadian population. Community Dent Oral Epidemiol 1998; 16:310-3.

Magnusson T. Changes in clinical signs of craniomandibular disorders fron the age of 15 to 25 years. J Orofac Pain 1994; 8:207-13.

Magnusson T, Syren M. Therapeutic jaw exercises and interocclusal appliance therapy. A comparison between two common treatments of temporomandibular disorders. Swed Dent J 1999;23(1):27-37.

Magnusson T, Egermark I, Carlsson GE. Treatment received, treatment demand, and treatment need for temporomandibular disorders in 35-year-old subjects. Cranio 2000;20(1):11-7.

Manheimer J, Lampe G. Clinical transcutaneous electrical nerve stimulation. Philadelphia: F. A. Davis,1984.

Marques AP. Cadeias musculares- um programa para ensinar avaliação fisioterapêutica global. São Paulo: Manole; 2005.

Marques AP, Ferreira EA, Matsutani LA, Pereira CA, Assumpção A. Quantifying pain threshold and quality of life of fibromyalgia patients. Clin Rheumatol 2005;24:266-7.

Marques AP, Mendonça LLF e Cossermelli W. Alongamento muscular em pacientes com fibromialgia a partir de um trabalho de reeducação postural global (RPG). Rev Bras Reumatol 1994;34(5):232-4.

Marzola FT, Marques AP, Marzola C. Contribuição da fisioterapia para odontologia nas disfunções da articulação temporomandibular. Rev Odonto Ciência [Fac Odonto /PUC-RS] 2002;17(36):119-34.

Matta MA, Honorato DC. Uma abordagem fisioterapêutica nas desordens temporomandibulares: estudo restrospectivo. Rev Fisioter Univ São Paulo 2003; 10(2):77-83.

Mcdonell MK, Sarhman SA, Van Dilen L. A specific exercise program and modification of postural alignment for treatment of cervicogenic headache: a case report. J Orthop Sports Phys Ther 2005;35(1):3-15.

Mchught MP, Magnusson SP, Gleim GW, Nicholas JA. Viscoelestic stress relaxation in human skeletal muscle. Med Sci Sports Exerc 1980;24:1375-82.

McKay DC, Christensen IV. Electrognathographic and electromyographic observations on jaw depression during neck extension, J Oral Rehabil 1999;26:865-76.

Mcneely ML, Armijo Olivo S, Magee DJ. A systematic review of the effectiveness of physical therapy interventions for temporomandibular disorders. Phys Ther 2006;86(5):710-25.

Mcneill $\mathrm{CH}$, editor. Temporomandibular disorders: guidelines for classification, assessment, and management. Chicago: The American Academy of Orofacial Pain.; Quintessence; 1993.

Medlicott MS, Harris SR. A systematic review of the effectiveness of exercise, manual therapy, electrotherapy, relaxation training, and biofeedback in the management of temporomandibular disorder. Phys Ther 2006;86(7):955-73.

Meyers WT. Trilhos anatômicos. São Paulo:Manole; 2003. 
Michelotti A, Martina R, Russo M, Romeo R. Personality characteristics of temporomandibular disorder patient using MMPI. Cranio 1998; 16(2):119-25.

Michelotti A, Steenks M, Farella M, Parisini F, Cimino R, Martina R. The additional value of a home physical therapy regimen versus patient education only for the treatment of myofascial pain of the jaw muscles: short-term results of a randomized clinical trial. J Orofac Pain 2004;18(2):114-25.

Michelotti A, Wijer A, Steenks M, Farella M. Home-exercise regimes for the management of non-specific temporomandibular disorders. J Oral Rehabil 2005;32:779-85.

Minoru A. Disfunção temporomandibular. São Paulo: Santos; 1995.

Molina F. Fisiopatologia craniomandibular. São Paulo: Pancast; 1989.

Moeller E, Suekuoleslam A, Lous I. Response of elevator activity during mastigation to treatment of functional disorders. Scand J Dent Res 1984;92:64.

Mongini F. ATM e músculos craniocervicofasciais: fisiopatologia e tratamento. São Paulo: Ed. Santos, 1998.

Munhoz WC. Avaliação global da postura ortostática de indivíduos portadores de distúrbios internos da articulação temporomandibular: aplicabilidade dos métodos clínicos, fotográficos e radiológicos [dissertação]. São Paulo: Faculdade de Medicina da Universidade de São Paulo; 2001.

Munhoz WC, Marques AP, Siqueira JTT. Evaluation of global body posture in Individuals with internal temporomandibular joint derangement. Cranio 2005;3(4):269-77.

Murphy G. Physical medicine modalities and trigger point injections in the management of temporomandibular disorders and assessing treatment outcome. Oral Surg Oral Med Oral Pathol Oral Radiol Endod 1997;83(1):118-22.

Nicolakis P, Erdogmus B, Kopf A, Djaber-Ansari A, Piehslinger E, Fialka-Moser V. Exercise therapy for craniomandibular disorders. Arch Phys Med Rehabil 2000; 81(9):1137-42.

Nicolakis P, Erdogmus B, Kopf A, Kollmitzer J, Piehslinger E, Wiesinger FG, et al.. An investigation of the effectiveness of exercise and manual therapy in treating symptoms of TMJ osteoarthritis. Cranio 2001a;19(1):26-32.

Nicolakis P, Erdogmus B, Kopf A, Ebenbichler G, Kollmitzer J, Piehslinger E, et al. Effectiveness of exercise therapy in patients with internal derangement of temporomandibular joint. J Oral Rehabil 2001b; 28:1158-64.

Nicolakis P, Erdogmus B, Kopf A, Nicolakis M, Pieslinger V, Fialka-Moser V. Effectivess of exercise therapy in patients with myofascial pain dysfuncton syndrome. $\mathrm{J}$ Oral Rehabil 2002;29:362-8.

Nissani M. A bibliographical survey of bruxism with special emphasis on non-traditional treatment modalities. J Oral Sci 2001;43(2):73-83.

Noble JE. Temporomandibular joint dysfunction at the general practioner level, part III: treatment. Aust Dent J 1965;10(1):58-62.

Okeson JP. Fundamentos da oclusão e desordens têmporo-mandibulares. $2^{\mathrm{a}}$ ed. São Paulo: Artes Médicas; 1998.

Pallegama RW, Ranasinghe AW, Weeransinghe VS, Sitheeque MAM. Influence of masticatory muscle pain on electromyographic activities of cervical muscles in patients with myogenous temporomandibular disorders. J Oral Rehabil 2004; 31:423-9.

Pallegama RW, Ranasinghe AW, Weerasinghe VS, Sitheeque MAM. Anxiety and personality traits in patients with muscle temporomandibular disorders. J Oral Rehabil 2005;32:701-7. 
Porto FR. Atuação fisioterapêutica nas desordens temporomandibulares. Revista Serviço ATM 2002; 2(2):67-9.

Raphael KG, Klausner JJ, Nayak S, Marbach JJ. Complementary and alternative therapy use by patients with miofascial temporomandibular disorders. J Orofac Pain 2003;17(1):36-41.

Reisine ST, Fertig J, Weber J, Leder S. Impact of dental conditions on patients' quality of life. Community Dent Oral Epidemiol 1989;17(1):7-10.

Rocabado M. Cabeza y cuello: tratamento articular. Buenos Aires: Intermedica, 1979.

Rohling D, Mello EB, Porto FR. Estudo comparativo de alternativas terapêuticas em trigger points miofasciais. Revista Serviço ATM 2003; 3(3):11-7.

Rolf I. A integração das estruturas humanas. São Paulo: Martins Fontes; 2002.

Rosário JLR. Alongamento muscular global e segmentar: um estudo comparativo [dissertação]. São Paulo: Faculdade de Medicina da Universidade de São Paulo; 2003.

Rosário JLR, Marques AP, Maluf AS. Aspectos clínicos do alongamento: uma revisão de literatura. Rev Bras Fisioter 2004;8(1):83-8.

Russel NT, Bandyt WD. Exccentric training and static stretching improve hamstring flexibility of high school males. J Athlet Train 2004; 39(3):254-8.

Sacco ICN, Konno GK, Rojas GB, Arnone AC, Pássaro AC, Marques AP, et al. Cabral CMN. Functional and EMG responses to a physical therapy treatment in patellofemoral syndrome patients. J Electromyogr Kinesiol 2006;16:167-74.

Sady SP, Wortman M, Blanke D. Flexibility training: ballistic, static or proprioceptive neuromuscular facilitation? Arch Physics Med Rehabil 1982; 63:261-3.

Sarlani E, Greenspan JD. Why look in the brain for answers to temporomandibular disorder pain? Cells Tissues Organs 2005;180(1):69-75.

Shimazaki T, Motoyoshi M, Hosoi K, Namura S. The effect of occlusal alteration and masticatory imbalance on the cervical spine. Eur J Orthod 2003;25(5):457-63.

Shrier I, Gossal K. Myths and truths of stretching. Phys Sportsmed 2000; 28(8):57-63.

Simons GD, Hong, CZ. Patophysiologic and electrophysiologic mechanisms of myofascial trigger points. Arch Phys Med Rehabil 1998;79:863-72.

Smith C. The warm-up procedure: to stretch or not to stretch. J Orthop Sports Phys Ther 1994;19:12-6.

So K, Komiyama O, Arai M, Kawara M, Kobayashi K. Influence of occlusal contact on cervical muscle activity during submaximal clenching. J Oral Rehabil 2004;31:417-22.

Souchard P. O stretching global ativo. São Paulo: Manole; 1996.

Souchard P. Reeducação postural global. São Paulo: É Realizações, 2005.

Steed PA. The longevity of temporomandibular disorder improvements after active treatment modalities. Cranio 2004; 22(2):110-4.

Steenks MH, Wijer A. Disfunção da articulação temporomandibular do ponto de vista da fisioterapia e da odontologia: diagnóstico e tratamento. São Paulo: Ed. Santos, 1996.

Stiesch-Scholz M, Fink M, Tschernitschek H. Rossbach A. Medical and physical therapy of temporomandibular joint disk displacement without reduction. Cranio 2002;20(2):85-90.

Sturdivant J, Fricton JR. Physical therapy for temporomandibular disorders and orofacial pain. Current Opinion in Dentistry 1991;1(4):485-96.

Suvinen TI, Read PC, Kononen M, Kenppainen EP. Vertical jaw separation and masseter muscle electromyographic activity: A comparative study between asymptomatic controls patients with temporomandibular pain dysfunction. J Oral Rehabil 2003;30:765-72. 
Suvinen TI, Hanes KR, Reade PC. Outcome of therapy in he conservative management of temporomandibular pain dysfuntion disorder. J Oral Rehabil 1997;24(10):718-24.

Svensson P, List T, Hector G. Analysis of stimulus-evoked pain in patients with myofascial temporomandibular pain disorders. Pain 2001;92:399-409.

Svensson P, Wang K, Sessle BJ, Arendt-Nielsen L. Associations between pain and neuromuscular activity in the human jaw and neck muscles. Pain 2004;109(3):225-32.

Tedeshi F, Marques AP. O papel da fisioterapia nas disfunções temporo-mandibulares. Rev Fisioter Univ São Paulo 1999;6(2):172-8.

Tollison C, Kriegel M. Interdisciplinary rehabilitation of low back pain. Baltimore: William \& Wilkins; 1989.

Torelli P, Jensen R, Olesen J. Physiotherapy for tension-type headache: a controlled study. Cephalalgia 2004;24:29-36.

Turner JA, Mancl L, Aaron LA. Brief cognitive-behavioral therapy for temporomandibular disorder pain: effects on daily electronic outcome and process measures. Pain 2005;117(3):377-87.

Truelove E, Huggins KH, Mancl L, Dworkin SF The efficacy of tradicional, low-cost and nonsplint therapies for temporomandibular disorder: a randomized controlled trial. J Am Dent Assoc 2006;137(8):1099-107.

Tsukimoto GR, Ribeiro M, Brito CA, Batistela LR. Avaliação longitudinal da Escola de Postura para dor lombar crônica através da aplicaçãodos questionários Roland Morris e Short Form Survey (SF-36). Acta Fisiatr 2006;13(2):63-9.

Uno HH. Estudo comparative das excursões máximas obtidas com e sem pressão bidigital, em pacientes com disfunção dolorosa da articulação temporomandibular. Rev Odontol Univ São Paulo 1993;7:245-9.

Vargo CP, Hickman DM. Cluster-like signs and symptons respond to myofascial /craniomandibular treatment: a report of two cases. Cranio 1997;15(1):89-93.

Visscher CM, Lobbezoo F, De Boer W, Van Der Zaag J, Naeije M. Prevalence of cervical spinal pain in craniomandibular pain patients. Eur J Oral Sci 2001;109:76-80.

Visscher CM, Lobbezzo F, Naeije M. Comparison of algometry and palpation in the recognition of temporomandibular disorder pain complaints. J Orofac Pain 2004;18(3):214-9.

Waide FL, Bade DM, Lovasko J, Montana J. Clinical management of a patient following temporomandibular joint arthroscopy. Physiotherapy 1992;72(5):355-64.

Warren CG, Lehamann JF, Koblansk JN. Heat and strech produces: an evaluation using rat tail tendon. Arch Phys Med Rehabil 1976;57(3):122-6.

Wexler GB, Stted PA. Psychological factors and temporomandibular outcomes. Cranio 1998;16:72-7.

Wijer A. Temporomandibular and cervical spine disorders: self-reported sins and simptoms. Spine 1996;21(14):1638-46.

Wijer A. Distúrbios temporomandibulares e da região cervical. São Paulo: Ed. Santos; 1998.

Wolfe F, Smythe HAA, Yunus MB, Bennett AM, Bombardier CE, Goldenberg DL. The American College of Rheumatology 1990. Criteria for the classification of fibromyalgia: report of the Multicenter Criteria Committee. Arthritis Rheum 1990;33:160-72.

Woo SLW, Young EP. Structure and function of tendons and ligaments. In: Mow WC, editor. Basic ortopedic biomechamics. New York: Raven Press; 1991.

Wright EF, Domenech MA, Fischer JR. Usefulness of posture training for patients with temporomandibular disorders. J Am Dent Assoc 2000;131(2):202-10. 
Yemm R. Temporomandibular dysfunction and masseter muscle response to experimental stress. J Brit Dent 1969;127(11):508-10.

Yoda T, Sakamoto I, Imai H, Honma Y. A randomized controlled trial of terapeutic exercice for clickink due to disc anterior displacement with reduction in temporomandibular joint. Cranio 2003;21(1):10-6.

Yoda T, Sakamoto I, Imai H, Ohashi K, Hoshi K, Kusama M, et al. Response of temporomandibular joint intermittent closed lock to different treatment modalities: a multicenter survey. Cranio 2006; 24(2):130-6.

Yoshino G, Higashi K, Nakamura T. Changes in head position due to occlusal supporting zone loss during clenching. Cranio 2003; 21(2):89-98.

Zakas A. The effect of stretching duration on the lower extremity flexibility of adolescent soccer players. J Bodywork Move Ther 2005;9(3)220-5. 


\section{ANEXO 1}

TERMO DE CONSENTIMENTO LIVRE E ESCLARECIDO

DADOS DE IDENTIFICAÇÃO DO SUJEITO DA PESQUISA:

Nome:

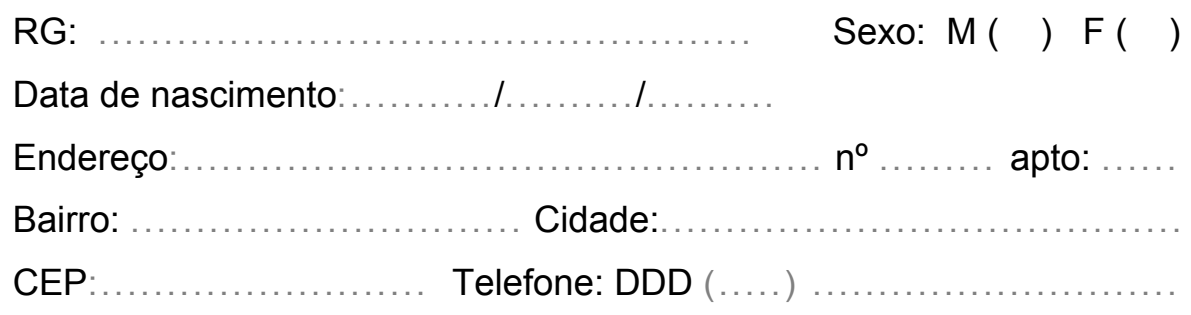

CONSENTIMENTO PÓS-ESCLARECIDO

Estou ciente de que estou participando de uma pesquisa científica e que todos os dados e informações por mim concedidos serão totalmente sigilosos, não sendo revelada, de forma alguma, minha identificação.

Estou ciente também de que não sou obrigado a participar deste estudo, podendo desistir a qualquer momento.

São Paulo,

(Assinatura da paciente / voluntária) 


\section{ANEXO 2}

\section{APROVAÇÃO DO COMITÊ DE ÉTICA}

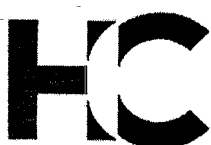

MOSPITAL DAS ELINIGAS

OA FACULDADE DE MEDICINA

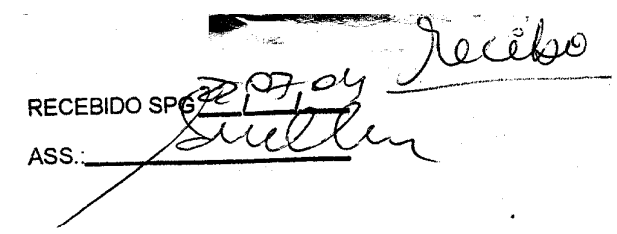

DIRETORIA CLÍNICA

\section{Comissão de Ética para Análise de Projetos de Pesquisa}

\section{APROVACÃO}

A Comissão de Ética para Análise de Projetos de Pesquisa - CAPPesq da Diretoria Clínica do Hospital das Clínicas e da Faculdade de Medicina da Universidade de São Paulo, em sessão de 14.07.04, APROVOU o Protocolo de Pesquisa $n^{\circ} 155 / 04$, intitulado: $\therefore$

"Reeducação postural global e alongamento segmentar estático nas desordens temporomandibulares: um estudo comparativo" apresentado pela ÁREA DE FISIOPATOLOGIA EXPERIMENTAL, inclusive o Termo de Consentimento Livre e Esclarecido.

Pesquisador(a) Responsável: Profa. Dra. Amélia Pasqual Marques

Pesquisador(a) Executante: Sra. Sâmia Amire Maluf

CAPPesq, 14 de Julho de 2004.

\section{lut rido}

PROF. DR. EUCLIDES AYRES DE CASTILHO

Encaminhe-se à CPG-FMUSP para as devidas pronidéncias. Presidente da Comissão de Ética para Análise S. $21,07,04$ de Projetos de Pesquisa

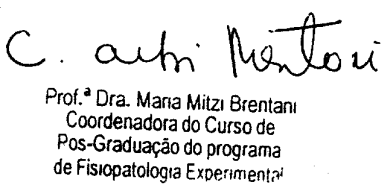

OBSERVAÇÃO: Cabe ao pesquisador elaborar e apresentar à CAPPesq, os relatórios parciais $e$ final sobre a pesquisa (Resolução do Conselho Nacional de Saúde $n^{\circ} 196$, de 10.10.1996, inciso IX.2, letra " $c$ ") 


\section{ANEXO 3}

FICHA DE AVALIAÇÃO E INTERPRETAÇÃO DO ÍNDICE DE HELKIMO

1. Nome:

2. Sexo: Masculino ( ) Feminino ( ) Idade ........

3. Profissão:

A. Índice Anamnésico

Indique se você apresenta ou apresentou nos últimos seis meses alguns dos seguintes sintomas:

( ) ruídos na ATM

( ) cansaço muscular

( ) rigidez na musculatura ao acordar ou aos movimentos da mandíbula

( ) dificuldade de abrir amplamente a boca

( ) travamento (dificuldade temporária ou permanente de abrir a boca)

( ) luxação (impossibilidade de fechar a boca espontaneamente)

( ) dor na ATM aos movimentos mandibulares

B. Índice de Disfunção

Grau de movimentação mandibular - Abertura bucal máxima $0 \ldots$. I... 5 .... Movimento lateral máximo para a direita: $0 \ldots . . . . .5 \ldots$.

Movimento lateral máximo para a esquerda : $0 \ldots \ldots \mid \ldots . . .5 \ldots$.

Movimento protrusivo máximo: $0 \ldots \ldots . \mid \ldots \ldots 5 \ldots \ldots$

- Diminuição da função da ATM : $0 \ldots \ldots . . . . . .5 \ldots \ldots$.

- Dor muscular á palpação: $0 \ldots . . . . . .5 \ldots . .$.

- Dor na ATM à palpação : $0 . \ldots . . . . . .5 \ldots . .$.

- Dor ao movimento mandibular : 0.... I ..... 5.....

- Estalo ..... Crepitação

C. Índice oclusal

- Número de dentes: $0 \ldots . . . . . . .5 \ldots \ldots$

- Número de dentes em oclusão: $0 . \ldots . \mid$ ।..... 5.......

- Interferência em RC $0 \ldots . . .1 . . . .5 \ldots . .$.

- Interferência excêntrica $0 \ldots . . . . . . . .5 \ldots . .$. 


\section{Interpretação do Índice de Helkimo}

1. Índice Anamnésico de Disfunção

- $\mathrm{Ai}=0$ Denota ausência completa de sintomas subjetivos de disfunção do sistema mastigatório (isto é, dos sintomas mencionados abaixo).

- $\mathrm{Ai}$ = I Denota sintomas moderados, como ruídos nas ATM tais como: cliques e crepitação; sensação de cansaço ou fadiga na mandíbula

- $\mathrm{Ai}=$ II Denota sintomas graves de disfunção. Um ou mais dos seguintes sintomas foram relatados na anamnese: dificuldade de abertura bucal ampla, travamento, luxações, dor ao movimento, dor facial e mandibular.

2. I Índice Clínico de Disfunção

- Di = 0 Denota ausência de sintomas clínicos de disfunção.

- $\mathrm{Di}=\mathrm{I}$ Denota sintomas médios de disfunção. Um a quatro dos seguintes sintomas foi encontrado: a) Desvios da abertura e/ou fechamento bucal $>2 \mathrm{~mm}$ da linha sagital; b) sons articulares (dique ou crepitação); c) dor muscular à palpação em I a 3 sítios; d) dor à palpação no pólo lateral da ATM; e) dor em associação com um movimento da mandíbula; f) máxima abertura bucal 30$39 \mathrm{~mm}$, movimento horizontal 4-6 $\mathrm{mm}$.

- $\mathrm{Di}=$ II Denota ao menos um sintoma grave, combinado com O a 4 sintomas moderados ou 5 sintomas médios apenas. A gravidade pode ser expressa por:

a) travamento/luxação da ATM; b) dor muscular à palpação em 4 ou mais sítios;

c) dor à palpação posterior da ATM; d) dor em 2 ou mais movimentos mandibulares; e) máxima abertura bucal $<30 \mathrm{~mm}$; f) um ou mais movimentos horizontais $<4 \mathrm{~mm}$.

- $\mathrm{Di}=$ III Denota 2 a 5 dos sintomas graves, possivelmente combinados com sintomas moderados. 


\section{ANEXO 4}

\section{FICHA DE AVALIAÇÃO UTILIZADA COM PACIENTES (MODELO)}

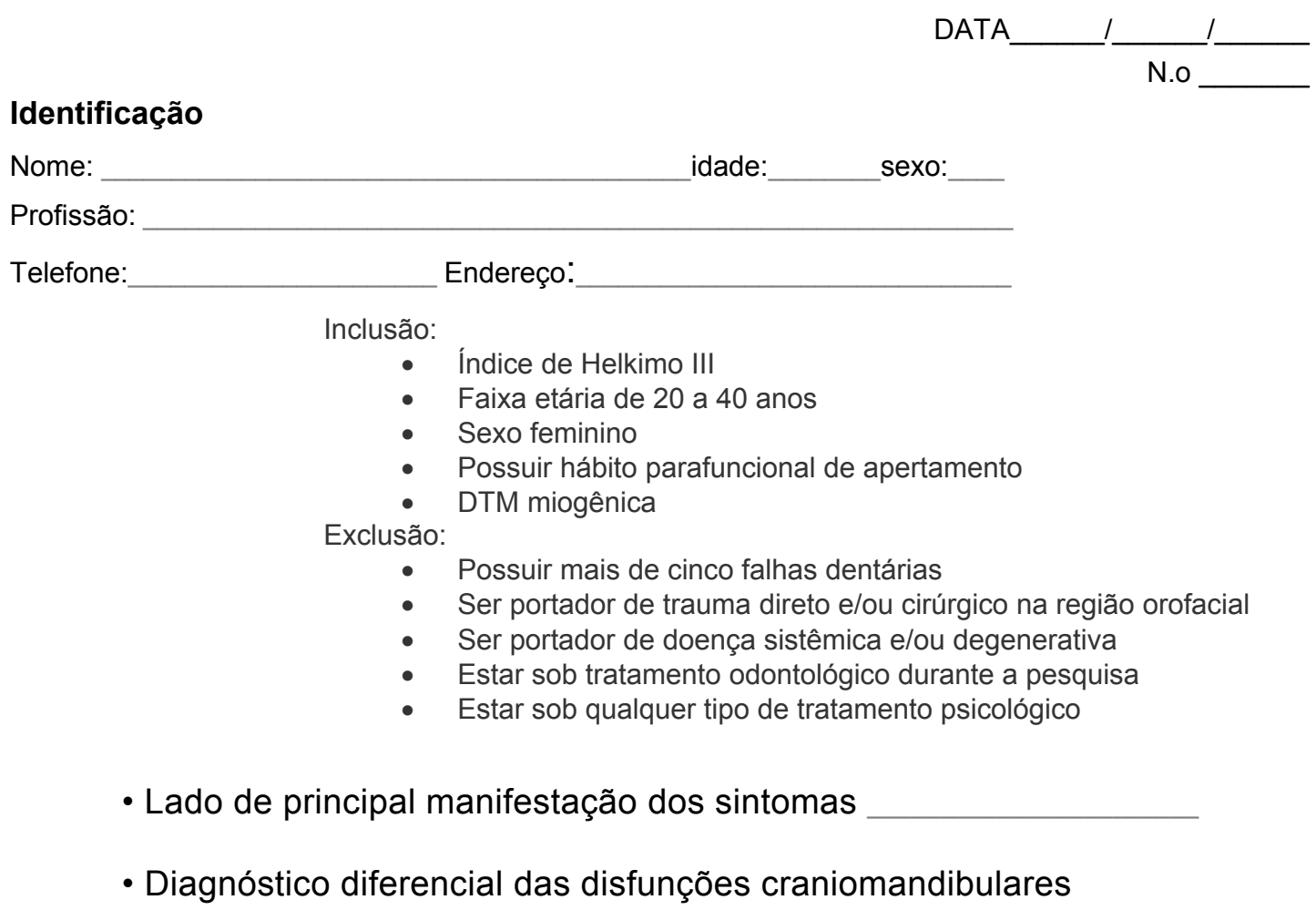

\begin{tabular}{|c|c|c|c|}
\cline { 2 - 4 } \multicolumn{1}{c|}{} & Desordem do disco & Desordens musculares & Resultado \\
\hline HMA / Tipo de dor & $\begin{array}{c}\text { Trauma (respirador bucal, } \\
\text { classe II) }\end{array}$ & $\begin{array}{c}\text { Sem história de trauma } \\
\text { (bruxismo, problema emocional) }\end{array}$ & \\
\cline { 2 - 4 } & $\begin{array}{c}\text { Dores constantes que } \\
\text { pioram com o tempo }\end{array}$ & $\begin{array}{c}\text { Dor moderada a severa, } \\
\text { relacionado ao estresse } \\
\text { flutuante) }\end{array}$ & (dor \\
\hline $\begin{array}{c}\text { Limitação de ADM } \\
\text { (restrição mandibular) }\end{array}$ & ADM ativa = passiva & ADM ativa < passiva & \\
\hline
\end{tabular}

- Dolorimetria nos pontos-gatilho (ponto motor)

Trapézio superior:

Esternocleidomastóideo:

Masseter:

Temporal:

- Amplitude de abertura da mandíbula: 
ESCALA ANALÓGICA VISUAL (VAS)

sem dor dor insuportável

$\mid \begin{aligned} & \\ & \text { sem dor dor insuportável }\end{aligned}$

$\mid$\begin{tabular}{|l} 
nenhuma dificuldade $\quad$ muificuldade
\end{tabular}

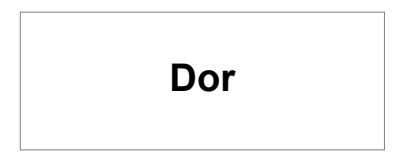

Cefaléia

\section{Cervicalgia}

Sintoma no ouvido

\author{
Apertamento
}

Dificuldade de dormir

Dificuldade de comer 


\section{ANEXO 5}

\section{QUESTIONÁRIO DE AVALIAÇÃO DE QUALIDADE DE VIDA SF-36}

Esta pesquisa questiona você sobre sua saúde. Estas informações nos manterão informados de como você se sente e quão bem você é capaz de fazer suas atividades de vida diária. Responda cada questão marcando a resposta como indicado. Caso você esteja inseguro em como responder, por favor solicite nossa ajuda e tente responder o melhor que puder.

1 Em geral, você diria que a sua saúde é :
(1) Excelente
(2) Muito boa
(3) Boa
(4) Ruim
(5) Muito ruim

2 Comparada a um ano atrás, como você classificaria sua saúde em geral, agora?

(1) Muito melhor agora do que há um ano atrás

(2) Um pouco melhor agora do que há um ano atrás

(3) Quase a mesma de um ano atrás

(4) Um pouco pior agora do que há um ano atrás

(5) Muito pior agora do que há um ano atrás

3 Os seguintes itens são sobre atividades que você poderia fazer atualmente durante um dia comum. Devido a sua saúde, você tem dificuldade para fazer essas atividades? Neste caso, quanto?

\begin{tabular}{|l|c|c|c|}
\hline ATIVIDADES & $\begin{array}{c}\text { SIM, } \\
\text { dificulta muito }\end{array}$ & $\begin{array}{c}\text { SIM, } \\
\text { dificulta um } \\
\text { pouco }\end{array}$ & $\begin{array}{c}\text { NÃO, } \\
\text { não dificulta de } \\
\text { modo algum }\end{array}$ \\
\hline $\begin{array}{l}\text { a) Atividades vigorosas, que exigem } \\
\text { muito esforço, tais como correr, } \\
\text { levantar objetos pesados, participar } \\
\text { em esportes árduos }\end{array}$ & 1 & 2 & 3 \\
\hline $\begin{array}{l}\text { b) Atividades moderadas, tais como } \\
\text { mover uma mesa, passar aspirador de } \\
\text { pó, jogar bola, varrer a casa }\end{array}$ & 1 & 2 & 3 \\
\hline c) Levantar ou carregar mantimentos & 1 & 2 & 3 \\
\hline d) Subir vários lances de escada & 1 & 2 & 3 \\
\hline e) Subir um lance de escada & 1 & 2 & 3 \\
\hline f) Curvar-se, ajoelhar-se ou dobrar-se & 1 & 2 & 3 \\
\hline g) Andar mais de 1 quilômetro & 1 & 2 & 3 \\
\hline h) Andar vários quarteirões & 1 & 2 & 3 \\
\hline i) Andar um quarteirão & 1 & 2 & 3 \\
\hline j) Tomar banho ou vestir-se & & 2 & 3 \\
\hline
\end{tabular}

4 Durante as últimas 4 semanas, você teve algum dos seguintes problemas com seu trabalho ou com alguma atividade diária regular, como conseqüência de sua saúde física?

\begin{tabular}{|l|c|c|}
\hline $\begin{array}{l}\text { a) Você diminuiu a quantidade de tempo que se dedicava ao seu trabalho ou } \\
\text { a outras atividades? }\end{array}$ & 1 & 2 \\
\hline b) Realizou menos tarefas do que você gostaria? & 1 & 2 \\
\hline c) Esteve limitado no seu tipo de trabalho ou em outras atividades? & 1 & 2 \\
\hline $\begin{array}{l}\text { d) Teve dificuldade de fazer seu trabalho ou outras atividades (por exemplo: } \\
\text { necessitou de um esforço extra)? }\end{array}$ & 1 & 2 \\
\hline
\end{tabular}


5 Durante as últimas 4 semanas, você teve alguns dos seguintes problemas com seu trabalho ou outra atividade regular diária, como conseqüência de algum problema emocional (como sentir-se deprimido ou ansioso)?

\begin{tabular}{|l|c|c|}
\hline $\begin{array}{l}\text { a) Você diminui a quantidade de tempo que se dedicava ao seu trabalho ou a } \\
\text { Outras atividades? }\end{array}$ & 1 & 2 \\
\hline b) Realizou menos tarefas do que você gostaria? & 1 & 2 \\
\hline $\begin{array}{l}\text { c) Não trabalhou ou não fez qualquer das atividades com tanto cuidado como } \\
\text { geralmente faz? }\end{array}$ & 1 & 2 \\
\hline
\end{tabular}

6 Durante as últimas 4 semanas, de que maneira sua saúde física ou problemas emocionais interferiram nas suas atividades sociais normais, em relação a família , vizinhos, amigos ou em grupo?

(1) De forma alguma (2) Ligeiramente (3) Moderadamente (4) Bastante (5) Extremamente 7 Quanta dor no corpo você teve durante as últimas 4 semanas?
(1) Nenhuma
(2) Muito leve
(3) Leve
(4) Moderada
(5) Grave
(6) Muito grave

8 Durante as últimas 4 semanas, quanto a dor interferiu com o seu trabalho normal (incluindo tanto o trabalho, fora e dentro de casa)?
(1) De maneira alguma
(2) Um pouco
(3) Moderadamente
(4) Bastante
(5) Extremamente

9 Estas questões são sobre como você se sente e como tudo tem acontecido com você durante as últimas 4 semanas. Para cada questão, por favor dê uma resposta que mais se aproxime da maneira como você se sente em relação as 4 últimas semanas.

\begin{tabular}{|c|c|c|c|c|c|c|}
\hline & 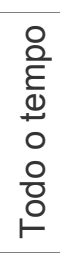 & 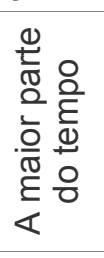 & 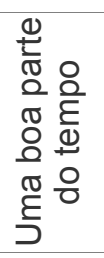 & 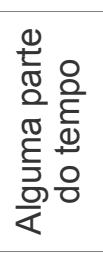 & 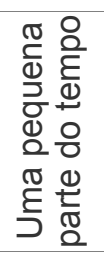 & $\begin{array}{l}\text { O } \\
\text { ऽ } \\
z\end{array}$ \\
\hline $\begin{array}{l}\text { a) Quanto tempo você tem se sentido cheio } \\
\text { de vigor, cheio de vontade, cheio de força? }\end{array}$ & 1 & 2 & 3 & 4 & 5 & 6 \\
\hline $\begin{array}{l}\text { b) Quanto tempo você tem se sentido uma } \\
\text { pessoa muito nervosa? }\end{array}$ & 1 & 2 & 3 & 4 & 5 & 6 \\
\hline $\begin{array}{l}\text { c) Quanto tempo você tem se sentido tão } \\
\text { deprimido que nada pode animá-lo? }\end{array}$ & 1 & 2 & 3 & 4 & 5 & 6 \\
\hline $\begin{array}{l}\text { d) Quanto tempo você tem se sentido calmo } \\
\text { ou tranqüilo? }\end{array}$ & 1 & 2 & 3 & 4 & 5 & 6 \\
\hline $\begin{array}{l}\text { e) Quanto tempo você tem se sentido com } \\
\text { muita energia? }\end{array}$ & 1 & 2 & 3 & 4 & 5 & 6 \\
\hline $\begin{array}{l}\text { f) Quanto tempo você tem se sentido } \\
\text { desanimado e abatido? }\end{array}$ & 1 & 2 & 3 & 4 & 5 & 6 \\
\hline $\begin{array}{l}\text { g) Quanto tempo você tem se sentido } \\
\text { esgotado? }\end{array}$ & 1 & 2 & 3 & 4 & 5 & 6 \\
\hline $\begin{array}{l}\text { h) Quanto tempo você tem se sentido uma } \\
\text { pessoa feliz? }\end{array}$ & 1 & 2 & 3 & 4 & 5 & 6 \\
\hline i) Quanto tempo você tem se sentido cansado? & 1 & 2 & 3 & 4 & 5 & 6 \\
\hline
\end{tabular}

10 Durante as últimas 4 semanas, quanto do seu tempo a sua saúde física ou problemas emocionais interferiram com suas atividades sociais (como visitar amigos, parentes, etc.)?
(1) Todo o tempo
(2) A maior parte do tempo
(4) Uma pequena parte do tempo
(3) Alguma parte do tempo
(5) Nenhuma parte do tempo

11- O quanto verdadeiro ou falso é cada uma das afirmações para você? 


\begin{tabular}{|c|c|c|c|c|c|}
\hline & 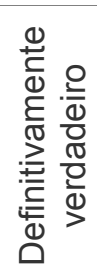 & 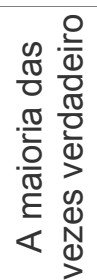 & $\begin{array}{l}\bar{\Phi} \\
\infty \\
0 \\
2 \pi \\
Z\end{array}$ & 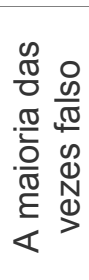 & 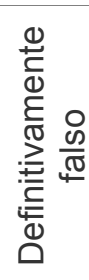 \\
\hline $\begin{array}{l}\text { a) Eu costumo adoecer um pouco mais facilmente } \\
\text { que as outras pessoas. }\end{array}$ & 1 & 2 & 3 & 4 & 5 \\
\hline $\begin{array}{l}\text { b) Eu sou tão saudável quanto qualquer pessoa } \\
\text { que eu conheço. }\end{array}$ & 1 & 2 & 3 & 4 & 5 \\
\hline c) Eu acho que a minha saúde vai piorar. & 1 & 2 & 3 & 4 & 5 \\
\hline d) Minha saúde é excelente. & 1 & 2 & 3 & 4 & 5 \\
\hline
\end{tabular}

\section{CÁLCULO DO ESCORE DO QUESTIONÁRIO SF-36}

\section{FASE I : Ponderação dos dados}

\section{Questão}

01

Se a resposta for:
1
2
3
4
5

A pontuação será:
5,0
4,4
3,4
2,0
1,0

02 Manter o mesmo valor

03 Soma de todos os valores

04 Soma de todos os valores

05 Soma de todos os valores

06 Se a resposta for:

$\begin{array}{cr}1 & \text { A pontuaç } \\ 2 & 5 \\ 3 & 4 \\ 4 & 3 \\ 5 & 2 \\ & 1\end{array}$

07 Se a resposta for: $A$ pontuação será:

$\begin{array}{ll}1 & 6,0 \\ 2 & 5,4 \\ 3 & 4,2 \\ 4 & 3,1 \\ 5 & 2,2 \\ 6 & 1,0\end{array}$

08 A resposta da questão 8 depende da nota da questão 7 :

Se $7=1$ e se $8=1$, o valor da questão é 6

Se $7=2$ a 6 e se $8=1$, o valor da questão é 5

Se $7=2$ a 6 e se $8=2$, o valor da questão é 4

Se $7=2$ a 6 e se $8=3$, o valor da questão é 3

Se $7=2$ a 6 e se $8=4$, o valor da questão é 2

Se 7 = 2 a 6 e se $8=5$, o valor da questão é 1

Se a questão 7 não tiver sido respondida, o escore da questão 8 passa a ser o seguinte:

Se a resposta for 1 , a pontuação será 6

Se a resposta for 2 , a pontuação será 4,75 
Se a resposta for 3 , a pontuação será 3,5

Se a resposta for 4 , a pontuação será 2,25

Se a resposta for 5 , a pontuação será 1,0

09 Nesta questão a pontuação para os itens $\mathbf{a}, \mathbf{d}, \mathbf{e}, \mathbf{h}$ deverá seguir a seguinte orientação:

Se a resposta for 1 , o valor será 6

Se a resposta for 2 , o valor será 5

Se a resposta for 3 , o valor será 4

Se a resposta for 4 , o valor será 3

Se a resposta for 5 , o valor será 2

Se a resposta for 6 , o valor será 1

Para os demais itens $(\mathbf{b}, \mathbf{c}, \mathbf{f}, \mathbf{g}, \mathbf{i})$, o valor será mantido o mesmo.

10 Considerar o mesmo valor

11 Nesta questão os itens deverão ser somados, porém para os itens b e d deve-se seguir a seguinte pontuação:

Se a resposta for 1 , o valor será 5

Se a resposta for 2 , o valor será 4

Se a resposta for 3 , o valor será 3

Se a resposta for 4 , o valor será 2

Se a resposta for 5 , o valor será 1 .

\section{Fase II: Cálculo do raw scale}

Nesta fase transformar-se-á o valor das questões anteriores em notas dos 8 domínios, que variam de 0 (zero) a 100 (cem), onde $0=$ pior e $100=$ melhor, para cada domínio. É chamado de raw scale, porque o valor final não apresenta nenhuma unidade de medida.

\section{Domínios}

1. Capacidade funcional

2. Limitação por aspectos físicos

3. Dor

4. Estado geral de saúde

5. Vitalidade

6. Aspectos sociais

7. Aspectos emocionais

8. Saúde mental

Para o cálculo de cada domínio, será aplicada a seguinte fórmula:

Domínio $=$ Valor obtido nas questões correspondentes - limite inferior X 100

$$
\text { Variação (score range) }
$$

onde os valores de "limite inferior" e "variação (score range)" são fixos e estão estipulados no quadro a seguir:

\begin{tabular}{|l|c|c|c|}
\hline \multicolumn{1}{|c|}{ Domínio } & $\begin{array}{c}\text { Pontuação da(s) questão(ões) } \\
\text { correspondentes }\end{array}$ & $\begin{array}{c}\text { Limite } \\
\text { inferior }\end{array}$ & $\begin{array}{c}\text { Variação } \\
\text { (score range) }\end{array}$ \\
\hline Capacidade funcional & 03 & 10 & 20 \\
\hline Aspectos físicos & 04 & 4 & 4 \\
\hline Dor & $07^{*} 08$ & 2 & 10 \\
\hline Estado geral da saúde & $01+11$ & 5 & 20 \\
\hline Vitalidade & 09 (somente os itens a + e + g + i ) & 4 & 20 \\
\hline Aspectos sociais & $06+10$ & 2 & 8 \\
\hline Aspectos emocionais & 05 & 3 & 3 \\
\hline Saúde mental & 09 (somente os itens $b+c+d+f+h)$ & 5 & 25 \\
\hline
\end{tabular}




\section{ANEXO 6}

\section{Procedimentos utilizados na intervenção}

\section{Pompage}

Na pompage diafragmática, a terapeuta posicionava uma das mãos na projeção do processo xifóide (fixando) e, com a região ulnar da outra mão, realizava a manobra acompanhando o bordo costal lateralmente, exercendo uma tração tangente durante a expiração da paciente. (Figura $1 \mathrm{a}$ e b) .
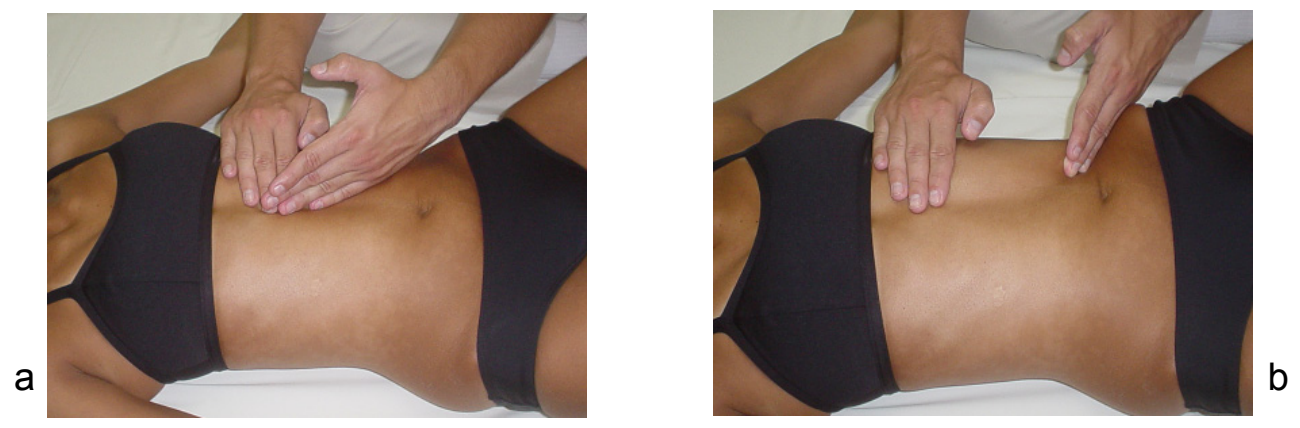

Figura-1 Pompage de diafragma

Na pompage lombar, a paciente apoiava a região toracolombar na mão da terapeuta que, lenta e progressivamente ,tensionava a fáscia no sentido caudal (Figura 2).

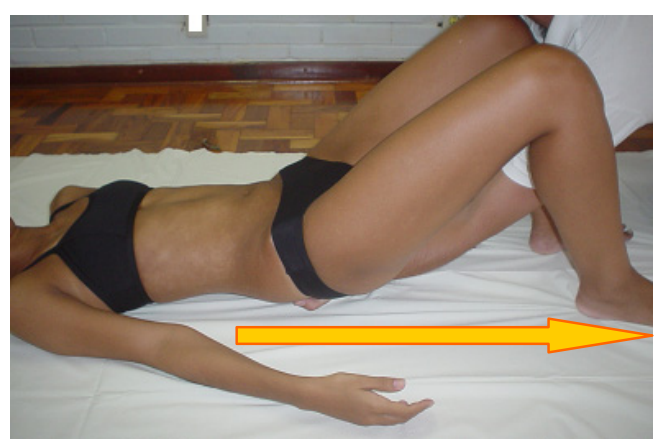

Figura 2 Pompage lombar

Na pompage dorsal, era solicitada à paciente uma leve flexão de tronco; a terapeuta posicionava uma das mãos na região da coluna torácica e tensionava lenta e progressivamente a fáscia em sentido cranial. A outra mão da terapeuta apoiava na região esternal, ajudando a expiração (Figura 3).

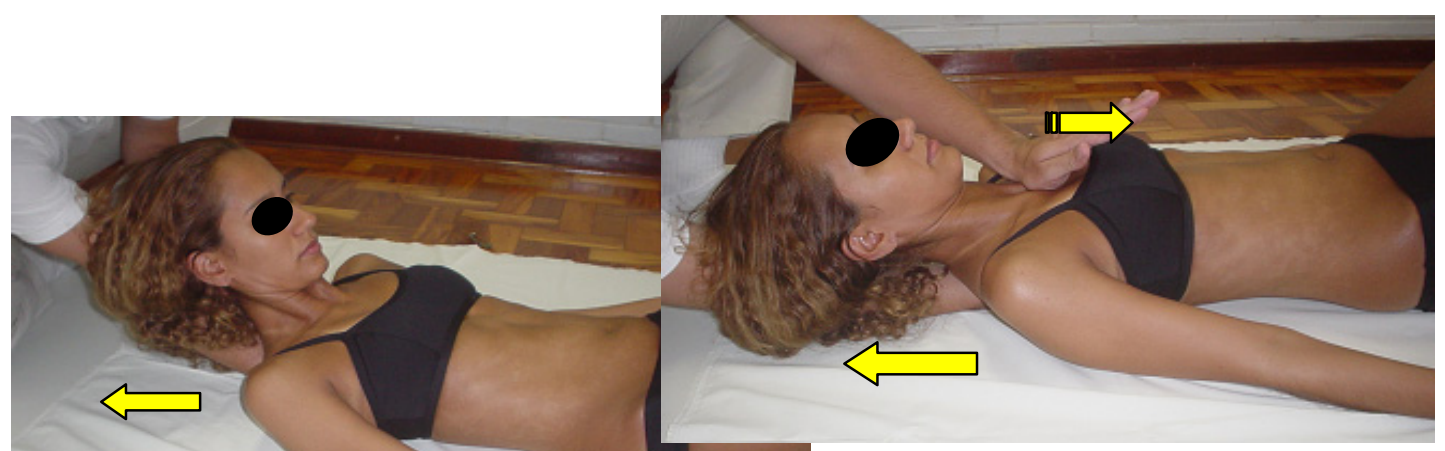

Figura 3 Pompage dorsal 
$\mathrm{Na}$ pompage global, a terapeuta colocava as mãos lateralmente na região cervical da paciente, tensionando lenta e progressivamente os tecidos em sentido cranial.(Figura 4).

Figura 4 Pompage global

A pompage do músculo trapézio superior foi executada inclinando-se a cabeça da paciente para o lado oposto ao que seria tratado; uma das mãos da terapeuta estabilizava o ombro em posição caudal, enquanto a outra, apoiada na base do occipital, tracionava a região cervical e cabeça (Figura 5).

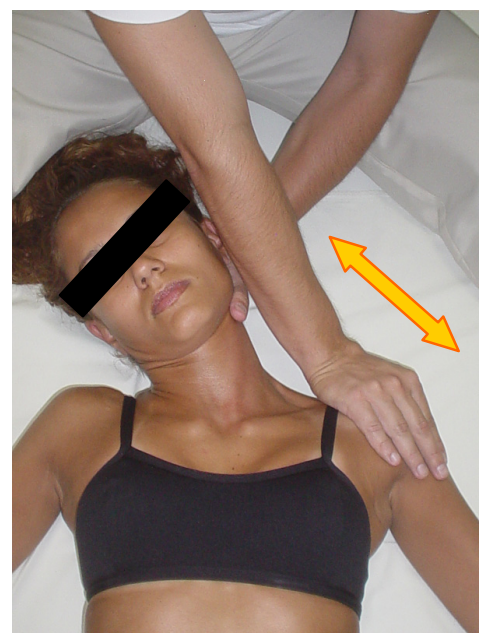

Figura 5 Pompage do m. trapézio superior

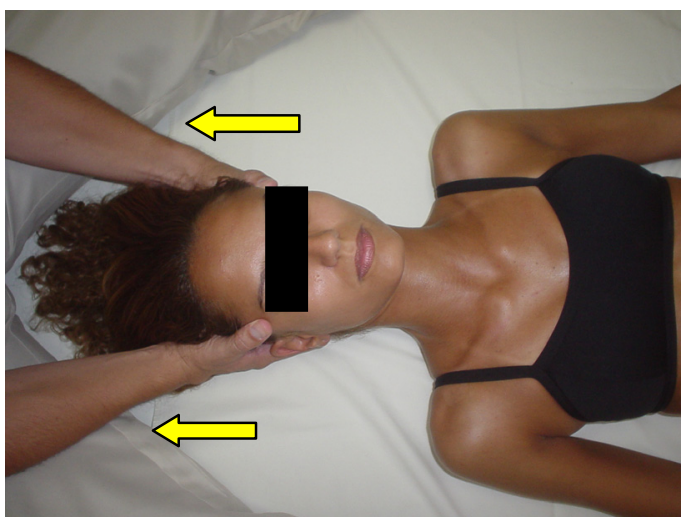

Na pompage do músculo esternocleidomastóideo, a cabeça da paciente era posicionada em $90^{\circ}$ de rotação; uma das mãos da terapeuta, posicionada no esterno, próxima à sua inserção, intensificava a expiração. tracionando em sentido caudal, enquanto a outra mão, posicionada no processo mastóide, estabilizava a cabeça e região cervical (Figura 6).

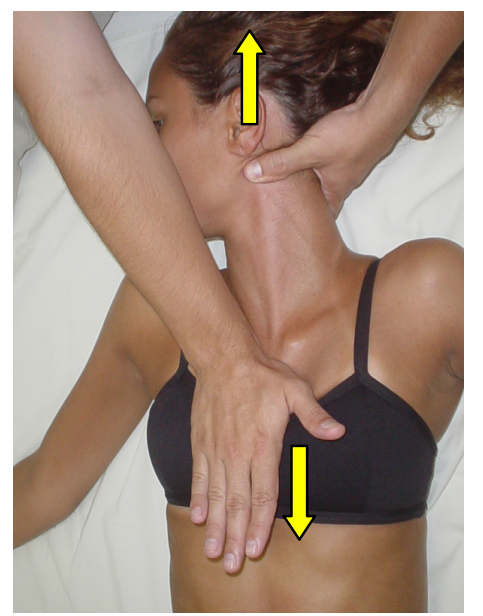

Figura 6 Pompage do m. esternocleidomastóideo

\section{Alongamento para o grupo RPG}

Para o alongamento da cadeia posterior (músculos trapézio superior, elevador da escápula, suboccipitais, paravertebrais, glúteo máximo, isquiotibiais, tríceps da perna e curtos do pé), foi executada uma postura em decúbito dorsal com flexão de quadril, membros superiores aduzidos e membros inferiores apoiados numa cinta (Figura 7a). Progressivamente, respeitando-se o limite da paciente, a postura foi evoluindo para flexão de 90 graus do quadril, extensão máxima possível da perna, 
dorsiflexão de tornozelo, mantendo o sacro, as regiões lombar, dorsal e posterior do crânio apoiadas na mesa (Figura $7 \mathrm{~b}$ ). Todas as compensações, como bloqueio inspiratório, protrusão de ombros, flexão e/ou pronação de antebraço e flexão de punho e dedos, bem como alteração da posição da cabeça, foram evitadas. A paciente foi orientada a manter a respiração com ênfase na expiração, devido à tendência ao tórax inspiratório.

a
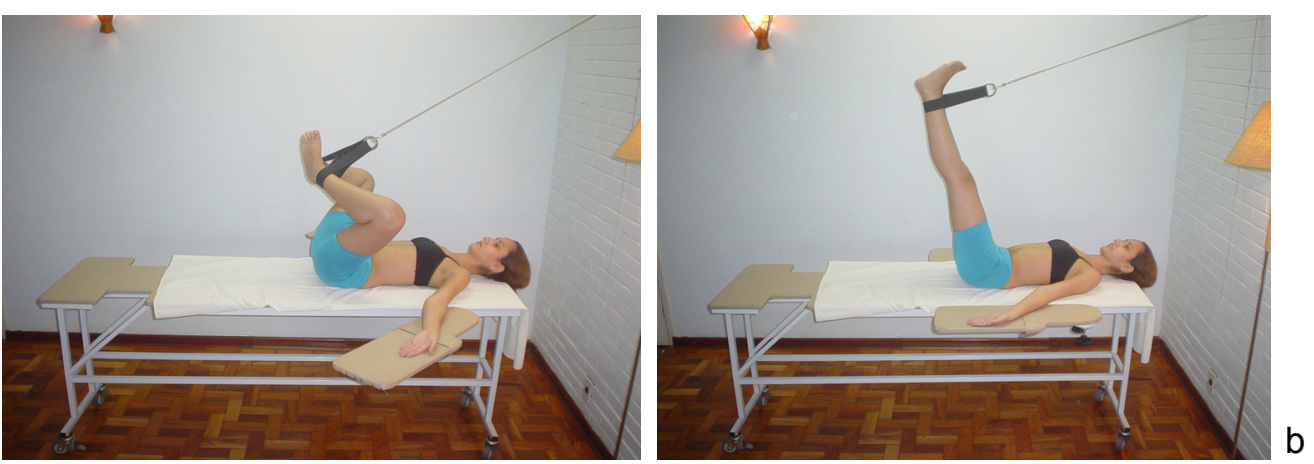

Figura 7 Postura para alongamento da cadeia posterior: $a=$ posição inicial; $b=$ posição final

Para o alongamento da cadeia anterior (músculos diafragma, peitoral menor, escalenos, esternocleidomastóideo, intercostais, adutores da coxa, iliopsoas, flexores do braço, antebraço, punho e dedos) a paciente ficava em decúbito dorsal, com a articulação coxofemural fletida, abduzida e em rotação lateral e completa da perna, a $90^{\circ}$ na articulação tibiotársica, artelhos relaxados, região lombar apoiada na mesa e $140^{\circ}$ de abdução no braço (Figura 8).

a
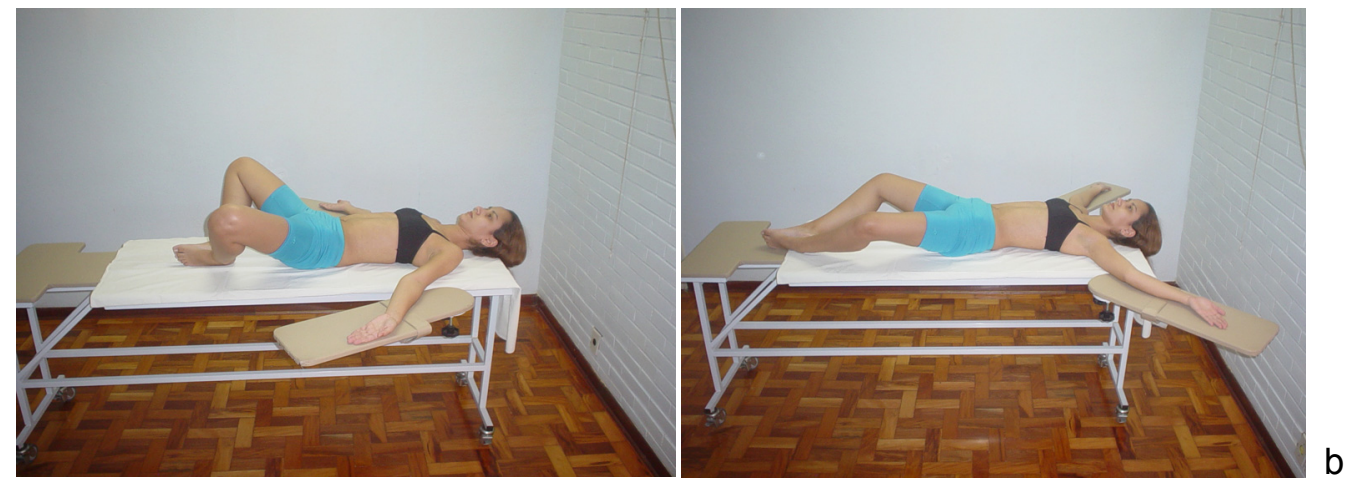

Figura 8 Postura para alongamento da cadeia anterior: $a=$ posição inicial; $b=$ posição final 


\section{Alongamento para o grupo AES}

Alongamento dos músculos da coluna cervical e cabeça

Posteriores: paciente deslocava o mento em direção ao esterno e, após um período de acomodação, apoiava as mãos entrelaçadas sobre a base do occipital (Figura 9a).

Laterais: paciente inclinava lateralmente a cabeça e pescoço em direção ao ombro, soltando a cabeça a favor da ação da gravidade e, após um período de acomodação, levava o membro superior contralateral em direção caudal; e, apoiando a outra mão sobre a cabeça, exercia uma leve tração para aumentar a tensão. $O$ procedimento era repetido bilateralmente (Figura 9b).

Anteriores: paciente deslocava o occipital em direção à coluna torácica alta (superior), soltando-a a favor da ação da gravidade, com a mandíbula semi-aberta (Figura 9c).

Rotadores: paciente rodava a cabeça e pescoço para um dos lados, segundo seu limite. O exercício era repetido do outro lado (Figura 9d).

a

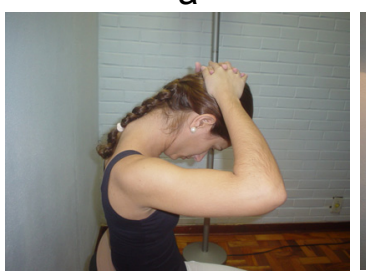

b

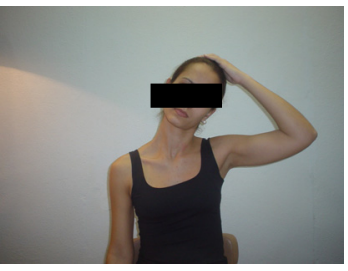

C

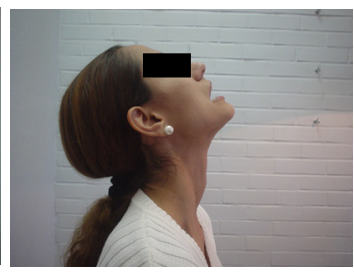

d

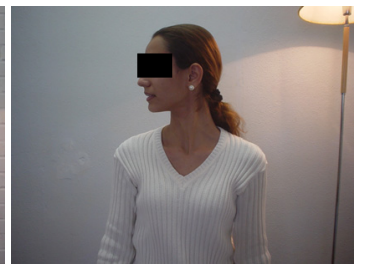

Figura 9 Alongamento para os músculos da coluna cervical e cabeça: $a=$ posteriores; $b=$ laterais; $c=$ posteriores; $d=$ rotadores

Alongamento dos músculos dos membros superiores

Elevadores do cíngulo escapular: paciente elevava os ombros na direção das orelhas na inspiração, em seguida os abaixava em direção ao chão, na expiração (Figura 10a).

Laterais do braço: paciente cruzava o braço estendido na frente do corpo (adução na horizontal) e, segurando o cotovelo com a mão oposta, tracionava-o contra o peito. $\mathrm{O}$ exercício era realizado bilateralmente (Figura 10b).

Anteriores do braço: paciente entrelaçava os dedos das duas mãos atrás do corpo e, em seguida, levantava os braços (Figura 10c).

Mediais do braço: paciente abduzia um braço acima da cabeça colocando a palma da mão na região inter-escapular e, com a outra mão, tracionava lateralmente o cotovelo (Figura 10d).

a

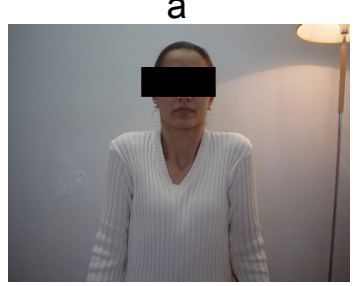

b

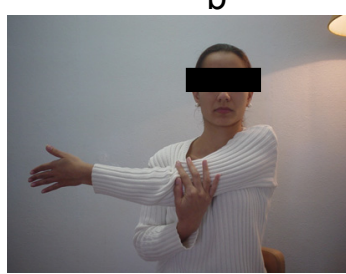

C

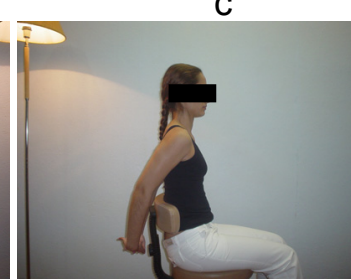

d

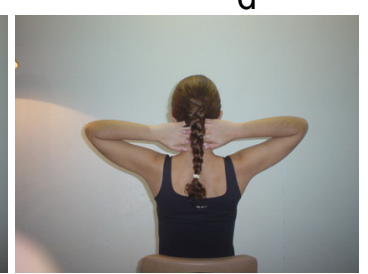

Figura 10 Alongamento dos músculos do ombro: a = elevadores; $\mathrm{b}=$ laterais; $\mathrm{c}=$ anteriores; $\mathrm{d}=$ mediais 
Alongamento dos músculos do punho

Posteriores do punho: paciente realizava flexão do punho (palma da mão voltada para baixo) com os dedos fletidos, antebraço estendido, braço fletido a 90 graus e, com a outra mão, exercia uma tração no sentido de aumentar a flexão (Figura 11a).

Anteriores do punho: paciente realizava extensão do punho (palma da mão virada para cima), antebraço estendido e, com a outra mão, exercia uma tração na palma e dedos no sentido de aumentar a extensão (Figura 11b).

Circundução do punho: paciente entrelaçava os dedos da mão direita com os da esquerda e realizava movimentos circulares com os punhos.

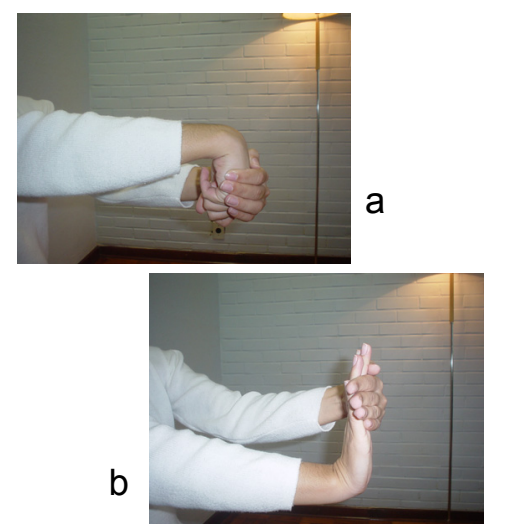

Figura 11 Alongamento dos músculos do punho: $a=$ posteriores; $b=$ anteriores

Alongamento dos músculos da mastigação

As pacientes realizavam os seguintes movimentos:

- abertura da boca com suavidade, soltando o peso da mandíbula com o rosto relaxado (Figura 12a).

- deslocamento da mandíbula para frente/protrusão, de tal forma que os dentes de baixo ficassem à frente dos dentes de cima (Figura 12b).

- deslocamento da mandíbula para o lado direito e depois para o esquerdo (Figura 12c).

- mobilização suave e circular com a mandíbula (combinação de todos os movimentos), buscando aumentar amplitude, respeitando a zona de conforto (Figura 12d).

Este último movimento foi acompanhado pela terapeuta que, portando luva de látex, colocava um dedo na face labial dos incisivos centrais superiores e outro dedo na face labial dos incisivos inferiores.

a

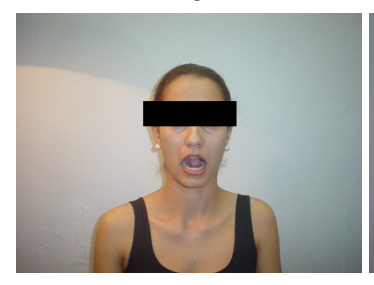

b

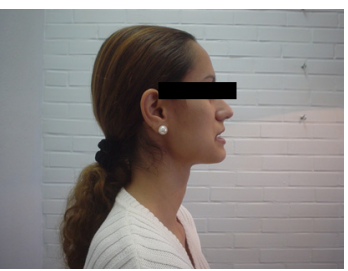

C

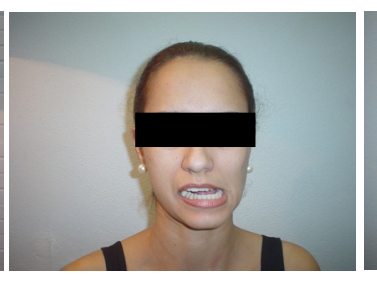

d

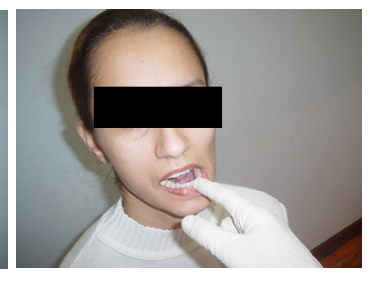

Figura 12 Alongamento dos músculos da mastigação: $a=$ abertura; $b$ = protrusão; $c=$ lateral; $d=$ circundução 